Aus dem Institut für Tierphysiologie und Tierernährung der Georg-August-Universität zu Göttingen

\title{
Untersuchungen zur \\ ernährungsphysiologischen Bewertung unterschiedlich behandelter Sojabohnen in der Broilerernährung
}

\author{
Dissertation \\ zur Erlangung des Doktorgrades \\ der Fakultät für Agrarwissenschaften \\ der Georg-August-Universität zu Göttingen
}

\author{
Vorgelegt von \\ Nassir Oumer Ahmed \\ geboren in Addis Abeba / Äthiopien
}

Göttingen März 2001 
Referent: Prof. Dr. F. Liebert

Korreferent Prof. Dr. E. Pawelzik

Tag der mündlichen Prüfung: 17. Mai 2001 
Meinem Sohn Jonas 

1. Einleitung .

2. Literaturübersicht

2.1 Antinutritive Inhaltsstoffe in der Sojabohne und ihre Wirkungsmechanismen beim Tier. 3

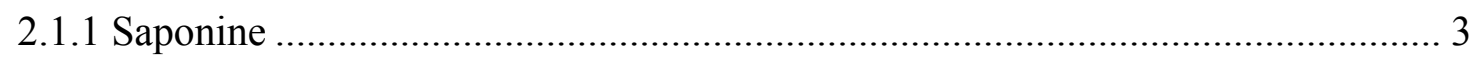

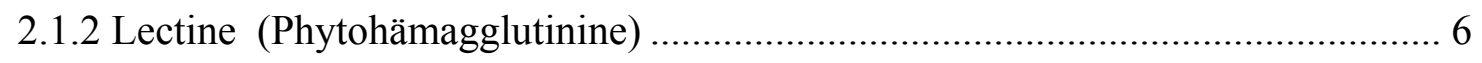

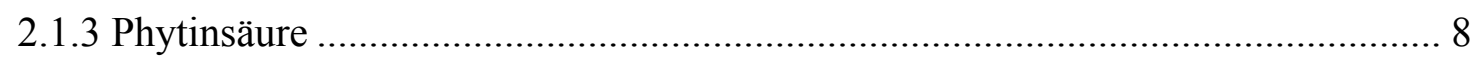

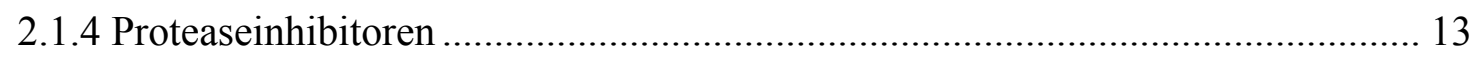

2.2 Behandlungsverfahren für die Ausschaltung antinutritiver Faktoren....................... 21

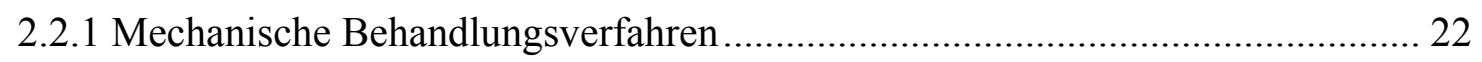

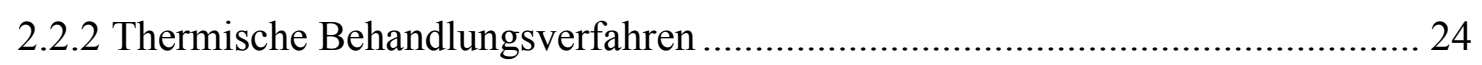

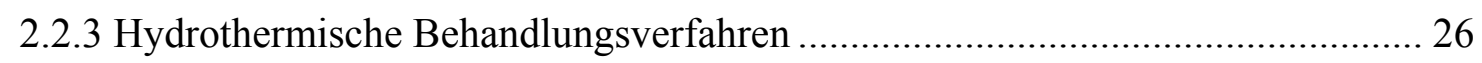

2.2.4 Druckthermische Behandlungsverfahren ..................................................... 28

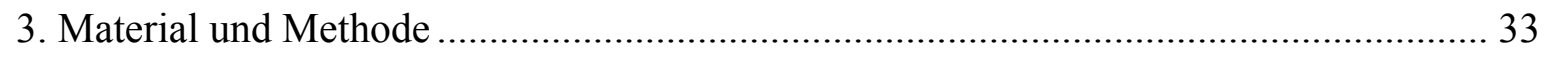

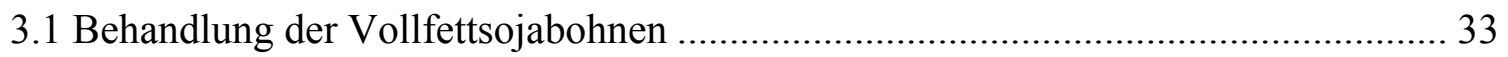

3.1.1 Herstellung der Versuchsdiäten ................................................................... 34

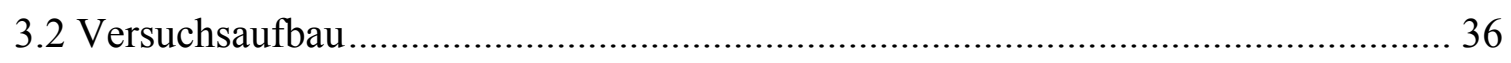

3.2.1 Wachstumsversuch und vergleichender Schlachtversuch ............................... 36

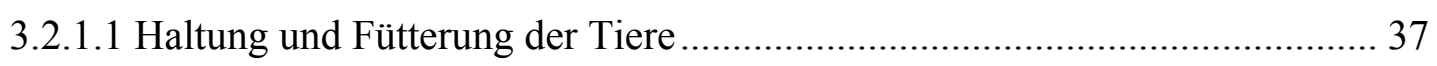

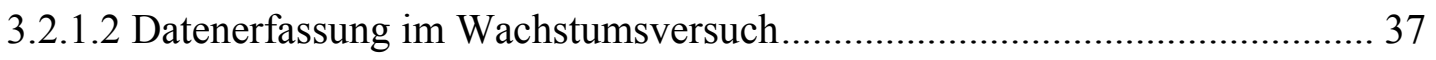

3.2.1.3 Schlachtung und Aufbereitung der Ganzkörperproben............................... 37

3.2.2 Bestimmung der ilealen Verdaulichkeit ausgewählter Aminosäuren................... 38

3.2.2.1 Gewinnung und Aufbereitung der Chymusproben .................................... 38

3.2.3 Stoffwechselversuch zur Ermittlung von Bilanzparametern,

N-Verdaulichkeit, umsetzbarer Energie und Trypsinaktivität im Chymus ......... 38

3.2.3.1 Haltung und Fütterung der Versuchstiere .................................................... 39

3.2.3.2 Gewinnung und Aufbereitung der Exkremente und des Chymus................. 39

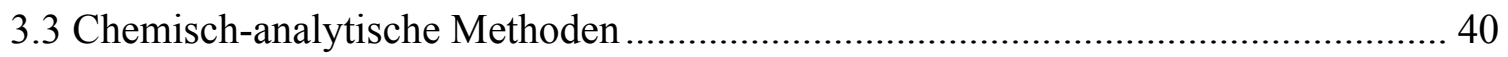

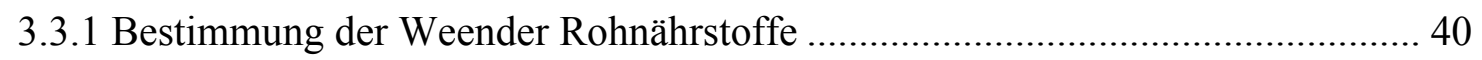

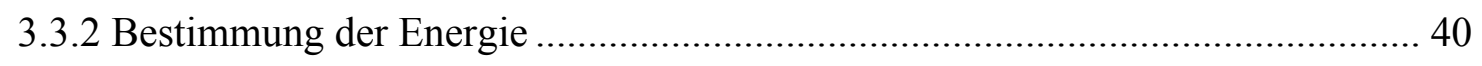

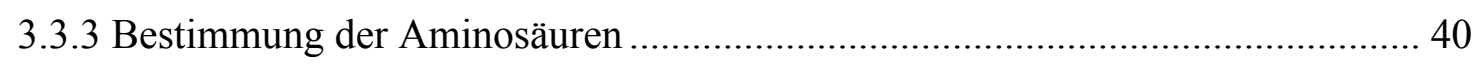

3.3.4 Bestimmung der HCl-unlöslichen Asche ....................................................... 41

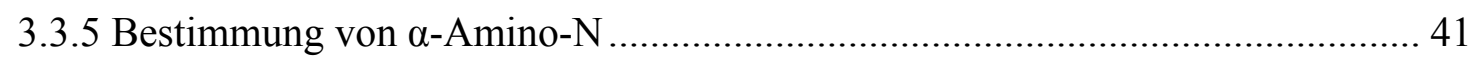


3.3.6 Bestimmung der Trypsinaktivität ................................................................ 43

3.3.7 Bestimmung der Trypsininhibitoraktivität ...................................................... 45

3.3.8 Bestimmung des Proteindispersibilitäts-Index ................................................ 47

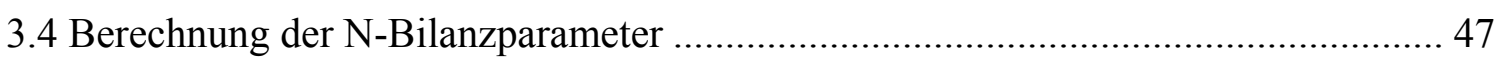

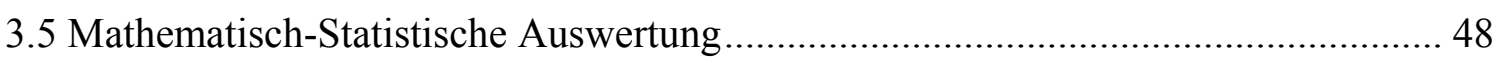

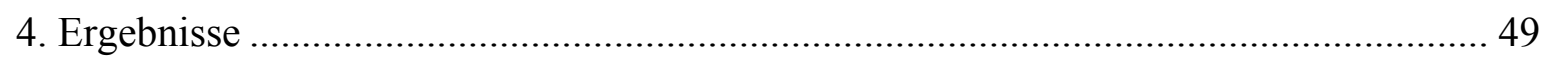

4.1 Die Trypsininhibitoraktivität in den unterschiedlich behandelten Sojabohnen ......... 49

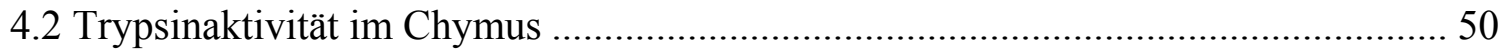

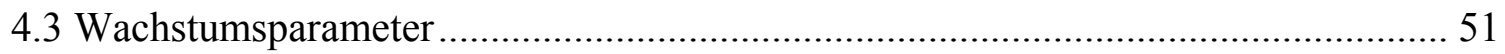

4.3.1 Futteraufnahme, Lebendmassezunahme und Futteraufwand ............................ 51

4.3.2 Energie- und Nährstoffansatz im Gesamtkörper ............................................. 54

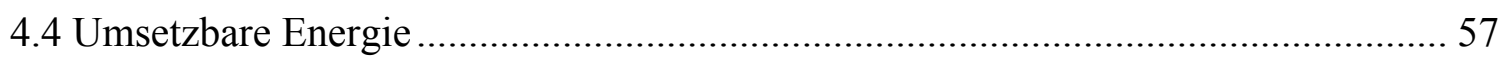

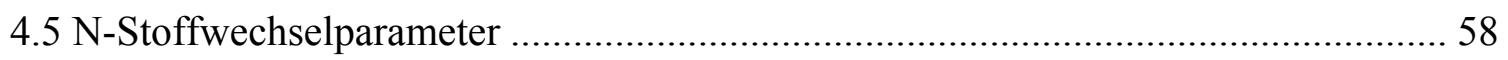

4.5.1 N-Bilanzmessung, Physiologischer Nutzwert und N-Verdaulichkeit ................. 58

4.6 Ileale Aminosäureverdaulichkeit (Arg, Met+Cys, Thr, Lys) und Lysinwirksamkeit 60

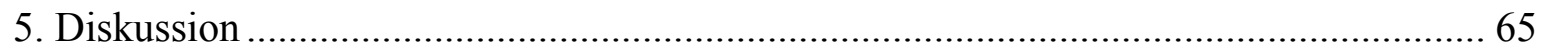

5.1 Einflüsse einer unterschiedlichen Sojabohnenbehandlung auf Wachstumsparameter,

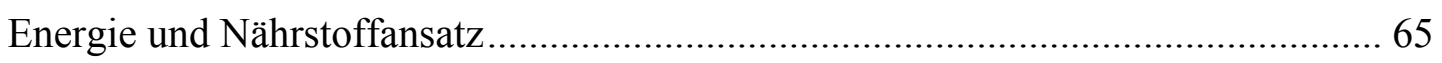

5.2 Einflüsse einer unterschiedlichen Sojabohnenbehandlung auf N-Bilanzparameter .. 68

5.3 Einflüsse einer unterschiedlichen Sojabohnenbehandlung auf die

$\mathrm{N}-$ Verdaulichkeit.

5.4 Einflüsse einer unterschiedlichen Sojabohnenbehandlung auf N-korrigierte umsetzbare Energie und Trypsinaktivität im Chymus

5.5 Einflüsse einer unterschiedlichen Sojabohnenbehandlung auf die scheinbare ileale

Verdaulichkeit ausgewählter Aminosäuren ........................................................... 73

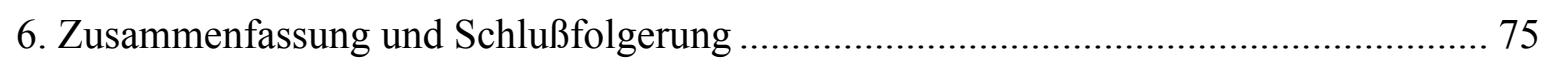

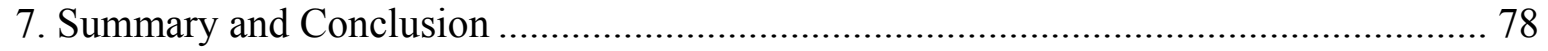

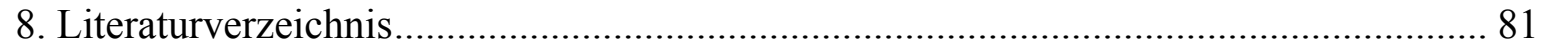

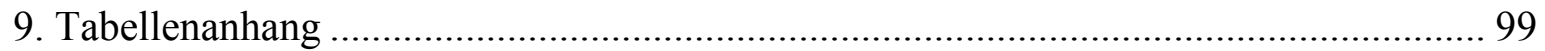


Tabellenverzeichnis Seite

Tab. 1: Saponingehalt in verschiedene Pflanzenarten (nach PRICE et al., 1986) 3

Tab. 2: Auswirkung der unterschiedlichen Futterbearbeitungsverfahren auf die antinutritiven Inhaltsstoffe der Sojabohne (nach ALETOR und OJO, 1989)....

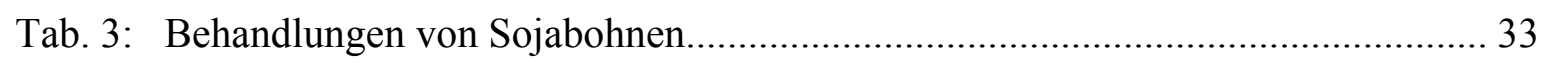

Tab. 4: Basisrezeptur der Futtermischung (g/kg Futter) ............................................. 34

Tab. 5: Ausgewählte Inhaltsstoffe der Komponenten (g/der T) ..................................... 35

Tab. 6: Mittlere Nährstoffzusammensetzung der Basismischungen (g/kg T).................. 35

Tab. 7: Trypsininhibitoraktivitäten der behandelten Sojabohnen ................................... 49

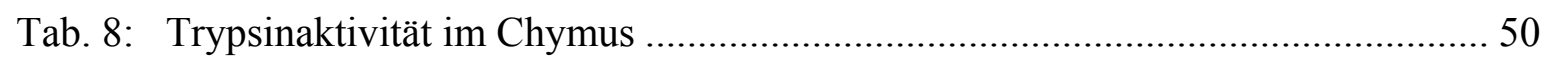

Tab. 9: Täglicher Futterverzehr, tägliche Lebendmassezunahme und

Futterverwertung der Versuchsgruppen ............................................................ 52

Tab. 10: Täglicher Energie- und Nährstoffansatz im Ganzkörper ..................................... 55

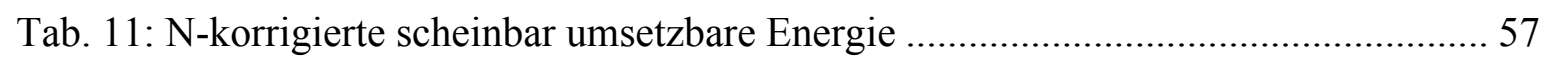

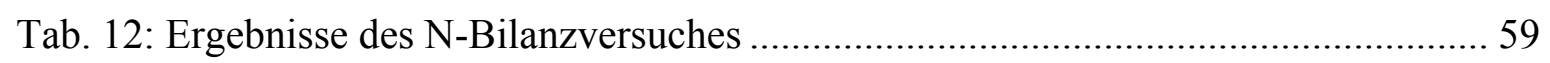

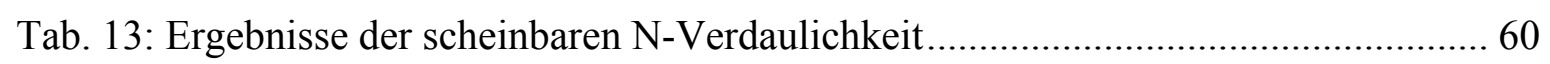

Tab. 14: Scheinbare ileale Aminosäureverdaulichkeit (\%) ausgewählter

Aminosäuren

Tab. 15: Ergebnisvergleich der scheinbaren ilealen Lysinverdaulichkeit und Lysinwirksamkeit 
Abb. 1: Sojasaponin 4

Abb. 2: Chemische Struktur der Phytinsäure und von Phytat 9

Abb. 3: Phytin-Protein-Komplexbildung im sauren (a) und alkalichen (b) Medium 12

Abb. 4: Funktionsprinzip des Expanders 29

Abb. 5: Relative Veränderungen des FV der Gruppen B - K gegenüber der Kontrolle A 53

Abb. 6: Relative Veränderungen der LMZ der Gruppen B- K gegenüber der Kontrolle A.

Abb. 7: Relative Veränderungen des FA der Gruppen B - K gegenüber der Kontrolle A.

Abb. 8: Relative Veränderungen des Energieansatzes der Gruppen B - K gegenüber der Kontrolle A 56

Abb. 9: Relative Veränderungen des Proteinansatzes der Gruppen B- K gegenüber der Kontrolle A

Abb. 10: Relative Veränderungen der N-korrigierten scheinbar umsetzbaren Energie der Futtermischungen der Gruppen B - K gegenüber der Kontrolle A 58

Abb. 11: Relative Veränderungen der scheinbaren ilealen Lysinverdaulichkeit und der Lysinwirksamkeit der Gruppen B - K gegenüber der Kontrolle A...... 64 Abb. 12: N-korrigierte scheinbar umsetzbare Energie 


\section{Abkürzungsverzeichnis}

$\begin{array}{ll}\text { Abb } & \text { Abbildung } \\ \text { AIA } & \text { HCl-unlösliche Asche } \\ \text { ANF } & \text { Antinutritive Faktoren } \\ \text { Arg } & \text { Arginin } \\ \text { BAPNA } & \text { Benzoyl-DL-arginin-p-nitroanilid-hydrochlorid } \\ \text { BBI } & \text { Bowman-Birk-Inhibitor } \\ \text { BHT } & \text { Butyl-Hydroxy-Toluol } \\ \text { bzw. } & \text { beziehungsweise } \\ \text { CCK-PZ } & \text { Cholecystokin-Pancreozymin } \\ \text { cm } & \text { Zentimeter } \\ \text { Cys } & \text { Cystin } \\ \text { d } & \text { Tag } \\ \text { DM } & \text { Dry matter } \\ \text { EDTA } & \text { Ethylendiamintetraacetat } \\ \text { exp. } & \text { expandiert } \\ \text { extr. } & \text { extrudiert } \\ \text { FA } & \text { Futteraufwand } \\ \text { FV } & \text { Futterverzehr } \\ \text { g } & \text { Gramm } \\ \text { h } & \text { Stunde } \\ \text { HM } & \text { Hammermühle } \\ \text { HP } & \text { Hauptperiode } \\ \text { kg } & \text { Kilogramm } \\ \text { kJ } & \text { Kilojoule } \\ \text { kond. } & \text { konditioniert } \\ \text { kWh } & \text { Kilowattstunde } \\ \text { KI } & \text { Kebenitz-Inhibitor } \\ \text { LMdindionin }\end{array}$




\begin{tabular}{|c|c|}
\hline MG & Molekulargewicht \\
\hline MJ & Megajoule \\
\hline $\mathrm{mg}$ & Milligramm \\
\hline$\mu \mathrm{g}$ & Mikrogramm \\
\hline $\min$. & Minute \\
\hline $\mathrm{ml}$ & Milliliter \\
\hline MW & Mittelwert \\
\hline $\mathrm{N}$ & Stickstoff \\
\hline $\mathrm{NfE}$ & N-freie Extraktstoffe \\
\hline NPU & Netto-Protein-Verwertung \\
\hline $\mathrm{NRC}$ & National Research Council \\
\hline $\mathrm{P}$ & Wahrscheinlichkeit \\
\hline PDI & Proteindispersibilitäts-Index \\
\hline PER & Protein efficiency ratio \\
\hline PKs & Proteolyse Säurekonstanz \\
\hline $\mathrm{PNu}$ & Physiologischer Nutzwert \\
\hline RA & Rohasche \\
\hline $\mathrm{s}$ & Standardabweichung \\
\hline SBTI & Sojabohnen-Trypsininhibitor \\
\hline $\mathrm{t}$ & Tone \\
\hline Tab & Tabelle \\
\hline $\mathrm{T}$ & Trockensubstanz/ -masse \\
\hline Thr & Threonin \\
\hline $\mathrm{TI}$ & Trypsininhibitor \\
\hline TIA & Trypsininhibitoraktivität \\
\hline $\mathrm{U}$ & Unit \\
\hline \multirow[t]{2}{*}{ VDLUFA } & Verband Deutscher Landwirtschaftlicher Untersuchungs- und \\
\hline & Forschungsanstalten \\
\hline VQ & Verdauungsquotient \\
\hline WS & Walzenstuhl \\
\hline$\propto$ & Alpha \\
\hline
\end{tabular}




\section{Einleitung}

Die Sojabohne (Glycine max) zählt mit zu den ältesten Nutzpflanzen der Welt, die von der Menschheit kultiviert wird. Nach FRANKE (1975) soll die Kultivierung der Sojabohne schon vor über 4000 Jahren in China und Japan begonnen haben. In Europa ist sie erst seit Beginn des 18. Jahrhunderts bekannt. Heute wird die Sojabohne in Brasilien, USA, Indonesien, Japan, China und Argentinien sehr stark angebaut, wobei in den USA über die Hälfte der Weltproduktion erzeugt wird.

Die Sojabohne enthält etwa $20 \%$ Fett und 40 \% Protein. Der hohe Nährstoffgehalt ermöglicht eine vielseitige Verwendung. Die Sojabohne wird in der menschlichen Ernährung als Tempe, Gemüse (der Keimling), Sojamilch und Sojakäse verwendet. Auch das Sojalecithin aus den Press- und Extraktionsrückständen der Sojabohne ist in der Humanernährung bekannt. In der Tierernährung wird die Sojabohne meistens nach der Ölgewinnung in Form von Sojaextraktionsschrot verwendet. Weil sie im Vergleich zu den anderen Körnerleguminosen (Ackerbohnen, Erbsen usw.) einen höheren Gehalt an Fett und Protein sowie eine bessere Aminosäurenzusammensetzung aufweist, hat ihre Verwendung in der Futtermittel- industrie als Futterkomponente stark zugenommen. Jedoch verhindern die unerwünschten Inhaltsstoffe in den Vollfettsojabohnen den direkten Einsatz als Rationskomponente. In den Sojabohnen sind neben den den Futterwert bestimmenden Inhaltsstoffen auch wertmindernde Inhaltsstoffe wie Proteaseinhibitoren, Saponine, Lectine und Phytinsäure vorhanden, die für die Tierernährung, insbesondere für monogastrische Tiere, eher von Nachteil sind, weil sie die Verwertbarkeit der Nährstoffe (z. B. Protein und Mineralien) vermindern und die Gesundheit der Tiere schädigen können. Deshalb ist die Ausschaltung der unerwünschten Stoffe von großer Bedeutung, um die Futterqualität der Sojabohne zu erhöhen.

Für die Einschränkung der Wirkung von antinutritiven Inhaltsstoffen in der Vollfettsojabohne gibt es verschiedene Behandlungsverfahren. Jedoch ist der Einsatz der thermischen Behandlungsverfahren weit verbreitet. Dazu zählen das Kochen, Rösten, Expandieren, die Extrusion und die Dampferhitzung. Die Effektivität dieser Bearbeitungsverfahren hinsichtlich der Senkung von antinutritiven Faktoren in den Sojabohnen und dadurch die Verbesserung des Futterwertes hängt von den festgelegten Behandlungsbedingungen ab. Das sind Temperatur, Futterstruktur, Feuchtigkeit, Energieeinsatz und Dampfeinsatz. 
Ausgehend hiervon besteht das Ziel der Arbeit darin, alternative Behandlungstechnologien hinsichtlich der Einflüsse des Proteaseinhibitors (PI) auf ernährungsphysiologische Parameter zu prüfen und damit unter Umständen den notwendigen Energieeinsatz für die Behandlungen zu reduzieren. Im einzelnen sollen dabei folgende Fragen beantwortet werden:

1. Spielt eine differenzierte Behandlungszeit, die Futterstruktur, der Energieeinsatz sowie die Dampfzufuhr eine Rolle, um die antinutritiven Faktoren (ANF) effektiv zu senken und wie groß ist der Unterschied hinsichtlich der Senkung der ANF zwischen Behandlungsverfahren, dargestellt am Beispiel des Trypsininhibitors ?

2. Wie wirkt sich der Einsatz von differenziert behandelten Sojabohnen in bedarfsgerechten Broilermischungen auf Leistung, Futteraufwand, Proteinverwertung, Verdaulichkeitsparameter sowie Trypsinaktivität im Chymus und Nährstoffansatz beim Broiler aus? 


\section{Literaturübersicht}

Der erste Teil der Literaturübersicht (2.1) befaßt sich mit unterschiedlichen antinutritiven Inhaltsstoffen, die in der Sojabohne und in anderen Leguminosenarten vorhanden sind und ihren Einfluss auf ernährungsphysiologische Parameter. Im zweiten Teil der Literaturübersicht (2.2) werden verschiedene Behandlungsverfahren zur Verminderung von ANF's vorgestellt.

\subsection{Antinutritive Inhaltsstoffe in der Sojabohne und ihre Wirkungsmechanismen beim Tier}

In diesem Kapitel wird überwiegend über verschiedene Arten von wertmindernden Inhaltsstoffen (Saponine, Lectine, Phytinsäure und Proteaseinhibitoren) und ihre Wirkungsmechanismen auf ernährungsphysiologische Parameter berichtet.

\subsubsection{Saponine}

Saponine kommen natürlicherweise in zahlreichen Pflanzenarten insbesondere in Leguminosen vor. Der Gehalt an Saponinen in verschiedenen Pflanzen variiert stark. PRICE et al. (1986) bestimmten den Saponingehalt in verschiedenen Pflanzenarten (Tab. 1). Dabei fanden die Autoren in der Sojabohne und Luzerne relativ hohe Gehalte an Saponin von 6,5 bis zu $17,1 \mathrm{mg} / \mathrm{g} \mathrm{T}$.

Tab. 1: Saponingehalt in verschiedenen Pflanzenarten (nach PRICE et al., 1986)

\begin{tabular}{lc}
\hline Pflanzenart & Gehalt $\mathbf{( m g / g ~ T )}$ \\
\hline Sojabohne (Glycine max) & 6,5 \\
Erbse (Cicer arietinum) & 2,3 \\
Erbse (Pisum sativum) & 1,8 \\
Bohne (Phaseolus vulgaris) & 3,5 \\
Bohne (Vicia faba) & 0,1 \\
Butterbohne & 1,0 \\
Luzerne (Medicago sativa) & 17,1 \\
\hline
\end{tabular}


Saponine sind Stoffwechselprodukte der Pflanzen, die aus Kohlenhydraten (Mono- oder Oligosacchariden) und Aglykonen bestehen. Nach ihrer chemischen Zusammensetzung gehören sie zu der Gruppe der Glykoside. Je nach der Anzahl der mit Aglykon verbundenen Kohlenhydrate werden sie als monodesmodische und bidesmodische Saponine bezeichnet. Beide Saponinverbindungen sind in Sojabohnen identifiziert worden.

Nach der chemischen Struktur des Aglykons unterscheidet man Steroide (C27) und Triterpenoide (C30). TSCHESCHE et al. (1969) konnten zwei Steroide (Avenacosid A und B) aus verschiedenen Pflanzenteilen des Hafers extrahieren. Dabei fanden die Autoren höhere Anteile an Saponin (Avenacosid A und B) in den Keimlingsblättern und dem Stroh als in den Samen. Beide Arten von Saponinen besitzen Aglykone. Nach Angabe von TSCHESCHE et al. (1969) hat das Avenacosid B einen bitteren Geschmack. Abb. 1 zeigt die chemische Struktur der Sojasaponine.

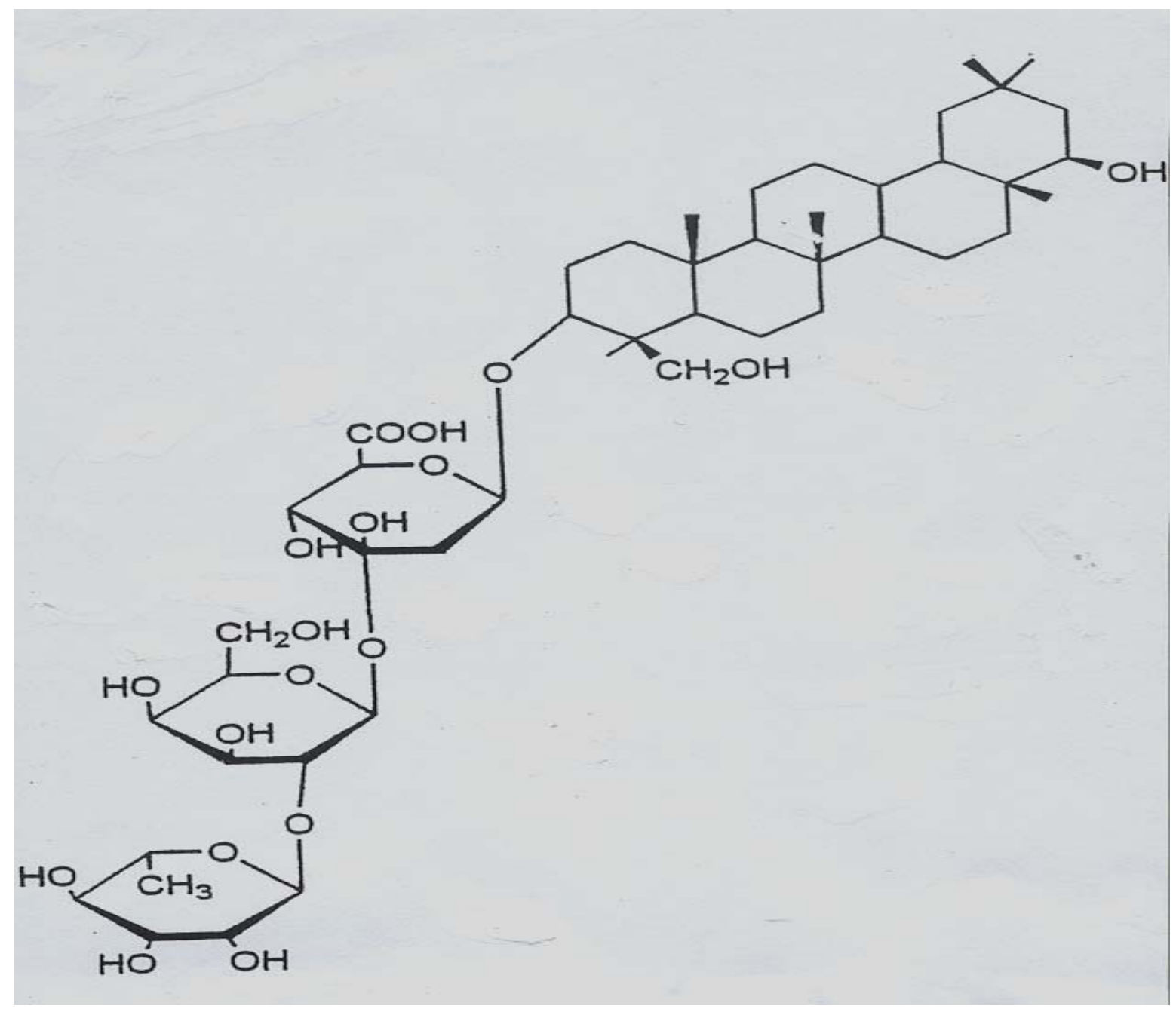

Abb. 1: Sojasaponin 
Saponine weisen membranolytische und hämolytische Eigenschaften sowie eine hohe Affinität gegenüber Cholesterin auf. Außerdem sind sie fähig, die Durchlässigkeit der Zellen zu erhöhen und mit einer unbekannten Seite der Plasmamembran eine chemisch irreversible Verbindung einzugehen. Nach der Angabe von ÖNNIG (1995) sind monodesmodische Saponine in ihrer Wirkung stärker als bidesmodische Saponine.

Ausgehend von den chemischen Eigenschaften der Saponine wurde über ihre ernährungsphysiologischen Einflüsse in einigen Studien diskutiert. Die Untersuchungen zeigen, dass Saponine sowohl nutritive als auch antinutritive Eigenschaften für Mensch und Tier haben.

Die nutritiven Eigenschaften für Menschen beruhen auf der Verringerung des Cholesterinspiegels im Plasma. Die Konzentration des Cholesterins im Plasma kann durch Saponine reduziert werden, dass ihre Reabsorption verhindert wird. Dies geschieht dadurch, dass Saponine mit Gallensäuren oder Cholesterin einen Komplex bilden. Die verminderte Reabsorption wurde durch den Befund von OAKENFULL et al. (1979) nicht bestätigt, da sie durch Fütterung von Ratten und Schweinen mit einem saponinreichen Futter eine erhöhte fäkale Gallensäurekonzentration bei gleich hoher Sterinausscheidung nachwiesen. JOHNSON et al. (1986) beobachteten, dass die Fütterung von Ratten mit saponinreichem Futter zur Verringerung der Absorption von Galactose, Glucose und Cholesterin führt. Die Autoren meinen, dass die niedrige Cholesterinabsorption mit den darmpermeabilitätreduzierenden Eigenschaften der Saponine verbunden sein könnten.

In anderen Untersuchungen wurde eine antinutritive Wirkung der Saponine in der Ernährung der Wiederkäuer festgestellt. In den von BRUNE (1956) bei Hammeln durchgeführten Untersuchungen bewirkte eine orale Zufuhr von Gypsophilasaponin (5 g/d) einen starken Abfall der Calciumbilanz, eine verminderte Rohproteinverdaulichkeit und N-Retention. Der gleiche Autor fütterte Ratten mit einer Ration, die unterschiedliche Konzentrationen von Saponinen enthielt. Dabei beobachtete der Autor eine Erhöhung der Mineralstoffkonzentration im Kot und Gleichgewichtsstörungen sowie zunehmenden Wasserkonsum und eine Verschlechterung der Calciumbilanz bei steigenden Konzentrationen. SOUTHON et al. (1988) untersuchten den Einfluss von Saponinen auf den Mineralstatus bei Ratten. Dabei fanden sie einen verringerten Eiseneinbau in der Leber. Die Autoren begründeten diesen Einfluss von Saponinen auf den Eiseneinbau mit den hämolytischen Eigenschaften der Saponine. Saponine bilden einen Komplex mit Eisen, so 
dass die Eisen-Absorption verhindert wird, was wiederum eine geringere Eiseneinlagerung beim Tier hervoruft.

Der Wirkungsintensität der Saponine hängt von der chemischen Struktur und Herkunft der Saponine ab. ISHAAYA et al. (1969) verglichen die ernährungsphysiologischen Wirkungen von Saponinen aus Luzerne und Sojabohnen bei Küken, Ratten und Mäusen. Dabei konnten

die Autoren eine verringerte Lebendmassezunahme nur bei der Fütterung der Luzernesaponine feststellen. Sojabohnensaponine zeigten hingegen keinen Einfluss auf die Lebendmassezunahme der Tiere. Die Autoren vermuteten dabei, dass die hämolytische Aktivität der Sojabohne im Vergleich zur Luzerne niedriger ist. Das interessante Ergebnis bei diesem Versuch war, dass die negative Wirkung der Luzernesaponine durch Cholesterinzusatz gehemmt werden konnte. In Verbindung mit diesem Versuch wurde auch der Cholesteringehalt im Plasma der Mäuse bestimmt. Daraus ergab sich, dass Luzernesaponin im Vergleich zu Sojabohnensaponin zur Verringerung des Cholsteringehaltes im Plasma führte. Nach Angabe von GESTETNER et al. (1968) verlieren Sojabohnensaponine durch die Interaktion mit dem Plasma ihre hämolytische Aktivität, so dass ihr Einfluss auf die Lebendmassezunahme gering bleibt.

\subsubsection{Lectine (Phytohämagglutinine)}

Der Begriff Lectin wird meistens in der Literatur als Synonym für Phytohämagglutinin verwendet. Das Molekulargewicht der Lectine liegt im Bereich von 60,000 bis 122,000. Nach LIENER (1976) besitzt Sojabohnenlectin ein Molekulargewicht von 122,000.

Lectine können wegen ihrer chemischen Eigenschaften die Enzyme von Pilzen und Bakterien inhibieren und dadurch die Pflanzen vor Krankheitsbefall schützen. Außerdem besitzen sie Schlüsselfunktionen im Pflanzenwachstum und in der Differenzierung der Embryonen sowie der N-Fixierung im Boden.

Lectine kommen in den Pflanzen insbesondere in den Leguminosen (Sojabohnen, Fababohnen und Phaseolusbohnen) und bei einigen Tierarten (in Meerestieren) vor. Nach ihrer Herkunft unterscheidet man in Phytolectine und Mycolectine. Sie machen 1-3 \% des gesamten Proteins der entfetteten Sojabohnen aus (LIENER und ROSE, 1953). Lectine sind in den verschiedenen Pflanzenteilen, z.B. in den Blättern, Wurzeln und Stengeln lokalisiert. Der Gehalt an Lectinen in den Leguminosen variiert je nach Anbaujahr, Sorte und 
Leguminosenart. PUSZTAI et al. (1979) untersuchten die chemische Zusammensetzung von 13 verschiedenen Sorten von Phaseolusbohnen. Dabei ergab sich eine Variationsbreite im Lectingehalt zwischen $1 \%$ und $4 \%$ des gesamten Proteins.

Lectine sind für ihre Affinität zu den Kohlenhydraten (z.B. Galactose und N-AcetylGalactosamin) bekannt, ferner haben sie die Fähigkeit, die Blutkörperchen (Erythrozyten) zu agglutinieren. Die Zuckerreste der Lectine reagieren dabei auf der Oberfläche der Erythrozyten. Die Galactosaminreste und Glucosaminreste der Sojabohnen bzw. Fababohnen reagieren gegen Erythrozyten. Diese Reaktion wird u.a. benutzt, um die Hämagglutininaktivität in den Leguminosen zu messen.

In Abhängigkeit von der Lectinherkunft ist die Affinität der Lectine gegen Erythrozyten unterschiedlich. VALDEBOUZE et al. (1980) zeigten in ihren Untersuchungen unter Nutzung von Kaninchenblutzellen eine unterschiedliche Hämagglutininaktivität in Fababohnen (25$100 \mathrm{U} / \mathrm{mg}$ ), Erbsen (100-400 U/mg) und Sojabohnen (2400 U/mg), d.h. Lectine aus Sojabohnen agglutinieren stärker als die von Fababohnen und Erbsen. In der Untersuchung von MARQURDT et al. (1975) wirkten sich Sojabohnenlectine auf Schweineblutzellen nur schwach und auf Kaninchenblutzellen stark aus. Im Gegensatz zu Sojabohnenlectin stellten die Autoren einen starken Einfluss der Fababohnenlectine auf Mäuse-, Schweine-, Puten-, Kaninchen- und Rattenblutzellen fest. Anders als bei Sojabohnen und Fababohnen konnten VALDEBOUZE et al. (1980) keine Hämagglutininaktivität in Lupinen feststellen (keine Agglutination der Kaninchenblutzellen). Andererseits zeigte die Untersuchung von TAGLE (1974), dass die Lupinen unter Nutzung von Rindererythrozyten eine mittlere Hämagglutininaktivität besitzen. Dabei lag die Hämagglutininaktivität der Sojabohnen und Lupinen unter Nutzung von Blutzellen von Schaf und Rind bei 0,4 bzw. 3,1 U/mg. In der Untersuchung von MARQURDT et al. (1975) wurden auch sortenabhängige Hämagglutininaktivitäten in den unterschiedlichen Fababohnen gezeigt. Die höchste Hämagglutininaktivität wurde dabei in der Sorte Erforida $\left(5,6 * 10^{3} \mathrm{U} / \mathrm{g}\right)$ und die niedrigste in der Sorte Herra und bei kleinkörnigen Fababohnen $\left(3,4 * 10^{3} \mathrm{U} / \mathrm{g}\right)$ festgestellt.

Die ernährungsphysiologische Wirkung der Lectine beruht vor allem auf ihren chemischen Eigenschaften. Die mit dem Futter aufgenommenen Lectine heften sich an die Darmzotten und führen damit zur Schädigung der Darmlumina. Dieses verursacht wiederum eine schlechtere Nährstoffverdauung und -absorption. GRANT et al. (1985) zeigten in einer lichtund elektronenmikroskopischen Studie bei Ratten eine starke Zerstörung und ungewöhnliche Entwicklung (z.B. Schwellung) der Darmzotten. Andererseits demonstrierten PUSZTAI et al. 
(1981), LIENER und ROSE (1953) in einer immunologischen Studie, dass Ratten und Kaninchen bei oraler Zufuhr der Lectine Antikörper gegen diese Abwehrstoffe bilden können. Im Zusammenhang mit den toxisch wirkenden Eigenschaften von Lectinen wurden in einer Reihe von Untersuchungen von PUZSTAI et al. (1981) und GRANT et al. (1985) bei Ratten und von MARQUARDT et al. (1976) bei Broilern mögliche Einflussgrößen der Lectine auf den Futterwert der Leguminosen untersucht. GRANT (1985) beschrieb, dass Lectine beim wachsenden Rind, bei Schweinen und Ratten einen Körpermasseverlust hervorrufen. In einem Vergleichsversuch beobachteten die gleichen Autoren bei Fütterung der Tiere mit rohen Bohnen eine niedrigere Netto-Protein-Verwertung (NPU=25-30 \%) als bei den mit Eiprotein gefütterten Tieren (NPU $=69-89 \%$ ). Aus den Bilanzversuchen von PUZSTAI et al. (1981) ergab sich auch bei Ratten eine höhere fäkale N-Ausscheidung und eine negative N-Bilanz, wenn die Ratten mit rohen Bohnen gefüttert wurden. Die N-Verwertung lag bei mit Casein gefütterten Ratten bei $95 \%$, während mit rohen Bohnen gefütterte Ratten nur eine NVerwertung von $46 \%$ aufwiesen.

Für die Inaktivierung der Lectine und für die Verbesserung der Nährstoffverwertung der Leguminosen ist die Denaturierung der Peptidkette in den Lectinen der entscheidende Faktor. Durch Denaturierung verlieren die Lectine ihre Affinität zu den Erythrozyten. Dies führt anschließend zur Verminderung der antinutritiv wirkenden Eigenschaften. Der Denaturierungsprozess kann durch NaCl-, Metall-Ionen- und Enzymeinsatz sowie durch thermische Behandlung erfolgen.

LIENER (1958) stellte in einer in vitro-Untersuchung eine optimale Inaktivierung der Sojabohnenlectine fest, wenn sie die Behandlung durch $\mathrm{AlCl}_{3}$ und $\mathrm{Fe}\left(\mathrm{NO}_{3}\right)_{3}$ bei pH 6,5 und $60{ }^{\circ} \mathrm{C}$ durchgeführt hatten. In anderen Untersuchungen beobachteten van der POEL et al. (1990), dass das Behandlungsverfahren bei einer Kombination von hohen Temperaturen und kurzen Einwirkzeiten im Vergleich zu niedrigen Temperaturen und langen Behandlungszeiten die Lectine in der Phaseolusbohne ausreichend reduziert. Andererseits deuteten MARQUARDT et al. (1976) darauf hin, dass eine Dampfpelletierung nicht ausreicht, um die Lectinaktivität effektiv zu minimieren.

\subsubsection{Phytinsäure}

Phytin wird in der Literatur als Sammelbegriff für Inositolphosphorsäureester (Phytinsäure und ihre Salze; Phytate) verwendet. Nach LANTZSCH (1990) wird durch Veresterung von 6 
mol Phosphorsäure mit einem Inositolmolekül Myo-Inositol 1, 2, 3, 4, 5 und 6 Hexadihydrogenphosphat gebildet, das als starke Phytinsäure bezeichnet wird. Die Struktur der Phytinsäure geht aus der Abb. 2a hervor.

Es sind insgesamt neun stereoisomere Formen des Hexaphosphorsäureesters möglich. Davon sind zwei Isomere optisch aktiv, die anderen Isomere sind Meso-Formen. Nach GRAF (1986) kommen die Ester des Myo-Inosits nur in höheren Pflanzen (z. B. Getreide, Körnerleguminosen) vor.

Phytinsäure ist bei schwach saurem bis neutralem $\mathrm{pH}$-Bereich größtenteils in dissoziierter Form vorhanden. Sie kann mit Mengenelementen wie $\mathrm{Ca}, \mathrm{Mg}, \mathrm{K}$ und $\mathrm{Na}$ sowie mit den Spurenelementen $\mathrm{Fe}, \mathrm{Cu}, \mathrm{Zn}$ und $\mathrm{Mn}$ schwerlösliche Metallverbindungen, die als Phytate bezeichnet werden, bilden. Bei der Bildung des Phytats werden zwei abspaltbare H-Atome der Phytinsäure durch Kationen (u.a $\mathrm{Ca}^{2+}, \mathrm{Cu}^{2+}, \mathrm{Zn}^{2+}$ und $\mathrm{Mn}^{2+}$ ) ersetzt (Abb. 2b). Die Stabilität dieser Metallverbindungen variiert in Abhängigkeit vom Bindungspartner. Die Untersuchungen von MADDAIAH et al., 1964) zeigten, dass zwischen zweiwertigen Kationen und Phytinsäure im pH-Bereich von 6 - 11 und im molaren Verhältnis von 1:1 folgende abnehmende Stabilitätsreihenfolge besteht: $\mathrm{Zn}^{++}>\mathrm{Cu}^{++}>\mathrm{Co}^{++}>\mathrm{Mn}^{++}>\mathrm{Ca}^{++}$.

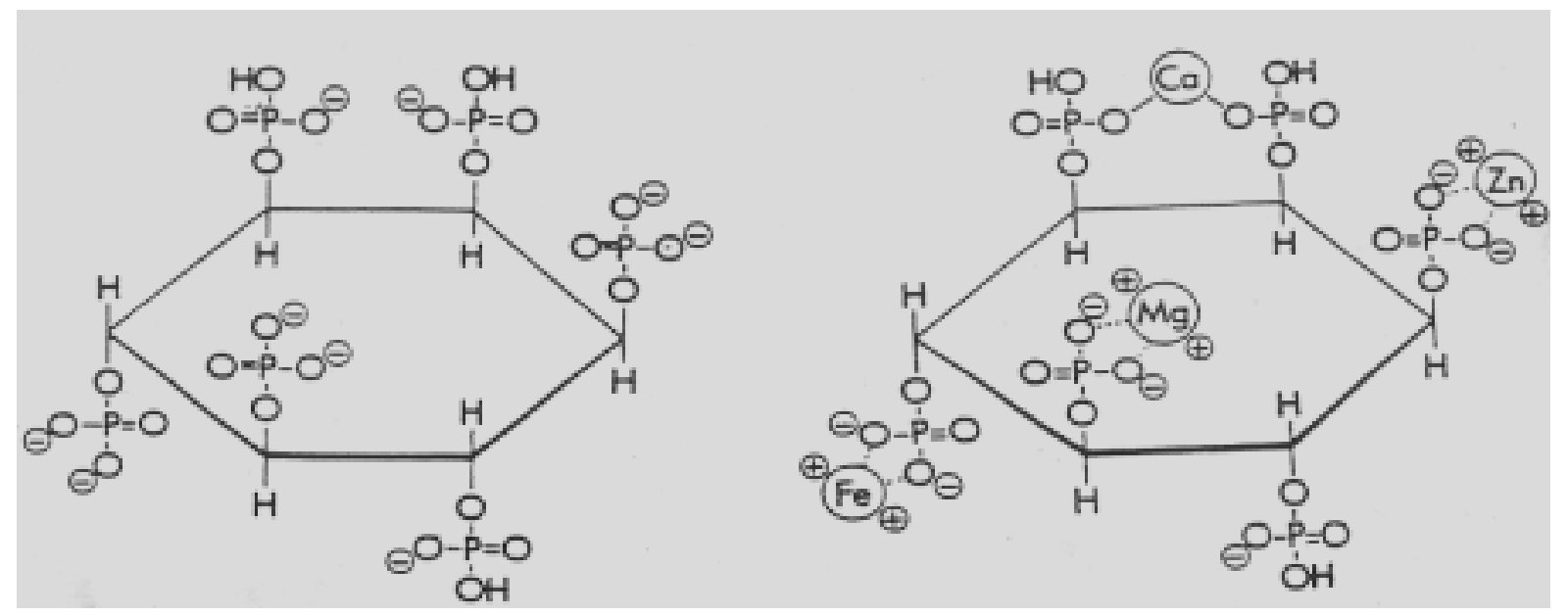

a) Struktur der Phytinsäure

b) Ca-, Mg-, Fe-, Zn-Phytat

bei neutralem $\mathrm{pH}$

\section{Abb. 2a,b : Chemische Struktur der Phytinsäure und von Phytat}

In den Samen von Getreide, Leguminosen, Nüssen und Ölpflanzen tritt Phytinsäure (der Hexaphosphorsäureester des Myo-Inositols) in Konzentrationen von $1-5 \%$ auf, während sie in Wurzeln, Blättern, Knollen und Stengeln sehr gering oder nicht nachweisbar ist (BECKER, 1950). Nach MAGA (1982) variieren die Phytingehalte der Sojabohne zwischen 10 bis 15 
g/kg. Nach Untersuchungen von ASHTON und EVANS (1962) werden im Getreidekorn vor allem Calcium-Magnesium-Phytate gebildet. Beschrieben wird auch, dass es sich bei Reis (OGAWA et al., 1975) um ein Magnesium-Kaliumphytat und bei Sesam (O'DELL und DEBOLD, 1976) um ein Magnesiumphytat handelt. In Dikotyledonen befindet sich Phytinsäure in Globoiden (glasige Kügelchen, die bei der Bildung des Aleurons entstehen) zusammen mit Protein im ganzen Samen verteilt (COSGROVE et al., 1980). Diese Globoide bestehen neben Protein aus Magnesium, Kalium, Eisen, Calcium, Mangan, Barium und Natrium (SCHEUERMANN et al., 1988).

Die physiologische Bedeutung der Phytinsäure besteht darin, dass sie den Pflanzen in erster Linie als wichtigster Phosphorspeicher zum Aufbau von Phosphatiden und Nukleoproteiden dient. Aus den Bindungseigenschften der Phytinsäure mit zweiwertigen Kationen läßt sich auch ableiten, dass sie an der Speicherung unter anderem von $\mathrm{P}, \mathrm{Ca}, \mathrm{Mg}$ und $\mathrm{K}$ eine Rolle spielt. PALLAUF et al. (1993) deuteten an, dass Phytinsäure während der Reifung (Ende der generativen Phase) vorwiegend in der Aleuronschicht von Gerste, Hafer, Reis und Roggen und im Keimling von Mais als lösliches Mischsalz eingelagert wird. Im Gegensatz hierzu ist Phytinsäure bei Leguminosen (Sojabohne) in den Kotyledonen akkumuliert.

Die antinutritiven Eigenschaften der Phytinsäure sind durch ihren Molekülaufbau begründet. Nach CHERYAN (1980) besitzen Phytinsäuren 12 austauschbare Protonen, von denen sechs stark (PKs 1,1-2,1) und sechs schwach (PKs 4,6-10) dissoziiert vorliegen. In Folge des Komplexbildungsvermögens von Phytinsäure mit Nährstoffen (z.B. zweiwertigen Kationen und Proteinen) kann die Nährstoffverfügbarkeit bei monogastrischen Tieren beeinträchtigt werden, weil ihnen das Enzym Phytase fehlt.

Unter bestimmten Bedingungen können diese Komplexe wasserunlöslich oder schwerlöslich sein. Da Phytasen nur gelöstes Phytat hydrolisieren können, ist die Löslichkeit des Phytats der entscheidende Faktor für die Näherstoffverfügbarkeit. Eine Reihe von Autoren beschrieben, dass die Löslichkeit des Phytats im wesentlichen durch die vorliegende Calciumkonzentration und den pH-Wert beeinflusst wird (CHAMPAGNE und PHILLIPPY, 1989; LANTZSCH, 1990). LANTZSCH (1990) untersuchte den Einfluss der Calciumkonzentration auf die Löslichkeit des Phytats. Die Ergebnisse zeigten, dass die niedrigere Löslichkeit (60\%) der Phytinsäure bei höherer Ca-Konzentration und im pH-Bereich von 5 liegt, während bei niedrigerer Ca-Konzentration die Löslichkeit der Phytinsäure in dem gleichen pH-Bereich bei 100 \% lag. In der gleichen Untersuchung führte die höhere Konzentration an Ca zur Erhöhung der Zink-bindenden Eigenschaften der Phytinsäure. 
Ausgehend von den komplexbildenden Eigenschaften der Phytinsäure wurden in zahlreichen Arbeiten die antinutritive Wirkungen hinsichtlich der eingeschränkten Verfügbarkeit von zweiwertigen Kationen bei Monogastriden diskutiert (OERLEAS, 1973; DAVIES und FLETT, 1978; O’DELL und SAVAGE, 1960; LIKUSKI und FORBES, 1965). In Untersuchungen von NWOKOLO und BRAGG (1977) wurde für Sojaextraktionsschrot und Rapsextraktionsschrot eine Zn-Verfügbarkeit von 66,5 bzw. 44,6 \% berichtet. Dieser Unterschied in der Zn-Verfügbarkeit zwischen beiden Futtermitteln könnte an deren unterschiedlichem Gehalt an Phytinsäure und Rohfaser liegen (NWOKOLO und BRAGG, 1977). Nach Angaben von LANTZSCH (1990) enthält Sojaextraktionsschrot eine um etwa 6 \% niedrigere Phytinsäurekonzentration als Rapsextraktionsschrot. Im Gegensatz hierzu steht die Auffassung von SETH et al. (1975), dass die Zn-Bindungskapazität bei Rapsextraktionsschrot stärker vom Tanningehalt beeinflusst wird.

Im Zusammenhang mit der Verbesserung der Mineralstoffverfügbarkeit des Futters untersuchten LANTZSCH et al. (1995) die Wirkung der Phytase in Gerste und Sojaextraktionsschrot auf die Ca-Absorption beim wachsenden Schwein. Dabei stellten die Autoren eine signifikant höhere Ca-Absorption (71 \%) bei einer Fütterungsgruppe mit Phytase als bei der Gruppe ohne Phytase fest. PAPATRYPHON et al. (1999) beobachteten auch eine verbesserte Phosphor-, Calcium-, Zink- und Eisenverdaulichkeit beim Fisch, wenn Phytase (2000 U) in einer phytatreichen Diät zugesetzt wurde. Ausgehend von den Versuchsergebnissen der Autoren ist zusammenzufassen, dass Phytase, die möglicherweise mit Phytinsäure gebundenen Nährstoffe freisetzt und dadurch gegen antinutritive Eigenschaften von Phytinsäure wirkt.

Eine andere antinutritive Wirkung der Phytinsäure könnte bei Monogastriden in der Verschlechterung der Proteinverwertung bei Monogastriden liegen. Dies wird dadurch verursacht, dass Phytinsäure mit Protein schwer lösliche Komplexe bildet und die Abspaltung der Peptidbindung durch proteolytische Enzyme einschränkt.

Die Bildung unlöslicher Phytat-Proteinkomplexe (Abb. 3) hängt vom pH-Wert und von der Proteinart ab (CHERYAN, 1980). Nach CHERYAN (1980) können ProteinPhytinsäurekomplexe in Wasser löslich und unlöslich sein, wenn die pH-Werte unter 3 liegen. Die Protein-Phytatkomplexbildung im sauren $\mathrm{pH}$-Bereich wird durch die $\mathrm{NH}_{3}{ }^{+}$-Gruppe der Aminosäuren gefördert (SCHEUERMANN, 1988). BARRE und HOUT (1965) identifizierten Lysin, Histidin und Arginin, vor allem terminale Aminosäuregruppen, wie die EpsilonAminogruppe von Lysin als Anknüpfungspunkte (Bindungsstelle) des Proteins mit Phytinsäure. Die Autoren ermittelten für Serumalbumin folgende Reihenfolge der 
abnehmenden Reaktionsfreudigkeit zwischen Aminosäuregruppen und Phytinsäure: Lysyl > Histidyl >Arginyl. Im Gegensatz dazu stellten die Autoren fest, dass die Affinität der Arginylreste von Eialbumin gegenüber Phytinsäure höher als die Lysyl- und Histidylreste sind.

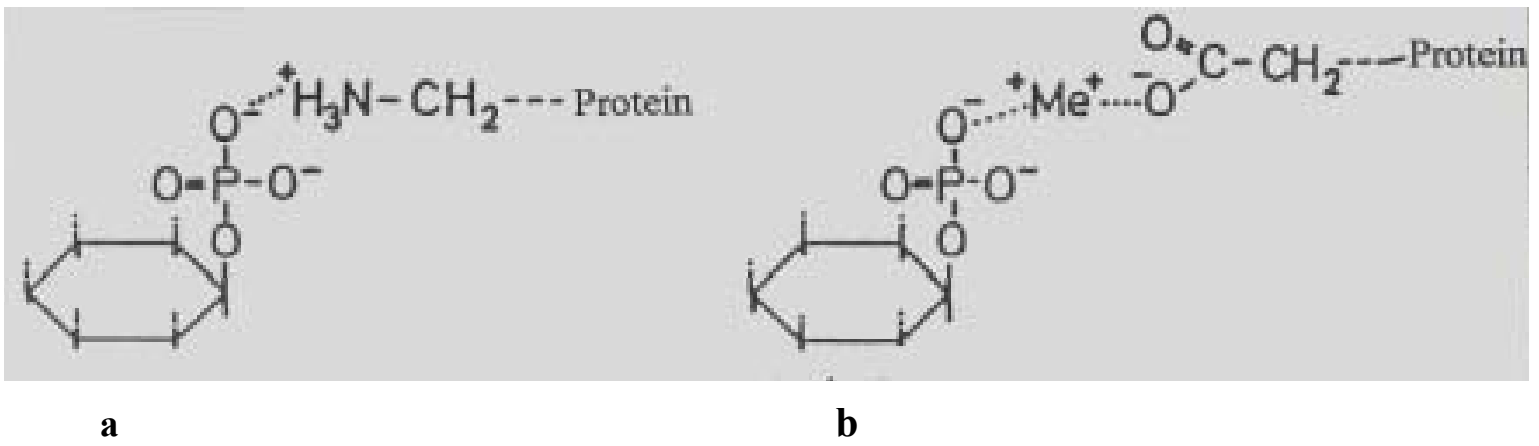

Abb. 3: Phytin-Protein-Komplexbildung im sauren (a) und alkalichen (b) Medium

THOMPSON und CHO (1984) beschrieben, dass die Proteinmoleküle im intermediären pHBereich mit Phytinsäure meistens über zweiwertige Kationen gebunden sind und in einem höheren pH-Bereich $(8-10)$ unlösliche Komplexe eingehen. Die pH-Abhängigkeit der Phytinsäurebindung an das Protein kann durch den Dissoziationsgrad der Phytinsäure erklärt werden.

KNUCKLES et al. (1985) zeigten in ihrer Untersuchung, dass phytingebundenes Serumalbumin im Vergleich zu phytingebundenem Casein durch Pepsin besser abgebaut wird. Nach der Auffassung der Autoren besitzen beide Proteinquellen unterschiedliche Konfigurationen und Reaktionsfreudigkeiten, sich mit Phytin zu komplexieren. O'DELL und DE BOLAND (1976) stellten fest, dass Sojaalbumine sich im Vergleich zu Sesamalbumin mit Phytinsäure stark komplexieren, während Maiskeimprotein keine Komplexbindung einging. Sie konnten jedoch keinen Zusammenhang zwischen der Aminosäurenzusammensetzung von Futtermitteln und der Phytatlöslichkeit ermitteln.

Für die Reduzierung der antinutritiven Eigenschaften des Phytats können thermische Verfahren eingesetzt werden. Unter Nutzung thermischer Verfahren, z. B. Autoklavieren, kann der Einfluss von Phytinsäure auf die ernährungsphysiologischen Parameter eingeschränkt werden. DE BOLAND et al. (1975) autoklavierten (1 h) reine Phytinsäure im Wasser bei pH 6. Dadurch reduzierte sich der Phytinsäuregehalt auf $50 \%$. Im Gegensatz hierzu hatte die Autoklavierung ( 0,5 und 2 h) der Ölsamen keinen signifikanten Effekt auf die Reduzierung des Phytinsäuregehalts. OLOGHOBO und FETUGA (1984) konnten auch durch das Kochen oder Autoklavieren der Sojabohnen keine signifikante Abnahme des 
Phytinsäuregehalts feststellen. Die Behandlung der Sojabohnen durch Mikrowellen für 9 und 15 min. führte zur Reduzierung der Phytinsäure um 23 \% bzw. 46 \%, während die Gammabestrahlung der Sojabohne keine Effekte auf die Reduzierung des Phytinsäuregehalts hatte (HAFEZ et al 1989). KRATZER et al. (1959) beobachteten, dass infolge der Abspaltung von Phytinsäure durch Autoklavieren eine Einsparung des Zn-Zusatzes für die Bedarfsdeckung von Puten in Sojabohnen- oder Sesamrationen möglich war. LEASE (1966) untersuchte den Effekt des Autoklavierens auf den Phytinsäuregehalt von Sesamschrot und die Verbesserung der Zn-Verfügbarkeit beim Broiler. Dabei sank der Phytinsäuregehalt nach $4 \mathrm{~h}$ Autoklavieren auf $78 \%$. In Fütterungsversuchen konnten auch erwartungsgemäss ZnMangelerscheinungen wie Knochendeformationen bei Broilern nur durch Autoklavieren für 4 $\mathrm{h}$ ohne Zn-Zusatz verhindert werden. Weiterhin ermittelten die Autoren bei Tieren, die mit einer unbehandelten Sesamschrotdiät gefüttert wurden, einen Zn-Gehalt in Höhe von $84 \mu \mathrm{g}$ Zn/g Knochenasche, während der Zn-Gehalt in der Knochenasche der Fütterungsgruppe, die mit einer vier Stunden lang autoklavierten Sesamdiät gefüttert wurden, bei $281 \mu \mathrm{g} \mathrm{Zn/g} \mathrm{lag.}$ Die Autoren vermuteten dabei, dass dieser Effekt an der möglichen Freisetzung des Zn durch thermische Zerstörung des Zn-Phytin-Proteinkomplexes oder des Zn-Phytinkomplexes liegen könnte.

Andererseits berichteten TABEKHIA et al. (1980), dass Phytat in der Bohne oder in Weizenkleie beim Kochen relativ hitzestabil ist und nicht zerstört werden kann. Nach CAMORE et al. (1981) kann das Toasten von Weizenkleie die metallionenbindende Eigenschaft der Phytinsäure sogar erhöhen. Im Zusammenhang mit der Verbesserung der Phytinphosphor-Verwertung von Mais und Sojaextraktionsschrot beim Broiler fanden EDWARDS et al. (1999) keinen Effekt der Behandlungsverfahren (Pelletierung und Extrusion) auf die Phosphorverwertbarkeit.

\subsubsection{Proteaseinhibitoren}

Für die ersten Schritte des hydrolytischen Abbaus der Eiweisse stehen im Magen-Darm-Trakt die Enzyme Pepsin bzw. Trypsin und Chymotrypsin zur Verfügung, die als Proteasen zusammengefaßt werden. Durch die Wirkung von Pepsin, Trypsin und Chymotrypsin auf die Peptidbindungen entstehen mehr oder weniger kleine Bruchstücke. Diese werden weiter durch die Pro-Carboxypeptidasen und Aminopeptidasen, die im Pankreas- bzw. Darmsekret vorhanden sind, bis zu den Aminosäuren abgebaut. Nach Auffassung von KIRCHGESSNER (1992) entstehen aus der Eiweißverdauung hauptsächlich freie Aminosäuren und niedere Peptide. 
Während die freien Aminosäuren direkt über die Darmmucosa absorbiert werden, werden die niederen Peptide nach der weiteren Abspaltung in der Darmmucosa als Aminosäuren absorbiert. Ein gewisser Anteil des nicht verdauten Eiweißes wird im Dickdarm durch Einwirkung der Mikroben zu $\mathrm{NH}_{3}$ abgebaut und über die Exkremente ausgeschieden.

Proteaseinhibitoren binden sowohl Trypsin als auch Chymotrypsin und können daher die Wirksamkeit des Trypsins und Chymotrypsins herabsetzen. Die Konsequenz daraus ist, dass auch die übrigen Proteasen aus der Bauchspeicheldrüse nicht aktiviert werden, so dass der Abbau der ins Duodenum gelangten Proteine nur unvollkommen abläuft. Da weiterhin die erforderlichen Rückkoppelungssignale ausbleiben, wird die Menge der sezernierten Vorstufen der Enzyme stark erhöht, was zu einer deutlichen Steigerung der endogenen N-Verluste für das Tier führt (LEPKOVSKY et al., 1966).

Proteaseinhibitoren (Trypsin- und Chymotrypsininhibitoren) kommen in Lebens- und Futtermitteln wie Eiklar, Leguminosen, Getreide und Kartoffeln natürlicherweise in unterschiedlichen Mengen vor. Nach Angaben von JEROCH et al. (1993) können diese Hemmstoffe etwa $15 \%$ des Sojaproteins ausmachen. Protease-Inhibitoren schützen die Pflanzen vor dem Befall durch Mikroorganismen und Pilze.

Die in den Leguminosen (Sojabohnen) verbreiteten Proteaseinhibitoren (PI) gehören zu den Familien der Bowman-Birk-, Kunitz- und Kartoffelinhibitoren (Potatoinhibitor). Chemisch gesehen besitzen Kunitz-Proteaseinhibitoren (MG ca. 2100) ein inhibitorisches Zentrum für Trypsin. Außerdem können sie gegen Chymotrypsin an zwei Zentren reagieren (LE GUEN et al., 1993). Beschrieben ist, dass Kunitz-Inhibitoren (KI) relativ hitze- und säurelabil sind und bei der üblichen Zubereitungsweise der Hülsenfrüchte weitgehend inaktiviert werden (FALBE und REGITZ, 1990). Im Gegensatz dazu werden die Bowman-Birk-Inhibitoren (BBI) durch ihr Molekulargewicht (MG ca. 8000) und ihren hohen Gehalt an Cystein charakterisiert, das sich an sieben Disulphidbrücken beteiligen kann. Bowman-Birk-Inhibitoren sind doppelköpfige Inhibitoren, die sich mit Proteasen, insbesondere mit Trypsin und Chymotrypsin, in verschiedenen aktiven Zentren verbinden können. Im Vergleich zu Kunitz-Inhibitoren weisen sie eine höhere Hitze- und Säurestabilität auf. Kartoffelinhibitoren werden aus Kartoffeln isoliert und weisen eine starke Hemmung gegen Chymotrypsin, Trypsin und Subtilisin, eine extrazelluläre einkettige alkalische Serinprotease, die von Bacillus subtilis gebildet wird, auf. Subtilisin dient den Bakterien beim Abbau der Nährstoffe.

Proteaseinhibitoren können hinsichtlich der Einschränkung der Carzinogenese beim Menschen eine große Rolle spielen. ZHANG et al. (1999) beschrieb, dass BBI aus Sojabohnen die mögliche Vermehrung von Lungen-Krebszellen im Vergleich zu Strahlen- 
und Chemotherapie stärker einschränkt. Bei Fütterung von Mäusen mit Diäten, die unterschiedliche Gehalte an BBI enhalten $(0-3 \%)$, stellten KENNEDY et al. (1996) eine Reduzierung der Tumorentwicklung sowie Verlängerung der Verdopplungszeit der Tumorzellen fest. Nach Auffasung von MOY und BILLINGS (1994) bilden die Krebszellen proteaseähnliche Enzyme, die durch Proteaseinhibitoren gehemmt werden.

In einer Reihe von Studien wurde darauf hingewiesen, dass bei Fütterung der Monogastrier mit inhibitorreichen Diäten negative Effekte auf Lebendmasseentwicklung, Proteinabbau und weitere physiologische Parameter sowie Pankreasvergrößerung, Reduzierung der Trypsinaktivität im Chymus und Steigerung der Trypsinaktivität im Pankreasgewebe zu erwarten sind.

\section{Einfluss des PI auf die proteolytische Aktivität im Chymus}

Im Zusammenhang mit der Fütterung von Monogastriden mit PI-reichem Futter gibt es zahlreiche Untersuchungen, die darauf hinweisen, dass PI einen Einfluss auf die Proteaseaktivität im Chymus nehmen. Z. B. berichteten HASDAI und LIENER (1983) und HARWOOD et al. (1983) bei Hamstern, NITSAN und LIENER (1976) bei Ratten sowie LEPKOVSKY et al. (1966) beim Broiler, dass rohe Sojabohnen im Vergleich zu erhitzten Sojabohnen die Trypsinaktivität reduzieren und die Chymotrypsinaktivität erhöhen. LIEBERT et al. (1996) fanden auch im Chymus des Jejunums der Tiere, die mit höheren TIA (23 U/g)- und niedrigeren TIA (6 U/g)- Konzentrationen gefüttert worden waren, eine Trypsinaktivität von 27 bzw. 38 U/g Chymusüberstand. YEN et al. (1977) berichteten, dass der TI mit Steigerung der TIA oder mit erhöhtem Anteil an rohen Sojabohnen in der Diät zu einer reduzierten Proteaseaktivität im Darmchymus beim Ferkel führt. Im Gegensatz zu der oben zitierten Arbeit von KHAYAMBASHI und LYMAN (1966) und ABBEY et al. (1979b) zeigte sich im Darminhalt von Ratten eine erhöhte Proteaseaktivität, wenn die Ratten durch Zulage des TI aus Sojabohnen und einer zusätzlichen Verabreichung von Aminosäuren in der Diät gefüttert wurden.

Die verschiedenen Darmabschnitte des Tieres weisen eine unterschiedliche Proteaseaktivität auf. GERTLER und NITSAN (1970) bestimmten z. B. die Proteaseaktivität im Chymus des Jejunums und Ileums. Dabei fanden die Autoren bei der Fütterung von Broilern mit einer aus rohen Sojabohnen hergestellten Diät eine niedrigere bzw. höhere Proteaseaktivität im Chymus des Jejunums bzw. Ileums. Die Wirkung für die erhitzte Sojabohnendiät war umgekehrt. In ähnlicher Weise untersuchten LE GUEN et al. (1993 ) beim Ferkel die Trypsinaktivität in verschiedenen Darmabschnitten. Dabei fanden sie eine niedrigere bzw. höhere 
Trypsinaktivität im Chymus des Ileums bzw. Jejunums. Im Gegensatz dazu fanden NITSAN und LIENER (1976) bei Ratten eine unveränderte Trypsinaktivität im Chymus des Duodenums und Ileums, wenn die Tiere mit einer Diät basierend auf rohen Sojabohnen gefüttert wurden. KAI et al. (1984) beobachteten in ihrer Untersuchung bei Ratten eine unveränderte Trypsinaktivität im proximalen Dünndarm aber eine erhöhte Aktivität im distalen Dünndarm.

\section{Einfluss des PI auf die Proteaseaktivität im Pankreas}

In einer Reihe von Literaturstudien wurde beschrieben, dass der PI die proteolytische Aktivität im Pankreas erhöht. Dies konnte z.B. in den Untersuchungen von GERTLER et al. (1967) und GERTLER und NITSAN (1970) festgestellt werden, wenn Küken und Ratten eine PI-reiche Diät bzw. unbehandelte Sojabohnendiät erhielten. NAIM et al. (1982) sowie ROY und SCHNEEMAN (1981) beobachteten ähnliche Auswirkungen des PI auf die Proteaseaktivität im Ratten- bzw. Mäusepankreas. In den Untersuchungen von KONIJN et al. (1970 a, b) synthetisierte das vergrößerte Pankreas der Ratten, die mit einer unbehandelten Sojabohnendiät gefüttert worden waren, mehr Trypsinogen und Chymotrypsinogen und weniger Amylase im Vergleich zu den Ratten, die mit einer ausreichend behandelten Sojabohnendiät gefüttert worden waren. Ähnliches zeigten auch die Untersuchungen von LIEBERT et al. (1996). Danach führte die höhere TI-Gehalte aufweisende Diät (Mais/Soja) beim Broiler im Vergleich zu der Diät mit niedrigeren TIA-Anteilen zur Erhöhung der Trypsinaktivität im Pankreasgewebe der Küken.

Neben der Erhöhung der Proteaseaktivität verringert die erhöhte Aufnahme des PI die Proteasekonzentration im Pankreas von Ratten (ABBEY et al., 1979b). Der zitierte Autor fand in seiner Untersuchung durch Fütterung von unbehandelten Sojabohnen eine verminderte Enzymkonzentration bis zum 21. Lebenstag der Ratten. Nach dem 21. Lebenstag nahm dabei die Wirkung des Proteaseinhibitors auf die Pankreassekretion ab. MADAR et al. (1974) beschrieb, dass die trypsinhemmende Seite des BBI im Vergleich zur chymotrypsinhemmenden Seite stärker an der Vergrößerung und Erhöhung der proteolytischen Aktivität beteiligt ist.

In anderen Untersuchungen von LEPKOVSKY et al. (1966) führte die Fütterung von Broilerküken mit einer unbehandelten Sojadiät zur Verringerung der Amylasekonzentration und Erhöhung der Proteasekonzentration im Pankreas. Bei gleichzeitiger Supplementation von Methionin, nahm die Amylasekonzentration im Pankreas wieder zu. Die Autoren vermuteten dabei, dass Methionin an der Amylasesynthese beteiligt sein könnte, d. h. die endogenen 
Verluste von Methionin, die durch eine erhöhte Pankreassekretion ausgeschieden wurden, können durch den Zusatz von Methionin kompensiert werden.

Ähnlich wie bei Ratten und Küken reagierte auch die Trypsin- und Chymotrypsinaktivität des Pankreas beim Ferkel, wenn sie mit rohen Erbsen gefüttert wurden (LE GUEN et al., 1991). Andererseits fanden SCHULZE et al. (1992) beim Ferkel keine Wirkung des Trypsininhibitors eines Sojabohnenkonzentrats auf die Proteaseaktivität im Pankreas.

\section{Einfluss des PI auf das Pankreas}

Mit dem Vorhandensein von PI im Futter kann auch eine Vergrößerung der Pankreasmasse bei kleinen Tieren erwartet werden. Dies wurde häufig bei Versuchen an Ratten (GERTLER et al., 1967 und MADAR et al., 1976 ) beobachtet, wenn die Tiere mit rohem Sojaschrot oder mit isoliertem nativen PI gefüttert wurden. Andererseits konnten NAIM et al. (1982) bei Ratten eine Pankreashypertrophie beobachten, obwohl die Diät mit einem sehr niedrigen PI-Zusatz angereichert worden war.

Die Reaktion des Pankreas auf PI hängt bei der Fütterung vom Rationsanteil der Leguminosen in der Diät ab. Pankreashypertrophie wurde z. B. in Rattenuntersuchungen von GREEN et al. (1986) beobachtet, wenn Sojabohnen (PI) in Caseindiäten mit einem Rationsanteil von 10 oder $20 \%$ zugesetzt wurden. Bei einem Rationsanteil von $5 \%$ aus Sojabohnen blieb die Wirkung des PI auf das Pankreas aus. Im Zusammenhang mit diesem Einfluss des PI fanden GUBMANN et al. (1989) bei der Prüfung der Wirkung eines Sojabohnenprotease- und Kartoffelinhibitors auf das Pankreas eine positive Korrelation zwischen den Diäten (mit unterschiedlichem Gehalt an PI abgestuft) und der Rattenpankreasmasse.

Die Untersuchungen von GERTLER et al. (1967) und GERTLER und NITSAN (1970) an Küken zeigen auch, dass eine Pankreasvergrößerung durch Zufuhr eines Proteaseinhibitors in einer auf erhitzten Sojabohnen basierenden Diät oder durch Fütterung mit einer Diät (basierend auf rohen Sojabohnen) verursacht wird. LIEBERT et al. (1996) beobachteten bei 12-tägiger Fütterung von Küken mit Diäten (Mais/Soja), die eine unterschiedliche TIA (6 TIU/mg Futter und 23 TIU/mg Futter) aufwiesen, eine signifikante Pankreashypertrophie mit erhöhter TIAufnahme. Die Autoren konnten keine Wirkung bei kurzzeitiger Verabreichung des TI ( isoliert aus Sojabohnen) auf das Pankreasgewicht feststellen. Im Gegensatz zu SojabohnenProteaseinhibitoren stellten BIRK und SMIRNOFF (1992) fest, dass der Zusatz von PI aus Kuherbsen (Vigna unguiculata) zu einer vorher erhitzten Sojaschrotdiät nicht immer zur Vergrößerung des Pankreas führt. Dabei scheint es, dass Proteaseinhibitoren in Abhängigkeit 
von der Herkunft der Proteaseinhibitoren auf das Pankreas einen unterschiedlichen Einfluss ausüben.

Anders als bei Küken und Ratten reagierte das Pankreas von erwachsenen Meerschweinchen, Hunden, wachsenden Schweinen, Kälbern und Menschen nicht bei einer PI-Aufnahme mit dem Futter bzw. mit Lebensmitteln (GALLAHER und SCHNEEMAN, 1986). Auch LIENER et al. (1985) konnten bei der Fütterung von Primaten mit einer Diät (basierend auf Sojabohnen) keine Veränderung des Pankreas beobachten. Bei der Verabreichung einer Ferkeldiät mit Rohsojabohnen oder mit aus Sojabohnen isoliertem PI stellten YEN et al. (1977) keine Veränderung des Pankreasgewichts der Tiere fest.

ABBEY et al. (1979b) stellten nach 7-, 14- und 21-tägiger Fütterung von Ratten mit Diäten auf Phaseolusbohnen-Basis (5 mg TI/kg T) eine Pankreasvergrößerung von 18, 37 bzw. 28\% fest. Dabei war die Wirkung des TI nach 14-tägiger Fütterungszeit nicht stark ausgeprägt. Andererseits beobachteten GERTLER und NITSAN (1970) bei der Fütterung der Broilerküken mit Sojaschrot eine Verminderung der Pankreasvergrößerung nach einer 21- tägigen Fütterungszeit. Mit verlängerter TI-Aufnahme im Futter können sich die Tiere also an das Futter gewöhnen, so dass die Wirkung des TI mit der Folge einer Pankreasvergrößerung reduziert wird. LIENER (1979a) deutet daraufhin, dass die Reaktion des Tierpankreas gegenüber rohen Sojabohnen und eines Trypsininhibitors (TI) von der relativen Pankreasgröße des Tieres (Pankreasmasse bezogen auf Körpergröße) abhängt. Der Autor beschrieb weiter, dass der Einfluss von TI auf die Pankreasvergrößerung nur bei kleinen Tieren (Maus, Ratte, Kaninchen und Küken) zu erwarten ist, wo das relative Pankreasgewicht des Tieres (im Vergleich zu der totalen Körpermasse) über 0,3 \% der gesamten Körpermasse liegt. Zu Wirkungsmechanismen des TI auf eine Pankreasvergrößerung vermuten einige Autoren wie LIENER (1979a) und GREEN et al. (1971), dass Hormone wie Cholecystokinin-Pancreozymin daran beteiligt sind oder, dass TI nach der intestinalen Absorption direkt auf das Pankreas wirken kann (FAUDEMAY et al., 1973). Allerdings konnte MADAR (1979) durch Fütterung von markiertem Sojabohnentrypsininhibitor (SBTI) an Küken nachweisen, dass eine SBTIAbsorption nicht erfolgen kann.

Andererseits berichtet LIENER (1979b), dass die Pankreassekretion vom Trypsin- und Chymotrypsingehalt im Darm abhängig ist. Wenn Trypsin und Chymotrypsin mit dem TI Komplexe bilden, wird der Gehalt an diesen Enzymen im Darm verringert. Mit erhöhter Komplexbildung kann der Gehalt des Enzyms im Darm unter einem Grenzwert liegen, so dass das Pankreas dadurch stimuliert wird mehr Enzyme zu synthetisieren. Diese Stimulation wird aber erst ausgelöst, wenn die Hormone Cholecystokinin-Pancreozymin (CCK-PZ) von der 
duodenalen Mukosa abgesondert wird (NIESS et al., 1972). In anderen Arbeiten von MIURA et al. (1997) wurde bewiesen, dass der Gehalt an CCK-PZ im Plasma der Ratten steigt, wenn SBTI im Protein des Futters vorhanden ist. SBTI stimuliert die CCK-PZ-Sekretion, die wiederum die Enzymsekretion des Pankreas erhöht. Aus dem Ergebnis der zitierten Autoren ergibt sich, dass sich eine langfristig hohe Aminosäureversorgung der Ratten auf die erhöhte Pankreassekretion auswirkt. Weiterhin zeigten MIURA et al. (1997), dass SBTI bei gleichzeitiger ausreichender Aminosäureversorgung keinen Einfluss auf CCK-PZ und Pankreassekretion hat.

\section{Einfluss des PI auf Leistungsparameter und N-Verwertung}

Die Folge der Hemmung von Proteasen kann eine niedrigere Verwertung des Proteins bei Ratten, Schweinen und Küken sein. PUSZTAI et al. (1992) beobachteten eine Reduzierung der Proteinverwertung um $20 \%$, wenn isolierte Erbsen-TI zu einer Laktalbumindiät zugesetzt wurden. Nach der Fütterung von Meerschweinchen mit einer Casein-, Sojaisolat- und Sojadrinkdiät als Proteinquelle verglich BLUM (1989) die Rohproteinausscheidung der jeweiligen drei Diätgruppen. Die Gesamtzufuhr an Trypsininhibitoren betrug 6,7 g, 30,4 g und 57,6 g für die Casein-, Sojaisolat- bzw. Sojadrinkdiät. Dabei fand sich im Kot der mit Sojadrink gefütterten Tiere eine höhere Konzentration an Rohprotein von 16,63 \% im Vergleich zu den Tieren, die Casein oder Sojaisolat erhielten. Diese höhere Rohproteinkonzentration im Kot war auf den höheren Trypsininhibitorgehalt in der Sojadiät zurückzuführen.

Die ileale und fäcale scheinbare Verdaulichkeit der Trockensubstanz (T), des Stickstoffs (N) und der Aminosäuren können auch bei monogastrischen Tieren vermindert werden, wenn PI in der Diät in unterschiedlicher Form, z.B. PI aus Kuherbsen (PUSZTAI et al., 1992), isoliertem Hemmstoffkonzentrat der Erbsen (HUISMAN et al., 1990) oder Erbsen (JONDREVILLE et al., 1992, PÉREZ und BOURDEN, 1992) vorhanden sind. In einem Ferkelversuch stellten LE GUEN et al. (1993) eine ileale N-Verdaulichkeit in Höhe von 70 \% für eine Diät mit rohen Erbsen bzw. 85 \% für eine Diät mit einem Isolat aus behandelten Erbsen (angereichert mit Hemmstoffkonzentrat aus Erbsen) fest. Im Gegensatz dazu konnten ABBEY et al. (1979a) bei Ratten keinen Unterschied in der N-Verdaulichkeit feststellen, obgleich die Tiere mit Caseindiäten, die unterschiedliche Gehalte an TI $(1,25 ; 2,5 ; 5$ und $10 \mathrm{~g} / \mathrm{kg})$ aufwiesen, erhielten.

LETERME et al. (1990) und JONDREVILLE et al. (1992) fanden beim Ferkel eine niedrigere N-Verdaulichkeit mit höherer TIA und eine höhere mit niedrigerer TIA für Erbsen. LE GUEN et al. (1993) sowie PÉREZ und BOURDEN (1992) stellten beim Ferkel zwischen TIA und den scheinbaren N-Verdaulichkeitskoeffizienten einen Korrelationskoeffizient von $-0,66$ bzw. $-0,70$ fest. Diese Korrelationskoeffizienten zeigen, dass der TI einer der wichtigsten negativen 
Faktoren ist, der die Verdaulichkeit der Erbsen beeinflusst. Ausgehend davon deuteten die Autoren daraufhin, dass $59 \%$ der verminderten N-Verdaulichkeit der Erbsen durch andere Faktoren hervorgerufen wird. Im Gegensatz dazu wurde für die Vielzahl der Erbsenarten keine große bedeutende Korrelation zwischen der scheinbaren N-Verdaulichkeit und TIA festgestellt. Das galt für Untersuchungen beim Schwein (GDALA et al., 1992) und Broilerküken (CARRÉ und CONAN, 1989).

Hinsichtlich der Proteinverwertung konnten PUSZTAI et al. (1992) eine um 20 \% reduzierte Proteinverwertung feststellen, wenn die Ratten mit einer Zulagen von TI (aus Kuherbsenisolat) in einer Lactalbumindiät gefüttert wurden.

Eine Wachstumsdepression kann in erster Linie durch PI verursacht werden, indem PI die Verdaulichkeit des Proteins sowie die Proteinverwertung vermindern. Nach KHAYAMBASHI und LYMAN (1966) kann eine Wachstumsdepression auf Grund des endogenen Verlustes an essentiellen Aminosäuren, insbesondere an Methionin, Cystin und Valin, verursacht werden, die infolge der PI-Aufnahme über eine erhöhte Pankreassekretion ausgeschieden werden.

Die negativ auswirkende Eigenschaft des PI auf die Lebendmasseentwicklung der Tiere wurde bereits von zahlreichen Autoren nachgewiesen. In der Untersuchung von HASDAI et al. (1989) erreichten Meerschweinchen einen LM-Zuwachs von 1,1 bzw. 3,1 g/d bei der Fütterung von nicht erhitzten bzw. erhitzten Sojabohnendiäten. HERKELMANN et al. (1992) fütterten Schweine mit zwei unterschiedlichen Sorten roher Sojabohnen (Sorte mit niedrigerem PIGehalt und herkömmliche Sojabohnen). Dabei wurde eine höhere Lebendmassezunahme von $9 \%$ in der Fütterungsgruppe von Sojabohnen mit niedrigerem PI-Gehalt im Vergleich zu der Gruppe, die mit der herkömmlichen Sojabohnendiät gefütterten wurde, festgestellt. In der Untersuchung von JONDREVILLE et al. (1992) führte die Fütterung mit rohen Erbsen (mit einem Rationsanteil von $40 \%$ in einem Ferkelfutter $\mathrm{zu}$ niedrigeren täglichen Lebendmassezunahmen in Höhe von 10 \% (rohe Erbsen mit höherer TrypsininhibitorAktivität) und $8 \%$ (rohe Erbsen mit niedrigerer Trypsininhibitor-Aktivität). Infolge einer Zulage des Erbsenkonzentrats in einer Ferkeldiät, die auf Proteinisolat basierte, beobachteten HUISMAN et al. (1990) beim Ferkel eine verminderte tägliche Lebendmassezunahme von 17 $\%$.

Bei der Rattenfütterung mit einer Caseindiät (mit unterschiedlichen TI-Gehalten von 1,25; 2,5; 5 und $10 \mathrm{~g} / \mathrm{kg}$ Futter) in verschiedenen Altersabschnitten (7., 14. und 21. Lebenstag) verglichen ABBEY et al. (1979a) die Wachstumsleistung der jeweiligen Diätgruppe. Dabei ergab sich eine signifikant hohe Wachstumsdepression (-35 \%) für die Fütterungsgruppe, deren Diät den 
höchsten PI-Gehalt (10 g PI/kg) aufwies. Außerdem stellten die Autoren fest, dass mit verlängerter PI-Aufnahme die Wachstumsdepression wieder abnimmt. Dies zeigt, dass die Tiere sich nach einer gewissen Fütterungszeit an den PI gewöhnen. Durch Zusatz einer PI aus der Kuherbse (Vigna unguiculata) in einer Rattendiät auf der Basis von Laktalbumin ergab sich in der Untersuchung von PUSZTAI et al. (1992) eine verminderte tägliche Lebendmassezunahme von $22 \%$.

Andererseits zeigten die Ratten- und Broileruntersuchungen von BIRK (1985) keine signifikante Wachstumsdepression, wenn die Tiere mit einer ausreichend erhitzten Sojabohnenration mit dem Zusatz von PI gefüttert wurden. In den Untersuchungen von KAKADE et al. (1976) wirkte sich der Zusatz eines gereinigten TI (aus Erbsen) im Futter auf das Wachstum von Kälbern nicht aus. In einem Broilerversuch von BARRIER et al. (1992) zeigte sich, dass eine Erbsendiät (Anteil der Erbsen 30 \%) keinen Einfluss auf das Wachstum von jungen Broilern hatte, obgleich die Erbsen sowohl niedrigere als auch höhere Trypsininhibitor-Aktivitäten (TIA) aufwiesen. Der Zusatz eines gereinigten PI aus Sojabohnen (GERTLER et al., 1967); GERTLER und NITSAN, 1970) oder Kichererbsen (BIRK und SMIRNOFF, 1992) zu einer Diät (basierend auf erhitztem Sojaextraktionsschrot) konnte den täglichen Lebendmassezuwachs (LMZ) der jungen Broiler nicht beeinträchtigen. Im Gegensatz dazu reduzierte die Fütterung von rohen Sojabohnen an wachsende Küken die tägliche LMZ stark (GERTLER et al., 1967). Es scheint daher, dass der Einfluss des TI auf Wachstumsparameter von der Herkunft des TI abhängt.

\subsection{Behandlungsverfahren für die Ausschaltung antinutritiver Faktoren}

Für die Beseitigung von unerwünschten Stoffen in Futtermitteln und die Verbesserung der Nährstofffverfügbarkeit und des Futterwertes eines Futters gibt es in der Praxis verschiedene Futterbehandlungsverfahren. Es handelt sich dabei um die folgenden Verfahren:

- mechanische Behandlungsverfahren

- thermische Behandlungsverfahren

- hydrothermische Behandlungsverfahren

- druckthermische Behandlungsverfahren

Die genannten Behandlungsverfahren lassen sich häufig miteinander kombinieren. Der Grad der Verbesserung des Futterwerts ist hierbei sehr stark abhängig von Einflussgrößen wie Druck, Temperatur, Feuchtigkeit und Verweilzeit. Bei der Futterbehandlung müssen diese Einflussgrößen berücksichtigt werden, um die gewünschten Effekte hinsichtlich der Verminderung antinutritiver Substanzen bei möglichst geringer Protein- und 
Aminosäurenschädigung zu erzielen. Wenn ein Futtermittel bei einer hohen Temperatur oder für lange Zeit erhitzt wird, können unerwünschte Nebenreaktionen (Maillardreaktion) auftreten, die sich negativ auf die Verdaulichkeit von Protein und insbesondere auf die Lysin- und andere Aminosäureverfügbarkeiten auswirken. Die Maillardreaktion entsteht dadurch, dass eine starke Erhitzung die im Futter vorhandenen Polysaccharide zu einfachem Zucker umwandelt und dieser mit freien Aminosäuren Komplexe bildet. Der gebildete Komplex ist durch Enzyme nicht mehr spaltbar. Durch starkes Erhitzen können auch andere Inhaltsstoffe wie Aromen, Vitamine und Zusatzstoffe geschädigt werden.

Die Effektivität der einzelnen Behandlungsverfahren hinsichtlich der Hemmstoffbeseitigung und der Verbesseung des Futterwertes sind nicht immer identisch. Durch hydrothermische Behandlungsverfahren wird z. B. bei einem relativ höheren PDI-Wert (ca. 25 \%) eine ausreichende Reduzierung der TIA im Vergleich zu thermischen Behandlungsverfahren (ca.16 \%) erreicht werden. Der PDI-Wert gibt den wasserlöslichen Eiweissanteil an. Die Bestimmung der PDI wird in der Praxis für die Beurteilung der Futterqualität verwendet. Dieser Wert sollte nach QIN (1996) mindestens bei $16 \%$ liegen. Ein erhitztes Futter, das einen PDI-Wert unter 16 $\%$ aufweist, wird als stark geschädigter Proteinträger bezeichnet. Deshalb ist die thermische Behandlung mit Risiken verbunden. Der Vorteil der hydrothermischen Behandlungsverfahren liegt darin, dass der Feuchtigkeitshaushalt des $\mathrm{zu}$ behandelnden Futters durch Verdampfungswärme geschützt werden kann, so dass diese Behandlungsverfahren eine möglichst geringe Proteinschädigung als thermische Behandlungsverfahren verursacht.

\subsubsection{Mechanische Behandlungsverfahren}

$\mathrm{Zu}$ diesen Behandlungsverfahren zählen die Zerkleinerung des Futters (Mahlen, Quetschen, Flockierung) in feinere und gröbere Komponenten sowie das Entschälen. Das Ziel der Zerkleinerung des Futters liegt unter anderem darin, die Effektivität der thermischen Behandlungsverfahren hinsichtlich der Senkung der antinutritiven Inhaltsstoffe zu steigern. Zugleich sind aber auch die unterschiedlichen verdauungsphysiologischen Konsquenzen, wie Magenverletzungen und Enzymeinwirkung, von Interesse.

\section{Zerkleinerungsverfahren}

Die Futtermittelzerkleinerung wird überwiegend mit der Hammermühle (HM) in horizontaler Rotoranordnung und zum Teil mit der Walzenmühle durchgeführt. In einer Hammermühle 
mit horizontaler Rotoranordnung wird das zu zerkleinernde Material durch die rotierenden Schläger zertrümmert und am Ende mittels auswechselbarer Siebe getrennt. Die Schlägergeschwindigkeit und die in der Hammermühle eingebauten Sieblochdurchmesser sowie der Durchsatz bestimmen die Feinheit des Mahlgutes. Eine Verringerung oder Erhöhung der Schlägergeschwindigkeit und Vergrößerung oder Verkleinerung des Sieblochdurchmessers kann zu gröberen bzw. feineren Zerkleinerungsprodukten führen.

Anders als bei der Hammermühle wird bei dem Walzenstuhl das Zerkleinerungsmaterial über Speisewalzen, den Mahlwalzen, zugeführt, wo das zu zerkleinernde Material mechanisch beansprucht wird. Eine Walzenmühle kann aus 2 bis 3 Paar Mahlwalzen bestehen, die vertikal angeordnet sind. Die Mahlspalte der letzten Walzenpaare hat die größte Wirkung auf die Partikelgrößenverteilung der Zerkleinerungsprodukte. In Walzenmühlen, die drei Paarwalzen besitzen, wird das Zerkleinerungsmaterial in den zwei oben liegenden Walzenpaaren vorzerkleinert und dadurch werden für den tieferliegenden Mahlspalt die Einzugsbedingung des Aufgabegutes verbessert. Der Mahlspalt des letzten Walzenpaares wirkt sich stärker auf die Partikelgrößenverteilung des Zerkleinerungsproduktes aus.

Die Walzen eines Paares haben normalerweise eine Drehzahldifferenz, die im Bereich von 1,2:1 bis 2:1 liegen kann. Durch die Einstellung des Abstandes zwischen den Paarwalzen und die Änderung der Drehzahl der Walzen wird der gewünschte Feinheitsgrad der Zerkleinerungsprodukte bestimmt. Eine Verringerung der Spaltenweite liefert z.B. ein feineres Zerkleinerungsprodukt. Die Vorteile der Walzenmühle im Gegensatz zur Hammermühle sind ein geringerer spezifischer Energieverbrauch, Feuchtigkeitsverlust des Produkts und geringerer Lärmpegel. Nach FRIEDRICH (1977) ist der spezifische Energieverbrauch des Walzenstuhles um etwa 30 - $40 \%$ geringer als bei der HM, da die Zerkleinerung zwischen den Walzen nur in engsten Spalten abläuft und keine ungünstigen weiteren Beanspruchungen und Bewegung des Mahlguts erforderlich sind, wie das bei Hammermühlen im Mahlraum geschieht.

Ein anderer wesentlicher Unterschied zwischen Hammermühle- und Walzenstuhl liegt insbesondere darin, dass die Zerkleinerungsprodukte von der Hammermühle im Vergleich zum Walzenstuhl relativ fein sind und eine breite Größenverteilung besitzen. Im Gegensatz dazu sind die Zerkleinerungsprodukte des Walzenstuhls relativ grob strukturiert und weisen eine engere Größenverteilung auf.

BEHNKE (1996) und HANCOCK (1998) berichten, dass Mahlgut vom Walzenstuhl im Vergleich zur Hammermühle leichter zu Magenverletzungen führen. Dies kann mit der Grobstrukturierung des Futters aus dem Walzenstuhl begründet werden. Nach BEHNKE (1996) kann eine geringere Festigkeit des Mageninhalts die Ursache für die erhöhten 
Magenverletzungen sein und, um dies zu vermeiden, ist die Grobstrukturierung der Partikel der sicherste Weg, die Festigkeit des Mageninhalts zu beeinflussen. Andererseits kann die Einheitlichkeit der Partikelgröße und -struktur des Mahlgutes vom Walzenstuhl für eine verbesserte Nährstoffverdaulichkeit von Bedeutung sein. GOIHL (1995) beschrieb, dass die Struktur des Mahlgutes von Hammermühlen anders als vom Walzenstuhl mehr kugelförmiger und gleicheckiger sind. Dieses kann die Zugänglichkeit der Enzyme zu den Nährstoffen und damit ihre Aufspaltung der Moleküle erschweren. WONDRA et al. (1995) und GOIHL (1995) verglichen den Futterwert von Maisdiäten beim Schwein, die mit Hammermühle oder Walzenstuhl zerkleinert waren. Die Autoren stellten dabei keinen signifikanten Unterschied zwischen dem Zerkleinerungsverfahren hinsichtlich der Wachstumsleistung der Tiere fest, während die Nährstoffverdaulichkeit in der Diät der Walzenstuhlgruppe besser als der der Hammermühlengruppe war.

\subsubsection{Thermische Behandlungsverfahren}

$\mathrm{Zu}$ den thermischen Behandlungsverfahren werden die Heißluftbehandlung (Jet sploder) und die Infrarotbestrahlung (Micronisation), Rösten und Mikrowelle gezählt (PEISKER, 1990). Diese Behandlungsverfahren erfolgen ohne zusätzliche Druckzugabe und zusätzlichen Wasserzusatz.

\section{Heißluftbehandlung}

Bei der Heißluftbehandlung werden die zu behandelnden Futtermittel bei hohen Temperaturen (ca. $115^{\circ} \mathrm{C}$ ) erhitzt. Die Prozeßluft wird von einem Modulationsbrenner auf ca. $300{ }^{\circ} \mathrm{C}$ erwärmt. Während des Behandlungsprozesses wird die Feuchtigkeit, die in den einzelnen Partikeln vorhanden ist, zum Verdampfen gebracht, anschließend wird das Produkt mit dem Flockierstuhl gequetscht.

WISEMAN (1984) verglich die Effektivität der Heißluftbehandlung mit Extrusion und Micronisation bei der umsetzbaren Energie von Vollfettsojabohnen. Die Autoren ermittelten dabei eine niedrigere umsetzbare Energie von 15,5 MJ/kg, während die umsetzbare Energie der extrudierten und mikronisierten Sojabohnen bei 17,9 bzw. 17,3 MJ/kg lag. Hierzu scheint, dass Stärke- und Fettaufschluss bei Heißluftbehandlung vergleichsweise eine untergeordnete Rolle spielt. 


\section{Mikrowellenbehandlung}

Bei diesem Behandlungsverfahren werden Mikrowellengeräte eingesetzt. Durch Mikrowellen werden in der Sojabohne Wassermoleküle zum Schwingen angeregt. Die Mikrowellenenergie wird über Wasser und freibewegliche Moleküle, die in der Sojabohnen vorhanden sind, absorbiert. Dies führt zur Reibung zwischen Molekülen und Erhöhung der Temperatur. Die Einflussgröße dieses Behandlungsverfahren sind Zeit und Feuchtigkeit.

HAFEZ et al. (1983) untersuchten in Abhängigkeit von der Zeit die Effektivität der Mikrowellen auf die Senkung der TIA von Sojabohnen sowie die Wachstumsparameter beim Broiler. Dabei wurde eine negative Korrelation $(r=0,96)$ zwischen TIA und Futteraufwand ermittelt. Die Autoren stellten weiterhin eine optimale Wachstumszunahme fest, wenn Sojabohnen bei 2450 MHZ für 9 oder 12 min. behandelt wurden. Bei unterschiedlichen Feuchtegehalten $(8 \%$ und 24 \%) der zu behandelnden Sojabohnen untersuchten YOSHIDA und KAJIMOTO (1988) die Effektivität der Mikrowelle auf die Senkung der TIA. Die Autoren ermittelten eine optimale Inaktivierung des TI, wenn Sojabohnen bei einem Feuchtegehalt von $24 \%$ behandelt wurden. Nach XIAN und FARRELL (1991) erzeugen Mikrowellen bei der Sojabohne vergleichbare Futterwerte wie extrudierte Sojabohnen.

\section{Rösten}

Das Rösten der Sojabohne erfolgt mit einem Röster. Der Röster besteht aus einem Zylinder, der mit einem Isolator bedeckt ist. An der Aussenseite des drehenden Zylinders stehen Flossen. Die zu behandelnden Sojabohnen werden durch die Flossen abwärts zur Flamme gebracht. Anschließend werden sie durch drehende Zylinder in den Gasraum eingeführt, in dem die Sojabohnen eine Ausgangstemperatur von $110{ }^{\circ} \mathrm{C}$ erreichten. Dieses Behandlungsverfahren führt zum Verlust an Wasser bis auf $30 \%$.

Zeit, Temperatur und Feuchtigkeit sind bei diesem Behandlungsverfahren für die ausreichende Senkung der ANF's entscheidende Faktoren. OSELLA et al. (1997) konnten in der bei $100{ }^{\circ} \mathrm{C}$ und $110^{\circ} \mathrm{C}$ für 5 min. gerösteten Sojabohne keine signifikante Reduzierung des TI feststellen, wenn jedoch die Behandlungszeit verlängert oder die Behandlungstemperatur erhöht wurde, nahm die TIA signifikant ab.

\section{Infrarotbestrahlung (Micronisation)}

Bei der Infrarotbestrahlung handelt es sich nach GÜNTER (1988) um eine kurzzeitige (0,5 bis 3 min. andauernde) trockene Hitzebehandlung. Dabei erhöht sich die Temperatur des 
behandelten Materials auf $156-170{ }^{\circ} \mathrm{C}$. Nach JANSEN und FRIEDRICH (1975) erfordert dieses Behandlungsverfahren eine intensive Kontrolle, um negative Erscheinungen wie die Maillardreaktion (Umsetzung zwischen Aldehygruppe der reduzierenden Zucker und freien Aminosäuren) zu vermeiden.

Die Infrarotbestrahlung teilt sich in drei Bereiche: kurzwellig $(0,76$ bis 2,5 $\mu \mathrm{m})$, mittelwellig $(2,5$ bis $50 \mu \mathrm{m})$ und langwellig $(>50 \mu \mathrm{m})$. Im allgemeinen wird der langwellige Teil des Infrarotspektrums als Wärmestrahlung bezeichnet. Bei diesem Behandlungsprozess ist der Energieverbrauch relativ hoch.

FABER und ZIMMERMANN (1973) berichten, dass Sojabohnen, die durch Infrarot für 3 min. behandelt wurden, trotz der ausreichenden Senkung der TIA eine geringere Protein- und Fettverdaulichkeit im Vergleich zu extrudierten (bei $138^{\circ} \mathrm{C}$ ) Sojabohnen haben. BENGALA et al. (1991) deuteten daraufhin, dass Extrusion die Zellstrukturen der Sojabohnen mechanisch zerstören und dadurch die Nährstoffe enzymatisch stärker abgebaut werden können.

\subsubsection{Hydrothermische Behandlungsverfahren}

Bei den hydrothermischen Behandlungsverfahren sind die Aufenthaltsdauer, Materialtemperatur und Feuchtigkeit die entscheidenden Faktoren, um den gewünschten Effekt zu erzielen. Die Behandlung des Futters kann bei Außendruck oder Überdruck erfolgen.

$\mathrm{Zu}$ diesem Verfahren wird die Autoklavierung, Extrusion, das Expandieren und Kochen (, Pressure-Cooking“) sowie die Konditionierung im Hydroreaktor gezählt.

Die Wirkung der hydrothermischen Verfahren beruht nicht nur auf der Zufuhr von Wärme mittels Dampf, sondern auch im Zusammenwirken mit der Produktfeuchtigkeit, die zu einer Strukturänderung der Stärke führen können.

\section{Autoklavieren}

Beim Autoklavieren wird ein Überdruck in einem geschlossenen Behälter durch das Erhitzen von Wasser erzeugt. Stärke wird aufgeschlossen und der Gehalt an antinutritiven Substanzen in den Futtermitteln vermindert. Unter Nutzung dieser Futterbearbeitungstechnologie liegen in der Literatur Hinweise vor, dass eine Verbesserung des Futterwertes möglich ist. Nach SIBBALD (1980) nahm die wahre umsetzbare Energie (TME) im Versuch mit Legehennen zu, wenn die Tiere mit autoklavierten Sojabohnenflocken gefüttert wurden.

ALETOR und OJO (1989) verglichen die Wirkung des Kochens, Röstens und Autoklavierens auf die antinutritiven Inhaltsstoffe bei Sojabohnen (Tab. 2). Die Ergebnisse zeigen, dass die TIA 
beim Autoklavieren nur um $70 \%$ verringert wurde. Dabei war eine lange Autoklavierdauer erforderlich, um die TIA deutlich zu senken.

Tab. 2: Auswirkung der unterschiedlichen Futterbearbeitungsverfahren auf die antinutritiven Inhaltsstoffe der Sojabohne (nach ALETOR und OJO, 1989)

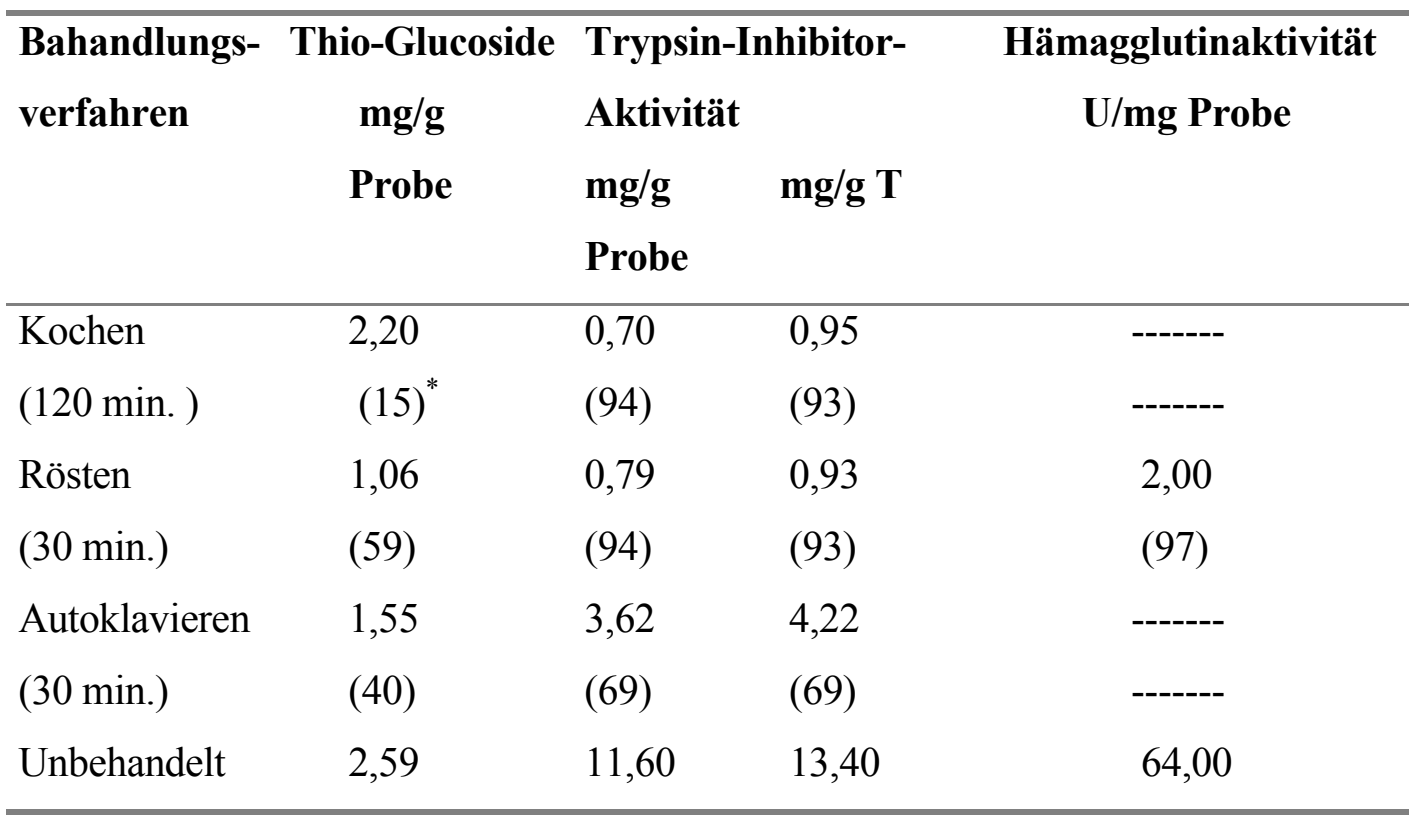

* Restgehalt im Prozent im Vergleich zu unbehandelten Sojabohnen (=100)

\section{Kochen}

Unter Kochen ist das Erhitzen von Wasser auf eine Temperatur von $100{ }^{\circ} \mathrm{C}$ zu verstehen. Anders als beim Autoklavieren oder bei der Expandierung wird beim Kochen nur Luftdruck ausgeübt. Nach McNAUGHTON und REECE (1980) wird unter "Cooking-Time" sowohl das Erhitzen mit trockener Hitze als auch das Autoklavieren verstanden. Untersuchungen von PETRES und CZUKOR (1990) ergaben, dass die Urease- und die Trypsininhibitoraktivität in Abhängigkeit von der Temperatur und der Dauer des Erhitzens reduziert werden. Dabei sank die Ureaseaktivität bei einer Temperatur von $95{ }^{\circ} \mathrm{C}$ und einer Verweilzeit von $20 \mathrm{~min}$. auf $0 \% \mathrm{ab}$.

\section{Hydroreaktor}

Eine hydrothermische Behandlung des Futters kann auch mit einem Hydroreaktor erfolgen. Ein Hydroreaktor besteht aus einem Gehäuse, in dem Platten in mehreren Stufen mit speziellen Öffnungen eingebaut sind. Während des Futterbehandlungsprozesses wird Dampf direkt in die einzelnen Stufen eingeführt . 
Die Behandlung des Futters mit dem Hydroreaktor wird wie folgt durchgeführt: Das Futter wird zunächst mit einem Walzenstuhl (Brechwalzen) grob zerkleinert. Das Vermahlen des Materials ist dabei nicht erforderlich. Das zu behandelnde Futter wird dann über den Durchlaufmischer dem Hydroreaktor zugeführt. Der Durchlaufmischer wird dabei auf die erforderlichen Prozessbedingungen eingestellt. Dort wird das Futter vor dem Eintritt in den Reaktor mit Wasser angefeuchtet und mit der Zufuhr von Dampf steigt die Temperatur des Futters von 85 bis auf $102{ }^{\circ} \mathrm{C}$ an. Im Reaktor wird die eigentliche Reaktion durchgeführt und das Produkt läuft von einer Stufe zur nächsten langsam über die Plattenöffnung nach unten durch.

Für den Erfolg dieses Behandlungsverfahrens sind die Verweilzeit des Produkts im Hydroreaktor (10 bis 40 min.), die Temperatur und der Feuchtgehalt des Produkts die entscheidenden Faktoren.

QIN et al. (1996) untersuchten die Effekte der Dampferhitzung unter Verwendung von Dampfdrucktoastern bei unterschiedlicher Temperatur und Zeit auf die Inaktivierung der ANF's und die ileale Verdaulichkeit der Sojabohnen beim Schwein. Dabei konnte eine maximale Minimierung der $\mathrm{ANF}$ 's bei $100{ }^{\circ} \mathrm{C}$ für $40 \mathrm{~min}$. und $134{ }^{\circ} \mathrm{C}$ für $1,5 \mathrm{~min}$. erzielt werden. Hinsichtlich der Nährstoffverdaulichkeit zeigten beide Temperatur-Zeit-Kombinationen ähnliche Resultate. Nach CAREW et al. (1962) ist die Fettverdaulichkeit der dampferhitzten Sojabohnen geringer als bei extrudierten Sojabohnen, weil bei der Dampferhitzung die mechanische Zerstörung der Zellwand entfällt.

\subsubsection{Druckthermische Behandlungsverfahren}

\section{Expandieren}

Expandieren bedeutet, dass das $\mathrm{zu}$ behandelnde Futter sich durch Erhitzung ausdehnt. Die Behandlung des Futters erfolgt mit einem Expander. Das Funktionsprinzip des Expanders geht aus der Abb. 3 hevor. Futter gelangt dabei in das Gehäuse des Expanders, wo Schnecken eingebaut sind. 


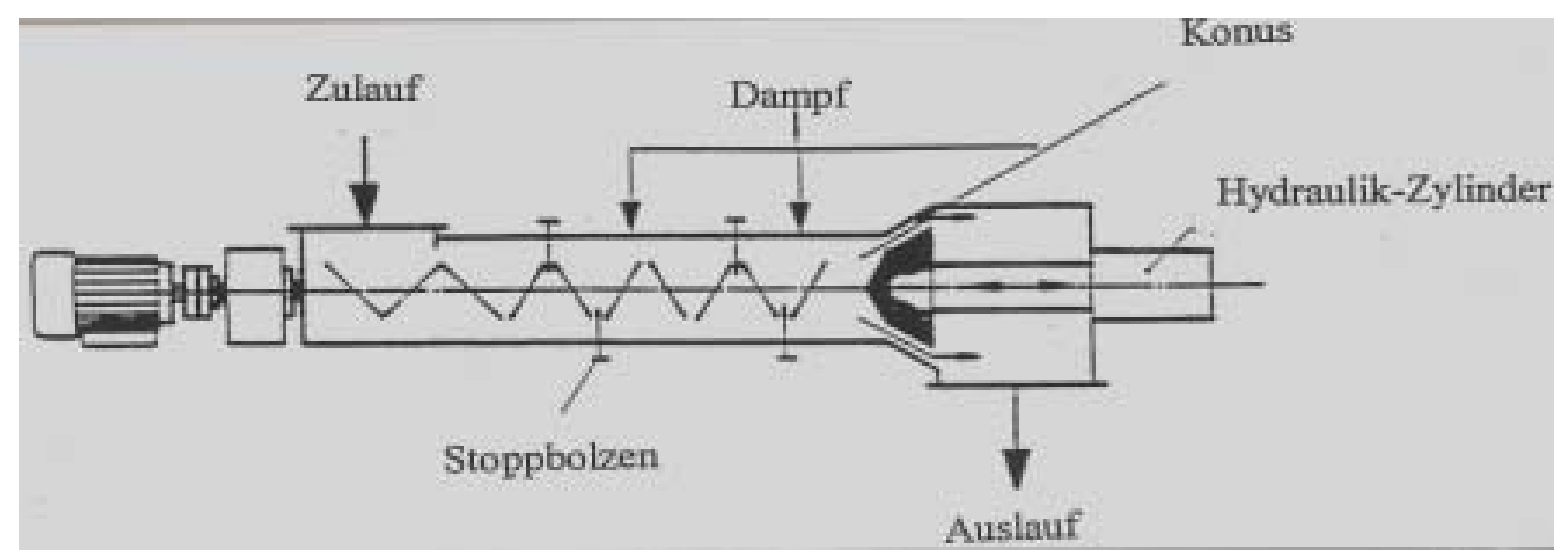

Abb. 4: Funktionsprinzip des Expanders

Durch die mechanische Bewegung der Schnecken wird das Futter zusammengedrückt und durch die Reibung erhöht sich die Temperatur im Futter. Außerdem wird am vorderen Teil des Expanders ein sogenannter Konus eingebaut, der sich hydraulisch bewegt und im Expander Überdruck erzeugt. Dieses führt zur Temperaturerhöhung im Expander. Während der Wirkungszeit im Expandergehäuse kann auch Dampf unter hohem Druck für kurze Zeit zugeführt werden. Anschließend wird das Futter plötzlich entlastet, wobei sich das Volumen des Originalmaterials auf das 8-fache vergrößern kann. Das Endprodukt wird dabei als Expandat bezeichnet. Die Behandlung des Futtermittels mit einem Expander (Druck-thermische Behandlung) kann mit einer Vorkonditionierung verknüpft werden.

Nach HEIDENREICH (1996) können die folgenden Haupteffekte als Ergebnis einer Behandlung mit dem Expander erwartet werden:

-Keimreduzierung und Hygienisierung

-Modifikation und Hydrolisierung der Stärke

-Abbau antinutritiver Substanzen

-Verringerung der Schüttdichte

-Erniedrigung der Proteinlöslichkeit in Wasser

-Änderung der sensorischen Eigenschaften.

Diese druckthermische Behandlung kann durch druck- und temperatursteigernde Elemente des Expanders erweitert werden. Dabei handelt es sich um die Änderung der Anzahl der Stoppbolzen, die geometrische Anordnung der Schnecken und des Konus sowie die Futterstruktur des zu behandelnden Materials. Durch die Erhöhung der Anzahl der Stoppbolzen oder der Schneckenelemente ist es möglich, einen höheren Druck und eine höhere Temperatur im Expander zu erzeugen, die dementsprechend auf die Modifizierung der Stärke und Zerstörung 
der unerwünschten Stoffe im Futter Einfluss nehmen. Hinsichtlich der Futterstruktur ist zu vermuten, dass ein fein strukturiertes Futter für die Temperatur- und Druckerhöhung im Expander besser als ein grob strukturiertes Futter sein kann. Im allgemeinen können durch die Erweiterungsmöglichkeiten des Expanders ein besserer Stärkeaufschluß und eine weitere Ausschaltung der antinutritiven Substanzen und damit eine höhere Proteinverdaulichkeit sowie eine ausreichende Verringerung der Keimzahl im Futter erzielt werden.

TRAYLOR et al. (1997) prüften beim Schwein die Effektivität der Expanderbehandlung auf die Nährstoffverdaulichkeit von Sojabohnen, die bei unterschiedlichem Druckeinsatz $(0,14,28$ $\mathrm{kg} / \mathrm{cm}^{2}$ ) erfolgte. Die Autoren fanden infolge der Druckerhöhung über den Konus eine kontinuierliche, lineare Steigerung der N-Verdaulichkeit in Höhe von 76, 77 bzw. 78 \%.

JOHNSTON et al. (1997) prüften die Effekte der hydrothermischen (Standardverfahren) und druckthermischen Behandlungsverfahren (Expander) auf Sojabohnen beim Schwein. Dabei wurde eine maximale Wachstumsrate in der hydrothermisch behandelten Fütterungsgruppe ermittelt. Dabei führte das hydrothermische Behandlungsverfahren im Vergleich zur Expandierung zu maximaler Wachstumsrate.

Beim Einsatz des Expanders konnten zusätzliche Effekte, wie Reduzierung der Pressenbelastung, Verbesserung der Preßfähigkeit und der Pelletqualität und Senkung des spezifischen Energieverbrauches erreicht werden. MELANDRI (1998) verglich die Pelletqualität des Futters vor und nach der Expandierung. Die Pelletqualität wurde dabei um $25 \%$ verbessert, wenn die Pelletierung des Futters nach der Expandierung durchgeführt wurde. Bei Fütterung von Puten mit expandiertem und pelletiertem Futter konnten die Tiere ein Wachstum von 8,6 kg erreichen, während die Lebendmasse der Tiere, die nur pelletiertes Futter bekamen, eine Endlebendmasse von $8 \mathrm{~kg}$ erreichten.

\section{Extrusion}

Die Extrusion des Futters wird mit Hilfe von Extrudern durchgeführt. In das Gehäuse des Extruders ist wie beim Expander eine rotierende Schneckenwelle eingebaut. Die Schneckenwelle wird mit einem Motor angetrieben.

Die Behandlung des Futters mit dem Extruder ist wie folgt: Das Futter wird zunächst nach der Vorkonditionierung mit Saatdampf dem Extruder zugeführt und dort mit den Schnecken verdichtet. Vom Grundprinzip her ist der Extruder eine Schneckenpresse, in der das zu behandelnde Material eine thermische und mechanische Behandlung erfährt. Je nach 
Betriebsbedingungen wird während der Extrusion die körnig vorliegende Stoffmatrix in einen plastischen und formbaren Zustand gebracht. Es baut sich ein Druck auf, der kurz vor der Austrittsöffnung des Extruders den höchsten Wert erreicht. Dort entstehen für kurze Zeit hohe Temperaturen von 140 bis $150^{\circ} \mathrm{C}$. Beim Austritt des Futters aus der Stoffmatrix verdampft ein Teil der Materialfeuchtigkeit.

Das Behandlungsverfahren mit dem Extruder bezieht folgende Faktoren mit ein: Temperatur, Feuchtigkeit, Druck und Verweilzeit. Eine Temperaturerhöhung oder Druckerhöhung wird durch Veränderung der Konfiguration von Schneckenwelle, Dampfzufuhr sowie durch Einsatz von Matritzen mit unterschiedlicher Form und Öffnungsgröße erreichbar.

Während des Extrusionprozesses spielt Scherkraft eine große Rolle für die Strukturierung des Proteins. Erhöhte Scherkraft denaturiert das Protein und macht damit den enzymatischen Abbau der Nährstoffe stärker zugänglich. Bei überschüssigem Energieeinsatz entsteht jedoch die Gefahr, dass unerwünschte Maillardreaktionen, die den Futterwert der Sojabohne vermindern, auftreten.

Bei geeigneten Betriebsbedingungen der Extrusion kann in der Vollfettsojabohne eine ausreichende Reduzierung der TIA erreicht werden. MARSMAN et al. (1993) ermittelten bei einer Temperatur von $115{ }^{\circ} \mathrm{C}$ und einem Feuchtegehalt von $23 \%$ bei extrudierten Sojaohnen eine TIA von $4 \mathrm{mg} / \mathrm{g}$ T, die für die Fütterung der Monogastriden in einer annehmbaren Höhe liegt (VALDEBOUZE, 1980). Im Gegensatz hierzu konnten LIEBERT et al. (1996) keine ausreichende Reduzierung der TIA durch Extrusion von Vollfettsojabohnen bei $115^{\circ} \mathrm{C}$ (keine Angabe von Feuchtgehalt) feststellen. Die unterschiedlichen Befunde von beiden Autoren können von den unterschiedlichen Betriebsbedingungen (z. B. Feuchtgehalt des Materials) abhängen. Bei einem geringeren Feuchtegehalt der Sojabohne ist eine höhere Temperatur bis auf $150{ }^{\circ} \mathrm{C}$ erforderlich, um eine ausreichende Reduzierung der TIA zu erreichen.

Durch Extrusion der Sojabohne kann auch eine höhere Gelatinisierung der Stärke erwartet werden. Die Untersuchung von MARSMAN et al. (1997) zeigt, dass die ileale Verdaulichkeit der Nicht-Stärke-Polysaccharide von Sojaextraktionschrot beim Broiler im Vergleich zur getoasteten Variante verbessert wurde $(267 \mathrm{~g} / \mathrm{kg}$ vs. $114 \mathrm{~g} / \mathrm{kg})$. Der besondere Vorteil der Extrudierung liegt darin, dass Rohfaser durch mechanische Behandlung (Scherkraft) strukturiert und homogenisiert wird, so dass ein besserer Aufschluß (Fermentation) der Rohfaser im Verdauungstrakt die Folge sein kann. 
Hinsichtlich der Verbesserung der umsetzbaren Energie im Futter verglich WISEMANN (1984) die Wirkung von Extrusion, Micronisation, Jet-Sploder Toaster auf die umsetzbare Energie der Vollfettsojabohne bei wachsenden Küken. Dabei fand der Autor den höchsten Gehalt an umsetzbarer Energie von 17,9 MJ/kg für extrudierte Vollfettsojabohnen, während bei mikronisierten und trocken erhitzten Sojabohnen 17,5 und 15,5 MJ/kg ermittelt wurden. 


\section{Material und Methode}

\subsection{Behandlung der Vollfettsojabohnen}

Die technologischen Behandlungen der Vollfettsojabohnen, die zur Differenzierung der TIAktivität in den Sojabohnen führen sollten, wurden in der Tab. 3 zusammengefaßt. Die einzelnen Behandlungsverfahren wurden dabei von A bis K gekennzeichnet. Für die Herstellung von zwei unterschiedlichen Futterstrukturen wurden Sojabohnen mit der Hammermühle oder dem Walzenstuhl zerkleinert. Die Konditionierung erfolgte bei den Behandlungsgruppen für 10 min. (Gruppe C, D, E, F und G) und 40 min. (Gruppe A und B) im Hydroreaktor unter Dampfeinsatz bei $100{ }^{\circ} \mathrm{C}$. Zur Expanderbehandlung mit differenziertem Energieeintrag (20 und $40 \mathrm{kWh} / \mathrm{t}$ ) kam der Expander Kahl Typ-OE.2 zum Einsatz. Für die Extrusion der Behandlungsvariante E wurde die Stoffmatrize eines Extruders nach Ausbauen des Expanderkopfes (Konus) angebaut.

\section{Tab. 3: Behandlungen von Sojabohnen}

\begin{tabular}{|c|c|}
\hline Zerkleinerung mit dem Walzenstuhl & Zerkleinerung mit der Hammermühle \\
\hline A) Standardverfahren & E) Konditionierung (10 min.), $100^{\circ} \mathrm{C}$ \\
\hline Konditionierung (40 $\mathrm{min}.), 100{ }^{\circ} \mathrm{C}$ & Extruder, $120^{\circ} \mathrm{C}(15 \mathrm{kWh} / \mathrm{t})$ \\
\hline B) Konditionierung (40 min.), $100{ }^{\circ} \mathrm{C}$ & F) Konditionierung (10 $\mathrm{min}.), 100^{\circ} \mathrm{C}$ \\
\hline Flockierung & \\
\hline C) Konditionierung (10 min.), $100^{\circ} \mathrm{C}$ & G) Konditionierung (10 min.), $100^{\circ} \mathrm{C}$ \\
\hline & Expander, $125^{\circ} \mathrm{C}(20 \mathrm{kWh} / \mathrm{t})$ \\
\hline D) Konditionierung (10 min.), $100{ }^{\circ} \mathrm{C}$ & H) Expander, $120^{\circ} \mathrm{C}(20 \mathrm{kWh} / \mathrm{t})$ \\
\hline Expander, $125^{\circ} \mathrm{C}(20 \mathrm{kWh} / \mathrm{t})$ & \\
\hline & I) Expander, $130^{\circ} \mathrm{C}(15 \mathrm{kWh} / \mathrm{t})$, \\
\hline & Dampfzusatz \\
\hline & K) Expander, $135^{\circ} \mathrm{C}(40 \mathrm{kWh} / \mathrm{t})$ \\
\hline
\end{tabular}

Die Sojabohnen wurden nach der Behandlung sofort bei kalter Luft für $2 \mathrm{~h}$ abgekühlt und bis zur Herstellung der Versuchsfuttermischungen im Kühlraum $\left(-20{ }^{\circ} \mathrm{C}\right)$ gelagert, um eine Fettoxidation zu vermeiden. Die gesamte Durchfürung der einzelnen Techniken sind in der Literaturübersicht erläutert (Abschnit 2.2). 


\subsubsection{Herstellung der Versuchsdiäten}

Die Basis der verwendeten Futtermischungen ist aus Tab. 4 zu entnehmen. In Tab. 5 und 6 sind die Nährstoffzusammensetzungen der Hauptfutterkomponenten bzw. Futtermischungen dargestellt.

Die Futtermischungen wurden generell mit einem Mischungsanteil behandelter Sojabohnen von $36 \%$ hergestellt. Um einen vergleichbaren Feinheitsgrad zwischen den behandelten Sojabohnen zu erreichen, wurden die behandelten Sojabohnen (A, B, C und D) vor der Herstellung der Futtermischungen zusätzlich mit einer Hammermühle zerkleinert.

Tab. 4: Basisrezeptur der Futtermischung (g/kg Futter)

\begin{tabular}{|c|c|}
\hline Anteil & Komponenten \\
\hline 544,0 & Maisschrot \\
\hline 360,0 & Sojabohnen differenziert behandelt (s. Tab. 3) \\
\hline 50,0 & Weizenkleber \\
\hline 18,6 & $\mathrm{CaCO}_{3}$ \\
\hline 10,6 & $\mathrm{MCP}\left(\mathrm{Ca}\left(\mathrm{H}_{2} \mathrm{PO}_{4}\right)_{2} \cdot \mathrm{H}_{2} \mathrm{O}\right)$ \\
\hline 3,8 & $\mathrm{NaCl}$ \\
\hline 10,0 & Vitamin- und Spurenelementvormischung (Vilomix)* \\
\hline 2,0 & DL-Methionin \\
\hline 1,0 & L-Threonin \\
\hline $\begin{array}{l}* 12000 \text { I.E. Vitamin } \\
3,60 \mathrm{mg} \text { Vitamin } \mathrm{B}_{6} \\
9 \mathrm{mg} \text { Calcium-Pantc } \\
80 \mathrm{mg} \text { Zink, } 50 \mathrm{mg} \\
100 \mathrm{mg} \text { BHT supple }\end{array}$ & $\begin{array}{l}\text { itamin } \mathrm{D}_{3}, 30 \mathrm{mg} \text { Vitamin } \mathrm{E}, 2 \mathrm{mg} \text { Vitamin } \mathrm{B}_{1}, 4,80 \mathrm{mg} \text { Vitamin } \mathrm{B}_{2} \text {, } \\
\text { Vitamin } \mathrm{B}_{12}, 3 \mathrm{mg} \text { Vitamin } \mathrm{K}_{3}, 27 \mathrm{mg} \text { Nikotinsäure, } \\
\text { mg Folsäure, 0,5 mg Biotin, } 800 \mathrm{mg} \text { Cholinchlorid, } 120 \mathrm{mg} \text { Mangan, } \\
\text { mg Kupfer, } 1,2 \mathrm{mg} \text { Jod, } 0,55 \mathrm{mg} \text { Kobalt, } 0,42 \mathrm{mg} \text { Selen, } \\
\text { e kg Futter }\end{array}$ \\
\hline
\end{tabular}


Tab. 5: Ausgewählte Inhaltsstoffe der Komponenten (g/der T)

\begin{tabular}{lccc}
\hline Inhaltsstoffe & Maisschrot & Sojabohne behandelt & Weizenkleber \\
\hline Rohprotein & 97,7 & 415,0 & 875,7 \\
Rohfett & 51,1 & 216,8 & 64,2 \\
Rohasche & 15,4 & 56,6 & 11,6 \\
Rohfaser & 26,4 & 58,0 & 5,0 \\
N-freie Extraktstoffe & 809,4 & 253,6 & 43,5 \\
Stärke & 747,7 & 20,6 & 77,9 \\
Zucker & 10,8 & 85,0 & 19,7 \\
Methionin + Cystin & 4,0 & 12,8 & 15,9 \\
Lysin* & 2,5 & 24,4 & 17,8 \\
Threonin & 3,0 & 14,7 & 19,8 \\
\hline
\end{tabular}

*) limitierende Aminosäure

Tab. 6: Mittlere Nährstoffzusammensetzung der Basismischungen (g/kg T)

\begin{tabular}{lc}
\hline Inhaltsstoffe & Anteil \\
\hline Rohprotein & $245,5 \pm 1,3$ \\
Rohfett & $107,0 \pm 2,8$ \\
Rohasche & $69,3 \pm 1,3$ \\
Rohfaser & $36,6 \pm 2,4$ \\
N-freie Extraktstoffe & 541,6 \\
Stärke & 412,4 \\
Zucker & 38,5 \\
Methionin + Cystin & 10,5 \\
Lysin* & 11,1 \\
Threonin & 9,3 \\
ME $\mathrm{N}-\mathrm{korr}(\mathrm{MJ} / \mathrm{kg} \mathrm{T})^{* *}$ & 14,86
\end{tabular}

*) limitierende Aminosäure

**) Berechnet nach der WPSA-Formel (1984)

Die Vormischung der Kleinkomponenten (Prämix, Aminosäuren und Mineralstoffe) der Versuchsdiäten erfolgte in einem Lödige-Mischer (TYP AD7IN24). Danach wurden die 
Vormischungen und die anderen Hauptfutterkomponenten (Mais, Sojaschrot und Weizenkleber) in einem großen Lödige-Mischer zusammengemischt.

Die Mineralstoff-, Spurenelement-, Vitamin-, und Aminosäureergänzung erfolgte in Anlehnung an den NRC (1994).

Für alle Futtermischungen wurden vergleichbare Energie-, Protein- Aminosäure- und Mineralstoffgehalte berechnet. Die N-korrigierte umsetzbare Energie (ME) wurde nach der WPSA-Formel (1984) geschätzt. Der Lysingehalt wurde für alle Mischungen $10 \%$ unter dem Bedarf der Broiler kalkuliert, um Lysin als die erst limitierende Aminosäure einzustellen.

\subsection{Versuchsaufbau}

Zur Prüfung der ernährungsphysiologischen Wirkungen der unterschiedlich behandelten Sojabohnen in den Futtermischungen für Broiler wurden Daten aus Wachstumsversuchen und parallel laufenden Stoffwechselversuchen einbezogen. Aus Gründen der Versuchskapazität erforderten die Untersuchungen zwei Abschnitte. Deshalb wurden die Tierversuche der Fütterungsgruppen von A bis E bzw. F bis K nacheinander durchgeführt.

\subsubsection{Wachstumsversuch und vergleichender Schlachtversuch}

Für die Gesamtuntersuchung wurden $2 \times 350$ männliche Eintagsküken (Genotyp Cobb) bezogen. Die Küken wurden zufällig auf mehretagige Käfige (20 Tiere/Käfig) verteilt und bis zum Versuchsbeginn (7. LT) mit einem handelsüblichen Broilerstarterfutter gefüttert.

Am 7. Lebenstag (LT) wurden die Tiere nach Lebendmasse sortiert, wobei Tiere, die von der durchnittlichen Lebendmasse (LM) zu weit abwichen, vom weiteren Wachstumsversuch ausgeschlossen wurden. Der Wachstumsversuch wurde mit insgesamt $6 \times 10$ Tieren je Behandlungsgruppe im Zeitraum vom 7. - 28. LT durchgeführt. Für jede Gruppe standen 6 Käfige zur Auswertung zur Verfügung. Zum Beginn der Versuche lag die mittlere Lebendmasse der Tiere im ersten und zweiten Versuchsdurchgang bei $159 \pm 12 \mathrm{~g}$ bzw. $149 \pm 9 \mathrm{~g}$. 


\subsubsection{Haltung und Fütterung der Tiere}

Über den gesamten Versuchszeitraum erfolgte die Fütterung (in Mehlform) und Wasserversorgung ad libitum aus Futtertrögen bzw. aus automatischen Tränken. Dabei wurde die auf praxisübliche Fütterung der Broiler in Pelletform verzichtet, um die Effektivität der Behandlungsvarianten (vgl. Tab. 3) auf Futterwert unabhängig von der weiteren Reduzierung der antinutritiven Substanz durch Pelletierung bewerten zu können. Die Tränken wurde zweimal täglich gereinigt. Die Länge der Futtertröge betrug $80 \mathrm{~cm}$, sie waren außerhalb des Käfigs befestigt.

Die Tiere wurden in einem klimatisierten Versuchsraum in mehretagigen Käfigen gehalten. Die Käfige hatten eine Standfläche von $80 \mathrm{~cm} \times 80 \mathrm{~cm}$ und eine Standhöhe von $35 \mathrm{~cm}$. Während der Aufzuchtperiode lag die Temperatur in der ersten Woche im Versuchsraum bei $33{ }^{\circ} \mathrm{C}$. Danach wurde die Temperatur während des Versuchs wöchentlich um $2{ }^{\circ} \mathrm{C}$ abgesenkt. Die relative Luftfeuchtigkeit lag zwischen 65 - 70 \%. Die Beleuchtungsdauer betrug $24 \mathrm{~h} / \mathrm{Tag}$.

\subsubsection{Datenerfassung im Wachstumsversuch}

Zur Ermittlung der Wachstumsdaten und des Futterverzehrs wurden die Küken (einzeln) und der Futterrest wöchentlich gewogen. Dabei wurde der Futterverzehr nach Abzug des Restfutters von der am Anfang gegebenen Futtermenge erfaßt und daraus der tägliche Futterverzehr ermittelt. Aus der täglichen LMZ (g) und dem Futterverzehr (g) wurde der Futteraufwand (g/g) rechnerisch ermittelt.

\subsubsection{Schlachtung und Aufbereitung der Ganzkörperproben}

Für die Bestimmung des Nährstoffansatzes wurden zu Versuchsbeginn (7. LT) 6 repräsentative Küken und 6 Küken je Behandlungsgruppe am Ende des Wachstumsversuchs (28. LT) ausgewählt und $10 \mathrm{~h}$ genüchtert. Die Körpermasse der ausgewählten Tiere sollte dabei der durchschnittlichen Körpermasse der Tiere in den einzelnen Fütterungsgruppen am Versuchsende nahe kommen.

Am Ende der Nüchterungszeit wurden die Tiere mit Ether verlustlos getötet, anschließend wurden sie in Plastiktüten einzeln verpackt und bis zur weiteren Aufbereitung bei $-20{ }^{\circ} \mathrm{C}$ im Gefrierraum aufbewahrt. 
Für die Nährstoffbestimmung wurden die Ganzkörper für $3 \mathrm{~h}$ bei $125^{\circ} \mathrm{C}$ autoklaviert, mit einem Fleischwolf zerkleinert und homogenisiert. Die N-Bestimmung erfolgte in 3 Wiederholungen, die Bestimmung von Trockensubstanz (T) und Rohasche in zwei Wiederholungen. Der Fettgehalt des Ganzkörpers wurde durch den Abzug des Protein- und Rohaschegehalts aus der Trockensubstanz errechnet und beinhaltet somit die Fraktion der N-freien Extraktstoffe.

\subsubsection{Bestimmung der ilealen Verdaulichkeit ausgewählter Aminosäuren}

Für die Bestimmung der ilealen Verdaulichkeit wurden Tiere des Wachstumsversuchs verwendet. $\mathrm{Zu}$ diesem Zweck erhielten die Tiere ab dem 21. LT bis zur Schlachtung Futtermischungen (ab 29. LT), die einen unverdaulichen Indikator (Celite) enthielten. Celite wurde mit $1 \%$ im Austausch gegen Mais in der Futtermischung eingesetzt.

Die Berechnung der Verdaulichkeit der Aminosäuren erfolgte nach folgender Formel:

$\mathrm{VQ}=[1-(($ ileale Nährstoffe $\times$ Diät AIA $) /($ Nährstoffe in der Diät $\times$ ileale AIA) $)] \times 100$

\subsubsection{Gewinnung und Aufbereitung der Chymusproben}

Nach Abschluß des Wachstumsversuches wurden zur Bestimmung der ilealen Verdaulichkeit zwei Stunden nach der letzten Fütterung insgesamt 36 Chymusproben in 4 gepoolten Proben je Versuchsgruppe gewonnen. Die Proben wurden aus dem Ileum (letzter Abschnitt des Ileums, $18 \mathrm{~cm}$ vor dem Ileumende) entnommen und in eisgekühlten Sammelgefäßen aufgefangen. Die gepoolten Chymusproben wurden anschließend bei $-20{ }^{\circ} \mathrm{C}$ für 12 Stunden gelagert und danach über 48 Stunden gefriergetrocknet. Die Analysen (HCl-unlösliche Asche und Aminosäuren) erfolgten in 4 gepoolten Chymusproben von jeweils 9 Tieren für die entsprechenden Futtermischungen.

\subsubsection{Stoffwechselversuch zur Ermittlung von N-Bilanzparametern, N-Verdaulichkeit, umsetzbarer Energie und Trypsinaktivität im Chymus}

Die Untersuchungen wurden mit 6 Tieren je Behandlung parallel zum Wachstumsversuch durchgeführt. 


\subsubsection{Haltung und Fütterung der Versuchstiere}

Beim Stoffwechselversuch teilte sich die gesamte Versuchszeit in Aufzucht-, Vor-, und Hauptperiode auf. Während der Aufzuchtperiode (bis zum 9. Lebenstag ) wurden die Tiere mit einem handelsüblichen Broilerstarterfutter gefüttert. Die Tiere wurden während dieser Periode in Käfigen gehalten. Am 10. LT kamen 6 Tiere je Versuchsgruppe einzeln in die Stoffwechselkäfige für eine 5-tägige Vorperiode (Eingewöhnungszeit an Käfig und Versuchsdiät). Dabei wurde von Broilerstarterfutter schrittweise auf die Versuchsdiäten umgestellt. Die mittlere Lebendmasse der Tiere lag zu Beginn dieser Periode bei $241 \pm 10$ g. Dann folgte die Hauptperiode über 6 Tage. Zu Beginn und Ende der Hauptperiode wurden die Tiere gewogen und die mittlere LM errechnet. Die Futtergabe erfolgte in der Vorperiode und Hauptperiode zweimal am Tag.

Die Tiere wurden in einem klimatisierten Versuchsraum einzeln in speziellen Stoffwechselkäfigen gehalten. Temperatur, Luftfeuchtigkeit und Beleuchtungsdauer im Versuchsraum war analog zu den Bedingungen im Wachstumsversuch. Die Käfige hatten eine Standfläche von $30 \mathrm{~cm} \times 25 \mathrm{~cm}$ und Standhöhe von $26 \mathrm{~cm}$.

\subsubsection{Gewinnung und Aufbereitung der Exkremente und des Chymus}

Die anfallenden Exkremente wurden während der Hauptperiode 3 mal täglich in Plastikeimern gesammelt und bei $-20{ }^{\circ} \mathrm{C}$ tiefgefroren. Vor Beginn der Exkrementsammlung erfolgte die Entfernung von Verunreinigungen (Hautschuppen, Federn und Futterpartikel). Die Exkremente wurden für die Laboranalyse aufgetaut und gründlich homogenisiert. Danach wurden in den Exkrementen die Gehalte an T, N, $\propto$-Amino-Stickstoff und Bruttoenergie bestimmt (vgl. 3.3.5). Nach Abschluß des Bilanzversuchs wurden die Tiere an drei aufeinander folgenden Tagen im Zeitraum vom 21. LT - 23. LT zwei Stunden nach der Morgenfütterung (Vorlage $30 \mathrm{~g}$ Futter/Tier) in 15-minütigem Abstand geschlachtet. Anschließend wurde Chymus aus dem Jejunum (Abschnitt Ende Duodenum bis zum MECKEL'schen Diverticulum) zur Bestimmung der Trypsinaktivität entnommen. Der Chymus wurde in eisgekühlten Sammelgefäßen aufgefangen, gewogen und in einer Kühlzentrifuge $\left(4^{\circ} \mathrm{C}\right)$ zentrifugiert. Um zeitabhängige Verluste an Trypsinaktivität in der Probe zu vermeiden, wurde die Bestimmung der Trypsinaktivität im Überstand der Probe sofort durchgeführt (vgl. 3.3.6.). 


\subsection{Chemisch-analytische Methoden}

\subsubsection{Bestimmung der Weender Rohnährstoffe}

Die Bestimmung der Rohnährstoffe in den Futtermischungen, Exkrementen bzw. Ganzkörpern erfolgte auf Grundlage der Vorschriften von NAUMANN und BASSLER (1976-1997) entsprechend den VDLUFA-Empfehlungen.

Die N-Menge im Futter nach Vermahlung (0,5 mm Siebgröße), in den Frischexkrementen und in den Ganzkörpern wurde nach Homogenisierung mit dem Verfahren von Dumas unter Verwendung des Kohlenstoff-Stickstoff-Analysators FP 2000 der Firma Leco Instruments bestimmt, wobei die Proben bei $1050{ }^{\circ} \mathrm{C}$ in reiner Sauerstoffatmosphäre verbrannt wurden. Durch Reduzierung der entstehenden Stickoxide $\left(\mathrm{NO}_{\mathrm{x}}\right) \mathrm{zu} \mathrm{N} \mathrm{N}_{2}$ an elementarem Kupfer und anschließender Adsorption des $\mathrm{CO}_{2}$ an $\mathrm{NaOH}$ auf einem Silikatcarrier konnte der N-Gehalt durch Wärmeleitfähigkeits-Detektion ermittelt werden. Er wurde danach mit 6,25 multipliziert, um den Proteingehalt zu erfassen.

\subsubsection{Bestimmung der Energie}

Um die Gehalte an N-korrigierter umsetzbarer Energie in den Futtermischungen ermitteln zu können, wurden die Gehalte an Bruttoenergie in Futterproben und gefriergetrockneten Proben aus den Exkrementen mit dem adiabatischen Bombenkalorimeter AC 350 der Fa. Leco Instruments bestimmt.

\subsubsection{Bestimmung der Aminosäuren}

In Proben von Futter und gefriergetrocknetem Chymus wurden nach Oxidation mit Perameisensäure und anschließender salzsaurer Hydrolyse über 24 Stunden bei $110{ }^{\circ} \mathrm{C}$ die proteingebundenen Aminosäuren in die freie Form überführt. Nach der Hydrolyse wurde durch geeignete Mengen an $\mathrm{NaOH}(7,5 \mathrm{~mol} / \mathrm{l})$ und an $\mathrm{NaOH}(2 \mathrm{~mol} / \mathrm{l})$ in den Lösungen ein $\mathrm{pH}$ von 2,2 eingestellt und Norleucin als interner Standard hinzugegeben (NAUMANN und BASSLER, 1976-1997).

Von den Hydrolysaten wurden zu Beginn jeder Analyse $50 \mu \mathrm{l}$ im automatischen Aminosäurenanalysator LC 3000 der Fa. Eppendorf injiziert. Durch Kationenaustausch wurde eine Auftrennung der Aminosäuren erreicht. Nach der Elution erfolgte automatisch die Zugabe 
von Ninhydrinreagenz. In einer zweistufigen Reaktion wird die $\mathrm{NH}_{2}$-Gruppe der Aminosäuren in einen Farbkomplex überführt und bei $570 \mathrm{~nm}$ sowie $440 \mathrm{~nm}$ detektiert.

Alle benötigten Lösungen für den Betrieb des Aminosäuren-Analysators wurden im Institut selbst hergestellt. Der automatische Betrieb des Gerätes erfolgte mit der Software LC.WIN, die Auswertung der erhaltenen Chromatogramme mit der Software EZ-CHROM.

\subsubsection{Bestimmung der HCl-unlöslichen Asche}

Es wurde von ausreichend Probenmaterial in einem Porzellantiegel durch Trocknung über 4 Stunden bei $105{ }^{\circ} \mathrm{C}$ zunächst der Trockensubstanzgehalt ermittelt. Danach wurde über Nacht bei $550{ }^{\circ} \mathrm{C}$ verascht und die Asche mit $100 \mathrm{ml} 4 \mathrm{n} \mathrm{HCl}$ partiell in Lösung gebracht. Danach wurde über einen aschefreien Filter filtriert, mit ca. 1 Liter aqua dest nachgespült und der Filter mit der ungelösten Asche nochmals über Nacht bei $550{ }^{\circ} \mathrm{C}$ verascht und gewogen.

\subsubsection{Bestimmung von $\alpha$-Amino-N}

Die chemische Trennung von Kot-N und Harn-N erfolgte nach PAHLE et al. $(1983,1985)$ und PRIEBS et al. (1987) über den Gehalt an $\alpha$-Amino-N.

\section{Prinzip:}

Durch Hydrolyse der Proben mit $6 \mathrm{n} \mathrm{HCl}$ bei $110{ }^{\circ} \mathrm{C}$ über einen Zeitraum von 24 Stunden werden alle proteingebundenen Aminosäuren in die freie Form überführt. Danach wird durch Wasserdampfdestillation der durch die Hydrolyse entstandene Ammoniak entfernt. Ein Aliquot des Hydrolysates wird mit Ninhydrinreagenz versetzt und 12 min. im Wasserbad gekocht. Nach dem Abkühlen wird bei $440 \mathrm{~nm}$ im Spektralphotometer die Extinktion ermittelt. Das Verfahren entspricht somit einer summarischen Aminosäurenbestimmung in Futter und Exkrementen und unterstellt, dass der Harn frei von Aminosäuren ist, bzw. schließt eine partielle Hydrolyse der Harnsäure und damit Freisetzung von Glycin aus.

\section{Reagenzien:}

1. $6 \mathrm{~N} \mathrm{HCL}$

2. $50 \%$ ige $\mathrm{NaOH}$

3. Ninhydrin (NDH) 
4. Ethylenglycolmonoethylether

5. Zinn-(III)- Chlorid

6. Wasserfreies Natriumacetat

7. Essigsäure (100\% ige)

8. Ammoniumchlorid

\section{Herstellung der Lösungen}

Für die Durchführung der Analyse müssen folgende Lösungen hergestellt werden

1. Acetatpuffer $4 \mathrm{~N}, \mathrm{pH} 5,5$

$2050,75 \mathrm{~g} \mathrm{Na}$ - Acetat wurden mit $400 \mathrm{ml}$ dest. $\mathrm{H}_{2} \mathrm{O}$ gelöst, $500 \mathrm{ml}$ Eisessig hinzugefügt und auf $500 \mathrm{ml}$ mit destilliertem Wasser aufgefüllt.

2. NDH-Lösung

2 g Nynihydrin wurden in $70 \mathrm{ml}$ Ethylenglycolmonoethylether mit Zusatz von $30 \mathrm{ml}$ Acetatpuffer und $250 \mathrm{mg}$ Zink- (III)-Chlorid gelöst.

3. Standardlösung

3,14008 g Ammoniumchlorid $\left(\mathrm{NH}_{4} \mathrm{Cl}\right)$ wurden in bidestilliertem Wasser gelöst und mit Wasser auf $1000 \mathrm{ml}$ aufgefüllt, so dass $1 \mathrm{ml}$ dieser Lösung 1,00 mg $\mathrm{N}$ enthielt.

4. Blindlösung

besteht aus $6 \mathrm{NHCl}(\mathrm{pH}=2)$

\section{Durchführung:}

$250 \mathrm{mg}$ homogenisierte Exkremente wurden in $250 \mathrm{ml}$ Laborflaschen eingewogen und mit $40 \mathrm{ml}$ 6 N HCL versetzt. Dies erfolgte in Anlehnung an die VDLUFA-Methode für Aufschlüße bei der Aminosäureanalytik (Trockenschrank $24 \mathrm{~h}$ bei $110^{\circ} \mathrm{C}$ ). Das Hydrolysat wurde abgekühlt und in Aufschlußröhren von Büchi überführt. Um Ammoniak $\left(\mathrm{NH}_{3}\right)$ mit Hilfe der Wasserdampfdestillation aus dem Hydrolysat auszutreiben, wurde das Hydrolysat mit $25 \mathrm{ml}$ $\mathrm{NaOH}(50 \%)$ versetzt und 10 min. destilliert. Das Destillat wurde dann verworfen und das abgekühlte Hydrolysat in ein $600 \mathrm{ml}$ Becherglas überführt. Der pH-Wert des Hydrolysats wurde mit Hilfe eines pH-Meters unter Zusatz etwa $40 \mathrm{ml} 6 \mathrm{~N} \mathrm{HCl}$ auf 2 eingestellt. Danach wurde filtriert und in einem Meßkolben auf $500 \mathrm{ml}(6 \mathrm{~N} \mathrm{HCl})$ aufgefüllt. Aus diesem Hydrolysat wurden Verdünnungen hergestellt, so dass sie zwischen 1 und $4 \mu \mathrm{g} \mathrm{N} / \mathrm{ml}$ aufwiesen. Danach wurde $1 \mathrm{ml}$ der jeweiligen Verdünnungsreihe mit $1 \mathrm{ml} \mathrm{NDH}$ im Reagenzglas gemischt und für 12 min. im kochenden Wasserbad inkubiert. Anschließend wurde die Extinktion mit dem Spektralphotometer bei $570 \mathrm{~nm}$ gegen den Blindwert gemessen. Die Blindlösung wurde so 
hergestellt, dass $10 \mathrm{ml} 6 \mathrm{~N} \mathrm{HCl}$ auf $250 \mathrm{ml}$ in einer Laborflasche aufgefüllt, destilliert und der $\mathrm{pH}-$ Wert auf 2 eingestellt wurde.

Für die Bestimmung von $\propto$-Amino-Stickstoff im Futter wurden $250 \mathrm{mg}$ des entsprechend gemahlenen Futters eingewogen. Die Probe wurde dann analog behandelt wie für die Exkremente dargestellt.

\section{Eichkurve:}

Für die Eichkurve wurde die Standardlösung $\left(\mathrm{NH}_{4} \mathrm{Cl}\right)$ so verdünnt, dass sie 1, 2, 3, 4 und $5 \mu \mathrm{g}$ Stickstoff $/ \mathrm{ml}$ enthielt. Zu den Verdünnungen wurde $1 \mathrm{ml}$ NDH-Lösung abpipettiert und die Extinktion ebenfalls wie die Probenlösung gegen den Blindwert gemessen.

\section{Berechnung des $\propto$-Amino -Stickstoff}

Die Berechnung der $\propto$-Amino- Stickstoff erfolgte nach folgender Formel:

$$
\mathrm{C}=\frac{\text { Extinktion }(\text { Probe })-\mathrm{a}}{\mathrm{b}}
$$

Dabei ist:

$\mathrm{C}=$ Konzentration von $\propto$-Amino- Stickstoff in der Probe $(\mu \mathrm{g} / \mathrm{ml})$

$\mathrm{a}=$ Schnittpunkt der Ordinate

$\mathrm{b}=$ Steigung der Eichkurve

\subsubsection{Bestimmung der Trypsinaktivität}

Die Bestimmung der Trypsinaktivität in den Chymusproben erfolgte mit Hilfe der Methode von NAGEL et al. (1965).

\section{Prinzip:}

Durch Zusatz einer BAPNA-Lösung (BAPNA = Benzoyl-DL-arginin-p-nitroanilin) im zentrifugierten und filtrierten Chymusüberstand wird p-Nitroanilin abgespalten, dessen Farbintensität sich mit dem Spekralphotometer bei $405 \mathrm{~nm}$ messen läßt. Unter standardisierten 
Versuchsbedingungen (Zeit und Temperatur) ist die gemessene Extinktion der Trypsinaktivität proportional.

\section{Reagenzien:}

1. Trispuffer $\left(0,05 \mathrm{M}\right.$ Tris- $\mathrm{HCl}$ mit $\left.0,02 \mathrm{M} \mathrm{CaCl}_{2}, \mathrm{pH} 8,2\right)$

2. BAPNA-Lösung (121,75 mg BAPNA im 5 ml DMSO (Dimethylsulfoxid)

3. Essigsäure (30\% ige)

4. Blindlösung (besteht aus 0,5 $\mathrm{ml}$ Probe, 0,5 $\mathrm{ml}$ Puffer, $1 \mathrm{ml}$ Essigsäure und 0,1 ml BAPNA-Lösung)

\section{Durchführung:}

Chymus wurde gleich nach der Gewinnung mit $15 \mathrm{ml}$ bidestilliertem Wasser vedünnt. Dann wurde bei $4000 \mathrm{U} / \mathrm{min}$. zentrifugiert und der Überstand wie folgt weiter verdünnt: $1 \mathrm{ml}$ Überstand $+1 \mathrm{ml}, 1 \mathrm{ml}+3 \mathrm{ml}$ und $1 \mathrm{ml}+5 \mathrm{ml}$.

\section{Durchführung der Reaktion:}

In Reagenzgläser wurden jeweils 0,5 ml der verdünnten Probe der jeweiligen Verdünnungsreihe und $5 \mathrm{ml}$ Trispuffer pipettiert und vermischt. Diese Lösung wurde im Wasserbad bei $37^{\circ} \mathrm{C}$ für 10 min. vorgewärmt. Die Reaktion wurde durch Zusatz von 0,1 ml BAPNA-Lösung (in einem Rhythmus von $30 \mathrm{sec}$.) gestartet. Genau nach 10-minütiger Reaktionszeit wurde $1 \mathrm{ml}$ Essigsäure im Abstand von 30 sec. abpipettiert, um die Reaktion dadurch zu stoppen. Anschließend wurde diese Lösung durch Membranfilter $(0,2 \mu \mathrm{m})$ filtriert und bei $405 \mathrm{~nm}$ die Extinktion gegen den Blindwert gemessen..

Die Berechnung der Trypsinaktivität (TA) erfolgte nach folgender Formel:

$$
\mathrm{TA}(\mu \mathrm{mol} / \mathrm{min})=\frac{\Delta \mathrm{E} / \mathrm{min} \times \mathrm{VF} \times \mathrm{EV}}{\varepsilon \times \mathrm{d} \times \mathrm{PV}}
$$

Dabei ist:

$\Delta \mathrm{E}=$ Extinktion nach $10 \mathrm{~min}$. Reaktionszeit

$\mathrm{VF}=$ Verdünnungsfaktor (2, 4 und 6)

$\mathrm{EV}=$ Endvolumen der Reaktionslösung $(6,6 \mathrm{ml})$ 
$\mathrm{PV}=$ Probenvolumen $(0,5 \mathrm{ml})$

$\varepsilon=\quad$ molarer Extinktionskoeffizient für p-Nitroanilin $=9,6(\mathrm{ml} / \mu \mathrm{mol} / \mathrm{cm})$

$\mathrm{d}=\quad$ Schichtdichte der Küvette $(\mathrm{cm})$

\subsubsection{Bestimmung der Trypsininhibitoraktivität}

Die Bestimmung der Trypsininhibitoraktivität in den behandelten und nicht behandelten Sojabohnen wurde mit Hilfe der Methode von VAN OORT et al. (1989) durchgeführt.

\section{Prinzip:}

Es wird die Änderung der Reaktionsstärke von reinem Trypsin und einem synthetischen Substrat (BAPNA) durch Zugabe eines salzsauren Extraktes der Leguminosensamen oder gereinigtem Sojabohnentrypsininhibitor (SBTI) gemessen.

Durch die Einwirkung des Trypsins auf das Substrat BAPNA wird p-Nitroanilin abgespalten. Dadurch entsteht eine gelbe Lösung. Mit Hilfe des Spektralphotometers wird die Extinktion bei $410 \mathrm{~nm}$ gemessen. Diese Extinktion ist unter festgelegten Laborbedingungen der Trypsinaktivität proportional.

Der Trypsininhibitor setzt die Aktivität des Trypsins herab, dadurch sinkt die Freisetzung von pNitroanilin aus BAPNA ab. Als Vergleichslösung wird Wasser anstelle des Probenextraktes verwendet. Die Messwerte der Proben- und der Vergleichslösung werden mit einer reinen Reagenzlösung verglichen, in der die Bildung von p-Nitroanilin durch Zugabe von Essigsäure verhindert wird. Die Differenz dieser Werte ergibt die Aktivität des Trypsininhibitors.

\section{Reagenzien:}

\section{1. $\underline{0,01 \mathrm{~N} \mathrm{NaOH}}$}

\section{2. $\underline{0,001 \mathrm{~N} \mathrm{HCl}}$}

3. $30 \%$ ige Essigsäure

4. Puffer $\left(0,05 \mathrm{M}\right.$ Tris-HCl mit $\left.0,62 \mathrm{M} \mathrm{CaCl}_{2}, \mathrm{pH} 8,2\right)$

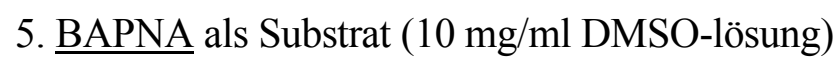

6. Reines Trypsin $(120 \mu \mathrm{g}$ in $10 \mathrm{ml} 0,001 \mathrm{HCl})$

\section{Durchführung:}

Es wurden zunächst $50 \mathrm{~g}$ Sojabohnen auf eine Partikelgröße von 0,2 - 0,3 mm fein gemahlen. Zur Extraktion der Probe wurde 1g der gemahlenen Probe in $50 \mathrm{ml}$ 0,001 N NaOH suspendiert. 
Die Suspension wurde $3 \mathrm{~h}$ mit dem Magnetrührer gerührt und für $30 \mathrm{~min}$. ruhig gestellt, anschließend wurde bei $10000 \mathrm{U} / \mathrm{min}$. für 5 min. zentrifugiert. Die Fettschicht wurde mit einer Pasteurpipette abgesaugt, dann wurde die Lösung für $30 \mathrm{~min}$. in den Kühlschrank gestellt. Anschließend wurden 5 Verdünnungslösungen so vorbereitet, dass von dem jeweiligen Überstand der Probenlösungen 0,1; 0,2;0,3;0,4; und O,5 ml in Eppendorfgefäße abpipettiert und

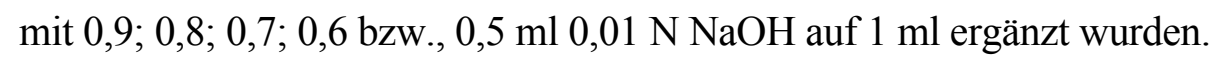

Für die Eichkurve wurde $1 \mathrm{mg}$ SBTI in $10 \mathrm{ml} \mathrm{0,01} \mathrm{N} \mathrm{NaOH}$ angesetzt und kühl gelagert. $1 \mathrm{ml}$ von dieser Lösung wurde zunächst mit $1,5 \mathrm{ml} \mathrm{NaOH}$ verdünnt. Aus dieser Lösung wurden folgende Verdünnungsreihen hergestellt:

$$
\begin{aligned}
& 100 \mu 1+900 \mu 1 \mathrm{NaOH} \\
& 200 \mu 1+800 \mu 1 \mathrm{NaOH} \\
& 300 \mu 1+700 \mu 1 \mathrm{NaOH} \\
& 400 \mu 1+600 \mu 1 \mathrm{NaOH} \\
& 500 \mu 1+500 \mu 1 \mathrm{NaOH}
\end{aligned}
$$

Dabei hatten die Lösungen eine Konzentration von $0,4 \mu \mathrm{g} ; 0,8 \mu \mathrm{g} ; 1,2 \mu \mathrm{g} ; 1,6 \mu \mathrm{g}$ bzw. $2,0 \mu \mathrm{g}$ SBTI je $100 \mu \mathrm{l}$ Lösung.

In zwei weiteren Eppendorfgefäßen wurden Blindwerte vorbereitet. Die Blindlösung bestand aus 0,1 ml Wasser, 1,5ml Puffer, 0,1ml BAPNA, 0,2 ml Essigsäure und 0,1 $\mathrm{ml}$ Trypsinlösung.

\section{Durchführung der Reaktion}

In $2 \mathrm{ml}$ Eppendorfreaktionsgefäßen (E-Cups) wurde zunächst 1,5 ml Trispuffer für die jeweiligen Doppelbestimmungen und Standardlösungen abpipettiert und im Wasserbad bei $37{ }^{\circ} \mathrm{C}$ vorgewärmt. Danach wurden $0,1 \mathrm{ml}$ der jeweilig Verdünnung in die Trispufferlösung pipettiert. Mit Zusatz von 0,1 ml Trypsin-Lösung in den E-Cups wurde die Lösung gemischt und für $5 \mathrm{~min}$. im Wasserbad $\left(37^{\circ} \mathrm{C}\right)$ inkubiert. Anschließend wurde $0,1 \mathrm{ml}$ der BAPNA-Lösung, die bei $37{ }^{\circ} \mathrm{C}$ vorgewärmt war, in die E-Cups im Abstand von $30 \mathrm{sec}$. hinzugefügt. Die Reaktion wurde genau nach 45 min. Inkubationszeit mit Essigsäure gestoppt. Danach wurde die Lösung zentrifugiert und der Überstand in Küvetten pipettiert. Die Extinktion des Überstands wurde gegen die Blindlösung gemessen.

\section{Berechnung der Trypsininhibitoraktivität}

Für die Berechnung der TIA wurde aus dem Volumen der 5 verschiedenen Verdünnungsstufen des Probenextraktes die Extinktionen auf der X- und Y-Achse aufgetragen. Danach wurde das 
Volumen X gesucht, bei dem die Extinktion um $50 \%$ abgenommen hatte. Außerdem wurde aus der Eichkurve das Volumen Y der SBTI-Lösung mit der bekannten Konzentration kalkuliert, die 50 \% der Trypsinaktivität gehemmt hatte. Die Berechnung der Trypsininhibitoraktivität erfolgte mit der Formel TIA $(\mathrm{mg} / \mathrm{g}$ Probe $)=(2,632 \times$ Verdünnung $\times$ Absorbtionsänderung $) / \mathrm{g}$ Probe Dabei drückt TIA (mg/g) die Trypsinmenge (mg), die durch 1 g Sojabohnenprobe unter gegebenen Laborbedingungen gehemmt wird, aus.

\subsubsection{Bestimmung des Proteindispersiblitäts- Index}

Die Bestimmung des Proteindispersiblitäts-Index (PDI) in Sojaschrot erfolgte auf Grundlage der Vorschriften von NAUMANN und BASSLER (1976-1997) .

Bei der Bestimmung des PDI handelt es sich um die Erfassung des Anteils von Rohprotein am Gesamtprotein, der in Wasser dispergierbar ist.

40 g Sojaschrot wurde in ein $500 \mathrm{ml}$ Becherglas eingewogen. Danach wurde $100 \mathrm{ml}$ Wasser dazupipettiert. Das Gemisch wurde zu einem Brei angerührt. Dies wurde mit Zusatz von $500 \mathrm{ml}$ Wasser und zwei Tropfen Silikonöl in ein Mixgerät überspült und 10 min. zerkleinert. Anschließend wurden $50 \mathrm{ml}$ der Mischung $10 \mathrm{~min}$. zentrifugiert. In den $5 \mathrm{ml}$ Überstand der Mischung wurde der Stickstoffgehalt nach Dumas bestimmt und durch Multiplikation mit 6,25 der Gehalt an dispergierbarem Protein ermittelt.

\subsection{Berechnung der N-Bilanzparameter}

Aus dem Stoffwechselversuch wurden Daten wie N-Aufnahme, N-Ausscheidung und N-Bilanz sowie $\alpha$-Amino-N-Verdaulichkeit ermittelt. Außerdem wurde die N-korrigierte umsetzbare Energie in den jeweiligen Futtermischungen bestimmt. Anschließend wurden der Physiologische Nutzwert $(\mathrm{PNu})$ als Kriterium der Proteinqualität und die Lysinwirksamkeit aus den Daten der Bilanzmessungen nach LIEBERT (1995a, b) mit Hilfe des exponentiellen NVerwertungsmodelles nach GEBHARDT (1966) abgeleitet. Dabei wurde der Zusammenhang zwischen der Höhe der N-Aufnahme (x) und N-Retention (y) wie folgt beschrieben:

$\mathbf{y}=\mathbf{A}\left(1-\mathbf{e}^{-\mathbf{b x}}\right)$

Wobei

$\mathrm{y}=(\mathrm{N}-$ Bilanz $+\mathrm{N}$-Erhaltungsbedarf $) / \mathrm{LM}_{\mathrm{kg}}{ }^{0,67}[\mathrm{mg} / \mathrm{Tag}]$

$\mathrm{A}=$ Maximalwert für (y), abhängig von Genotyp und Alter 
$\mathrm{b}=$ Parameter für den Anstieg der N-Wirkungskurve; abhängig von der Proteinqualität, unabhängig von der N-Aufnahme

$\mathrm{x}=\mathrm{N}$-Aufnahme/ $\mathrm{LM}_{\mathrm{kg}}{ }^{0,67}[\mathrm{mg} / \mathrm{Tag}]$

$\mathrm{e}=$ Grundzahl der natürlichen Logarithmen

Nach Logarithmierung der Gleichung (1) wird b wie folgt erechnet:

$b=[\ln A-\ln (A-y)]: x$

Nach der Berechnung des $\mathrm{b}$-Werts wurden $\mathrm{PNu}$ und Lysinwirksamkeit aus folgenden Beziehungen ermittelt:

PNu $=100\left[\mathrm{~A}\left(1-\mathrm{e}^{-\mathrm{bx}}\right): \mathrm{x}\right]$

Lysinwirksamkeit $=\mathbf{b c}^{-1}$. Dabei ist $\mathbf{c}$ die Konzentration des Lysins in $\mathrm{g} / 16 \mathrm{~g} \mathrm{~N}$.

In der vorliegenden Untersuchung wurden für A und den N-Erhaltungsbedarf Arbeitswerte in Höhe $3400 \mathrm{mg} / \mathrm{Tag}$ bzw. $500 \mathrm{mg} / \mathrm{Tag}$ verwendet. Diese Werte wurden aus den Untersuchungen von RIMBACH und LIEBERT (1999) für den Genotyp Cobb abgeleitet.

\subsection{Mathematisch-statistische Auswertung}

Die Mathematisch-statistische Auswertung erfolgte mit Hilfe des SPSS-Programms für Windows (Version 8) unter Verwendung des Tukey-Tests. Dabei wurden einzelne Werte, die vom Mittelwert der Versuchsgruppe deutlich abwichen, nach Durchführung eines Ausreissertests nach DIXON (SACHS, 1968) aus der Stichprobe ausgeschlossen. Bei den Signifikanzprüfungen wurde mit einer Irrtumswahrscheinlichkeit $\mathrm{P} \leq 0,05$ gearbeitet. 


\section{Ergebnisse}

\subsection{Die Trypsininhibitoraktivität in den unterschiedlich behandelten Sojabohnen}

Die Ergebnisse der Trypsininhibitoraktivität in den behandelten Sojabohnen sind in Tab. 7 aufgeführt.

\section{Tab. 7: Trypsininhibitoraktivitäten der behandelten Sojabohnen}

\begin{tabular}{lccc}
\hline Gruppe* & $\begin{array}{c}\text { TIA } \\
(\mathbf{m g} / \mathbf{g})\end{array}$ & $\begin{array}{c}\text { Relative TIA } \\
(\mathbf{\%}) * * *\end{array}$ & $\begin{array}{c}\text { Proteinlöslichkeit } \\
\mathbf{( \% )}\end{array}$ \\
\hline A (WS, kond. für 40 min.) & 2,46 & 16 & 25 \\
B (WS, kond. für 40 min. + flockiert) & 2,40 & 16 & 21 \\
C (WS, kond. für 10 min.) & 4,15 & 27 & 33 \\
D (WS, kond. für 10 min. + exp., 20 kWh/t) & 3,38 & 22 & 16 \\
E (HM), kond. für 10 min. + extr., 15 kWh) & 3,23 & 21 & 22 \\
F (HM, kond. für 10 min.) & 3,85 & 25 & 31 \\
G (HM, kond. für $10 \mathrm{~min} .+$ exp., 20 kWh/t) & 3,38 & 22 & 21 \\
H (HM + exp., 20 kWh/t) & 11,53 & 75 & 40 \\
I (HM + exp., 15 kWh/t + Dampf) & 4,92 & 32 & 16 \\
K (HM + exp., 40kWh/t) & 7,38 & 48 & 21 \\
\hline
\end{tabular}

*) vgl. Tab. $3 \quad * *)$ rohe Sojabohne $=100$

In den behandelten Sojabohnen der Gruppen H (HM, Expander, $20 \mathrm{kWh} / \mathrm{t}$ ) und K(HM, Expander, $40 \mathrm{kWh} / \mathrm{t}$ ), d.h. Expanderbehandlung nach Vermahlung ohne Dampfzusatz war noch eine gravierende Restaktivität des Trypsininhibitors vorhanden. Der erhöhte Energieeintrag bei K (HM, Expander, $40 \mathrm{kWh} / \mathrm{t}$ ) reduzierte zwar die Trypsininhibitoraktivität im Vergleich zu H (HM, Expander, $20 \mathrm{kWh} / \mathrm{t}$ ), lag aber noch deutlich über dem Verfahren der Standardbehandlung (A). Der Dampfeinsatz beim Expandieren ( $\mathrm{I}=\mathrm{HM}$, Expander, Dampfzusatz) verminderte die Trypsininhibitoraktivität im Vergleich zu H deutlich, erreichte aber noch nicht das Niveau nach 40-minütiger Konditionierung. Die behandelten Sojabohnen der Gruppen D und E zeigten ähnlich hohe Aktivitäten des Trypsininhibitors. Somit bestand zwischen den Behandlungsverfahren Expandieren und Extrusion kein Unterschied hinsichtlich der Senkung der Trypsininhibitoraktivität. Auch beim Vergleich der behandelten Sojabohnen der Gruppen C mit F sowie D mit G ergaben sich ähnliche Restaktivitäten des 
Trypsininhibitors. Der Einfluss der Vermahlungsart durch Hammermühle bzw. Walzenstuhl dürfte in diesem Zusammenhang von geringerer Bedeutung gewesen sein.

Hinsichtlich der Proteinlöslichkeit in Wasser wurden höhere Werte von $40 \%$ bei der nur mit dem Expander behandelten Sojabohne $\mathrm{H}$ als bei den anderen behandelten Sojabohnen festgestellt. Dies zeigt, dass die Intensität der Behandlung relativ gering war. Beim Vergleich der Sojabohne A mit C oder F ist zu beobachten, dass die Proteinlöslichkeit in Abhängigkeit von der Verweilzeit abnimmt.

\subsection{Trypsinaktivität im Chymus}

Die Ergebnisse der Trypsinaktivitätsmessung im Chymus sind in Tab. 8 dargestellt.

Tab. 8: Trypsinaktivität im Chymus

\begin{tabular}{lcc}
\hline Gruppe* $^{*}$ & $\begin{array}{c}\text { Trypsinaktivität } \\
\text { (Units/g Chymus) }\end{array}$ & s \\
\hline A (WS, kond. für $40 \mathrm{~min}$.) & $5.93^{\mathrm{a}}$ & $\pm 1,77$ \\
B (WS, kond. für 40 min. + flockiert) & $6,85^{\mathrm{a}}$ & $\pm 6,85$ \\
C (WS, kond. für $10 \mathrm{~min}$.) & $5,54^{\mathrm{a}}$ & $\pm 3,16$ \\
D (WS, kond. für $10 \mathrm{~min} .+$ exp., 20 kWh/t) & $6,64^{\mathrm{a}}$ & $\pm 3,96$ \\
E (HM, kond. für $10 \mathrm{~min} .+$ extr., 15 kWh) & $6,52^{\mathrm{a}}$ & $\pm 3,03$ \\
F (HM, kond. für $10 \mathrm{~min}$. ) & $4,91^{\mathrm{abc}}$ & $\pm 1,07$ \\
G (HM, kond. für $10 \mathrm{~min} .+$ exp., 20 kWh/t) & $5,79^{\mathrm{a}}$ & $\pm 2,41$ \\
H (HM + exp., 20 kWh/t) & $0,73^{\mathrm{c}}$ & $\pm 0,62$ \\
I (HM + exp., 15 kWh/t + Dampf) & $5,33^{\mathrm{ab}}$ & $\pm 0,85$ \\
K (HM + exp., 40kWh/t) & $1,11^{\mathrm{bc}}$ & $\pm 0,66$ \\
\hline
\end{tabular}

Unterschiedliche Hochbuchstaben innerhalb einer Spalte bedeuten signifikante

Differenzen $\left.(\mathrm{P} \leq 0,05),{ }^{*}\right)$ vgl. Tab. 3

Die Trypsinaktivität im Chymus zeigt eine kontinuierliche Abnahme, die zu der Restaktivität des Trypsininhibitors in den Sojabohnen in reziproker Beziehung steht (vgl. Tab. 7). Analog zur NVerdaulichkeit (vgl. Tab. 13) ergeben sich auch für die statistische Prüfung hinsichtlich der Trypsinaktivität signifikante Unterschiede zwischen Gruppe H und den anderen Gruppen (A, B, C, D, E, G, I). Bei Gruppe H ist die Trypsinaktivität im Chymus durch die Restaktivität des Trypsininhibitors signifikant vermindert. Wenn die Sojabohnen jedoch durch zusätzliche Dampfzufuhr und zusätzlichen Energieeintrag behandelt wurden, nahm die Wirkung des Trypsininhibitors auf die Trypsinaktivität $\mathrm{ab}$ und die Werte (insbesondere bei der Gruppe I) 
stehen im Vergleich zur Kontrolle A sowie den anderen Gruppen auf vergleichbarem Niveau. Zwischen den Fütterungsgruppen $\mathrm{C}$ und $\mathrm{F}$ sowie $\mathrm{D}$ und $\mathrm{F}$ bestehen keine signifikanten Unterschiede. Somit ist ein Einfluss der Zerkleinerungsart auf die Trypsinaktivität im Chymus nicht erkennbar.

\subsection{Wachstumsparameter}

\subsubsection{Futteraufnahme, Lebendmassezunahme und Futteraufwand}

Die Ergebnisse des täglichen Futterverzehrs (FV), der Lebendmassezunahme (LMZ) und des Futteraufwandes (FA) sind in Tab. 9 dargestellt. In den Abb. 5, 6 und 7 sind die relativen Veränderungen des FV, der LMZ und des FA der verschiedenen Versuchsgruppen im Vergleich zur Kontrolle A aufgezeigt.

Wie aus Tab. 9 ersichtlich wird, ergeben sich teilweise signifikante Unterschiede $(\mathrm{P}<0,05)$ zwischen den Fütterungsgruppen hinsichtlich des FV, der täglichen LMZ und des FA. Den höchsten FV erreichte Gruppe E, deren Futtermischung extrudierte Sojabohnen enthielt, während die niedrigsten Werte für den FV bei Gruppe H festgestellt wurden (Sojabohne nach kurzzeitigem Konditionieren bei $20 \mathrm{kWh} / \mathrm{t}$, expandiert). Der niedrigere FV bei der Gruppe H, verbunden mit höchster TIA in der Sojabohne, war im Vergleich zur Standardgruppe (A) und den Fütterungsgruppen $\mathrm{C}, \mathrm{E}, \mathrm{F}$ und $\mathrm{K}$ statistisch gesichert. Insgesamt zeigten die Behandlungsverfahren A, C, E, F und K ähnliche Ergebnisse bezüglich des FV. Eine relativ niedrige Futteraufnahme wurde bei der Fütterungsgruppe B im Vergleich zur Kontrolle A und anderen Fütterungsgruppen beobachtet. Die Ursache ist wahrscheinlich mit dem Flockierungsverfahren zu erklären, da nach Flockierung der Sojabohnen eine im Vergleich zu anderen Behandlungsvarianten geringere Futterdichte auftrat, die eine verminderte Nährstoffaufnahme bei den Tieren auslösen kann.

Über die gesamte Versuchsdauer betrachtet, liegen die erzielten täglichen Lebendmassezunahmen in Bereich von 37,9-50,5 g/d (Tab. 9). Dabei bestehen zwischen den geprüften Gruppen teilweise signifikante Unterschiede. Insbesondere ist die LMZ bei den Gruppen H und G signifikant niedriger als bei der Kontrolle A und den anderen Gruppen ( B, C, D, E, F, G, I und K). 
Tab. 9: Täglicher Futterverzehr, tägliche Lebendmassezunahme und Futterverwertung der Versuchsgruppen

\begin{tabular}{|c|c|c|c|}
\hline Gruppe* & $\begin{array}{c}\text { FV } \\
(g / d)\end{array}$ & $\begin{array}{l}\text { LMZ } \\
(\mathrm{g} / \mathrm{d})\end{array}$ & $\begin{array}{l}\text { FA } \\
(g / g)\end{array}$ \\
\hline A (WS, kond. für $40 \mathrm{~min}$.) & $\begin{array}{l}75,0^{\mathrm{ab}} \\
\pm 2,7\end{array}$ & $\begin{array}{l}48,2^{\mathrm{abc}} \\
\pm 1,3\end{array}$ & $\begin{array}{l}1,55^{\mathrm{bcd}} \\
\pm 0,02\end{array}$ \\
\hline B (WS, kond. für $40 \mathrm{~min} .+$ flockiert) & $\begin{array}{l}69,1^{\mathrm{cd}} \\
\pm 2,9\end{array}$ & $\begin{array}{l}45,5^{\text {bcd }} \\
\pm 1,6\end{array}$ & $\begin{array}{l}1,52^{\mathrm{cd}} \\
\pm 0,04\end{array}$ \\
\hline $\mathbf{C}$ (WS, kond. für $10 \mathrm{~min}$.) & $\begin{array}{l}74,2^{\mathrm{abc}} \\
\pm 3,1\end{array}$ & $\begin{array}{l}49,0^{\mathrm{ab}} \\
\pm 2,2\end{array}$ & $\begin{array}{l}1,51^{\mathrm{cd}} \\
\pm 0,02\end{array}$ \\
\hline $\begin{array}{l}\text { D (WS, kond. für } 10 \mathrm{~min} .+ \text { exp. } \\
20 \mathrm{kWh} / \mathrm{t})\end{array}$ & $\begin{array}{l}70,4^{\text {bcd }} \\
\pm 3,4\end{array}$ & $\begin{array}{l}46,8^{\text {abcd }} \\
\pm 2,7\end{array}$ & $\begin{array}{l}1,50^{d} \\
\pm 0,02\end{array}$ \\
\hline $\begin{array}{l}\mathbf{E} \text { (HM, kond. für } 10 \mathrm{~min} .+ \text { extr., } \\
\qquad 15 \mathrm{kWh} / \mathrm{t})\end{array}$ & $\begin{array}{l}76,1^{\mathrm{a}} \\
\pm 3,5\end{array}$ & $\begin{array}{l}50,5^{\mathrm{a}} \\
\pm 2,6\end{array}$ & $\begin{array}{l}1,51^{\mathrm{d}} \\
\pm 0,03\end{array}$ \\
\hline F (HM, kond. für 10 min.) & $\begin{array}{l}71,9^{\mathrm{abc}} \\
\pm 2,5\end{array}$ & $\begin{array}{l}46,2^{\text {bcd }} \\
\pm 2,0\end{array}$ & $\begin{array}{l}1,56^{\mathrm{bcd}} \\
\pm 0,02\end{array}$ \\
\hline $\begin{array}{l}\text { G (HM, kond. für } 10 \mathrm{~min} .+ \text { exp., } \\
20 \mathrm{kWh} / \mathrm{t})\end{array}$ & $\begin{array}{l}69,5^{\mathrm{cd}} \\
\pm 3,1\end{array}$ & $\begin{array}{l}44,4^{\mathrm{d}} \\
\pm 2,2\end{array}$ & $\begin{array}{l}1,57^{b c} \\
\pm 0,03\end{array}$ \\
\hline $\mathbf{H}(\mathrm{HM}+$ exp., $20 \mathrm{kWh} / \mathrm{t})$ & $\begin{array}{l}65,1^{\mathrm{d}} \\
\pm 3,2\end{array}$ & $\begin{array}{l}37,9^{\mathrm{e}} \\
\pm 2,0\end{array}$ & $\begin{array}{l}1,72^{\mathrm{a}} \\
\pm 0,04\end{array}$ \\
\hline I (HM + exp., 15 kWh/t + Dampf) & $\begin{array}{l}70,1^{\text {bcd }} \\
\pm 1,4\end{array}$ & $\begin{array}{l}45,0^{\mathrm{cd}} \\
\pm 1,5\end{array}$ & $\begin{array}{l}1,56^{b c d} \\
\pm 0,02\end{array}$ \\
\hline $\mathbf{K}(\mathrm{HM}+$ exp., $40 \mathrm{kWh} / \mathrm{t})$ & $\begin{array}{l}71,5^{\mathrm{abc}} \\
\pm 1,7\end{array}$ & $\begin{array}{l}45,2^{\mathrm{bcd}} \\
\pm 0,6\end{array}$ & $\begin{array}{l}1,58^{\mathrm{b}} \\
\pm 0,03\end{array}$ \\
\hline
\end{tabular}

Unterschiedliche Hochbuchstaben innerhalb einer Spalte bedeuten signifikante Differenzen $\left.(\mathrm{P} \leq 0,05),{ }^{*}\right)$ vgl. Tab. 3

Die Ursache für die verminderte LMZ bei Gruppe $\mathrm{H}$ liegt offensichtlich an der höchsten Restaktivität des TI. Die Ergebnisse konnten jedoch verbessert werden, wenn die Tiere mit den Futtermischungen $\mathrm{I}$ und $\mathrm{K}$ gefüttert wurden, allerdings lagen die erbrachten Wachstumsleistungen bei der Fütterung mit den Futtermischungen I und $\mathrm{K}$ immer noch signifikant unter den Gruppen A, C und E. Bei I und K handelte es sich um die Behandlung der Sojabohnen mit zusätzlicher Dampfzufuhr bzw. Erhöhung des Energieeintrags, die in den Sojabohnen zu einer geringeren TIA als bei H führten. Zwischen den Gruppen B und E sowie $\mathrm{G}$ und $\mathrm{E}$ ist ebenfalls ein signifikanter Unterschied in der LMZ festzustellen. Die Ursache für die verminderte LMZ bei B und G kann nicht auf die TIA sondern auf einen geringeren FV 
zurückzuführen sein, da die TIA in den Sojabohnen der Gruppen B, E und G auf gleichem Niveau liegen.

Hinsichtlich des Futteraufwands zeigte Gruppe H signifikant höhere Werte im Vergleich zu den anderen Gruppen A, B, C, D, E, F, G, I und K. Bei der Gruppe K lag der Futteraufwand signifikant höher als bei B, C, D und E. Insgesamt kann aus den vorliegenden Ergebnissen eine negative Wirkung der TI-Restaktivität auf die geprüften Parameter (FV, LMZ und FA) abgeleitet werden. $\mathrm{Zu}$ den Abb. 5-7 sind diese Zusammenhänge als relative Veränderungen im Vergleich zu A zusammenfassend dargestellt.

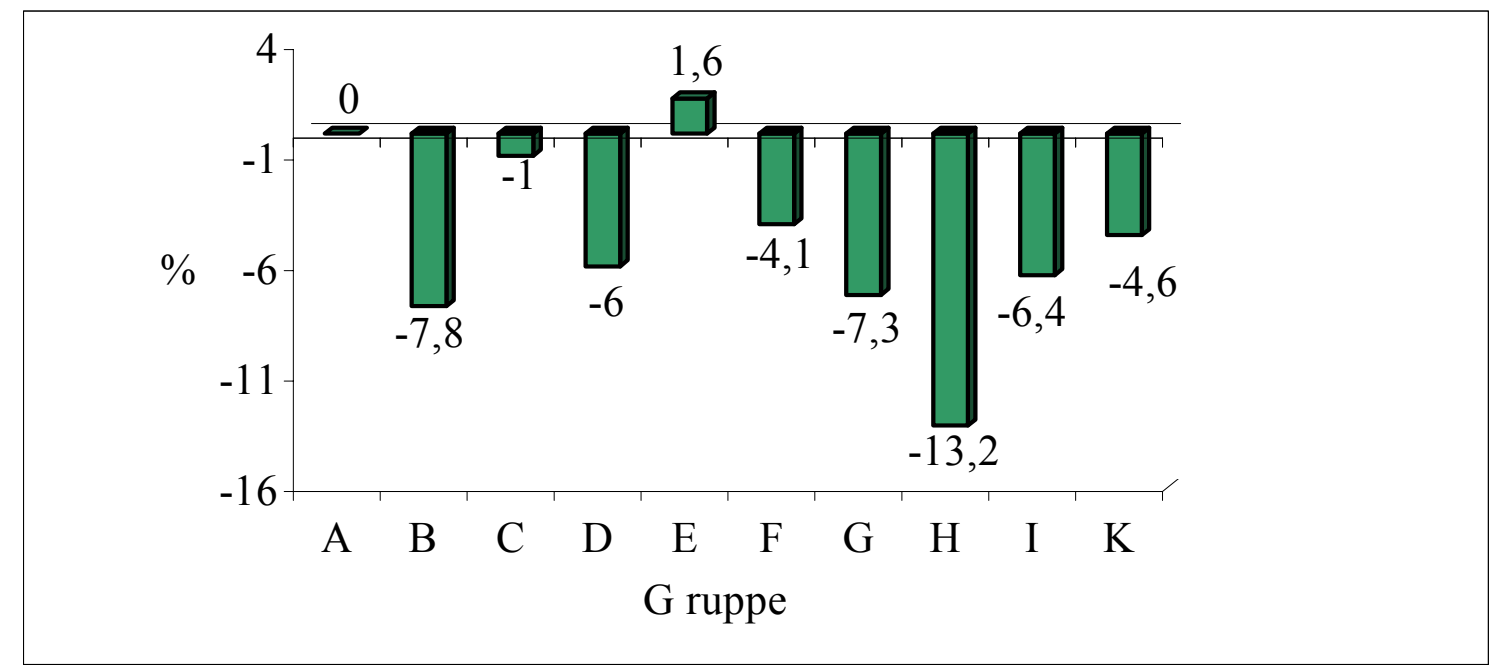

Abb. 5: Relative Veränderungen des FV der Gruppen

$B$ - K gegenüber der Kontrolle A

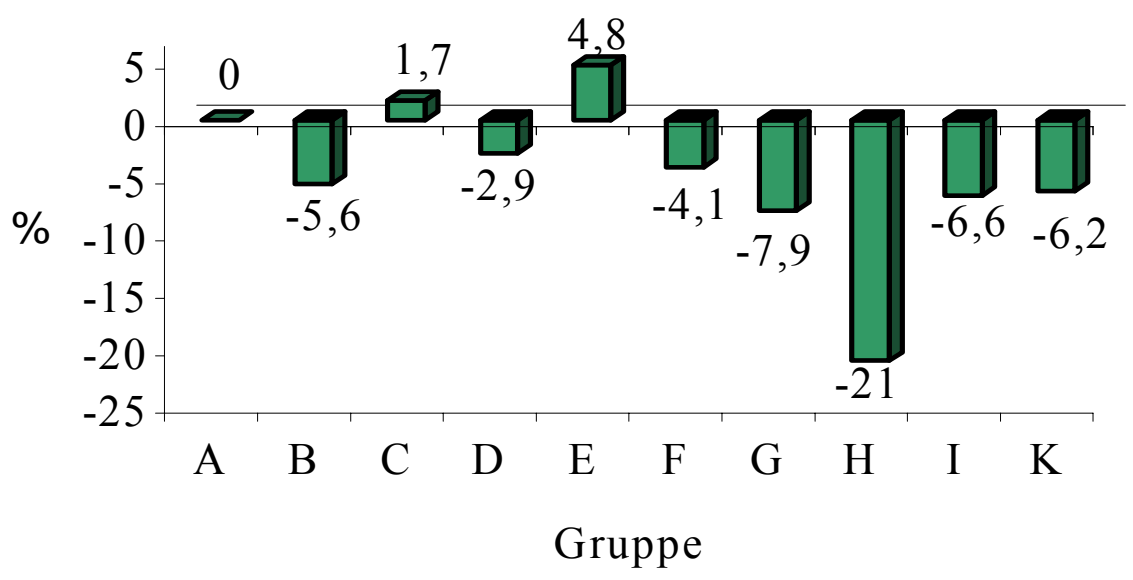

Abb. 6: Relative Veränderungen der LMZ der Gruppen

$B-$ K gegenüber der Kontrolle A 


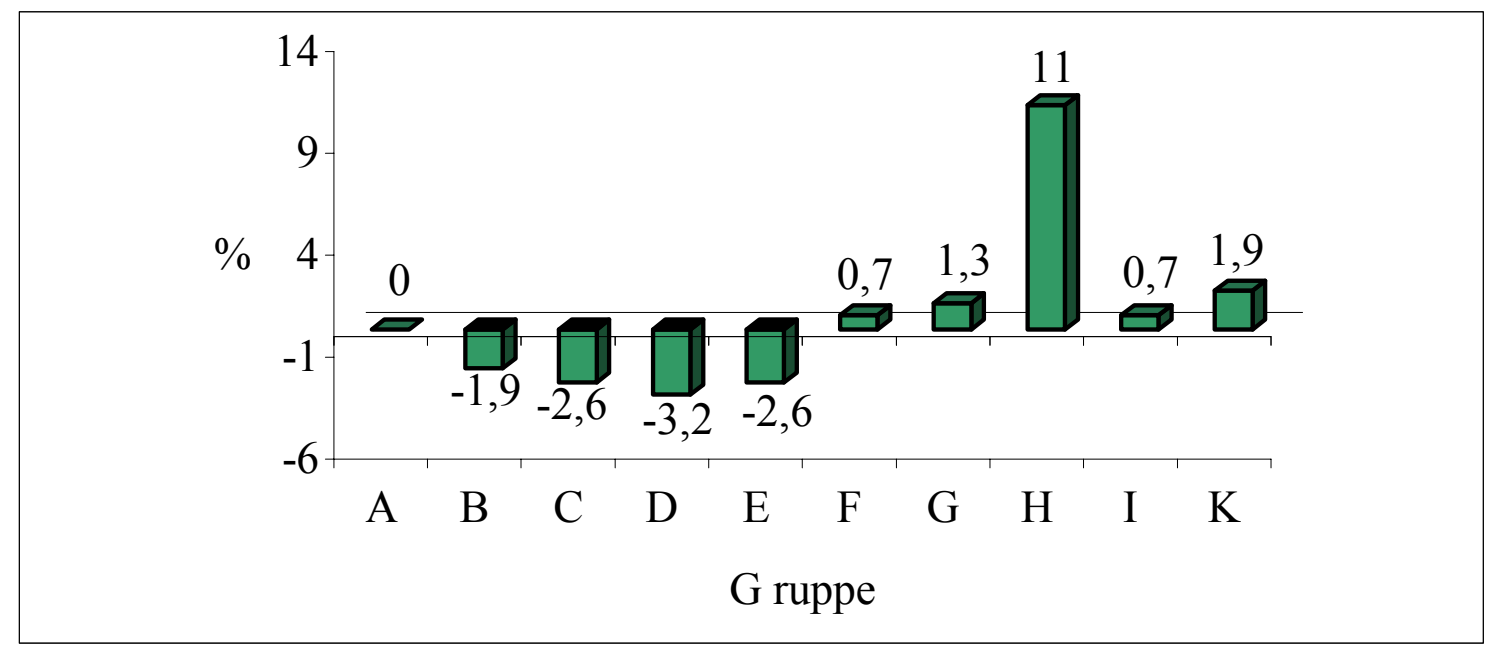
Abb. 7: Relative Veränderungen des FA der Gruppen B - K gegenüber
der Kontrolle A

\subsubsection{Energie- und Nährstoffansatz im Gesamtkörper}

Die Ergebnisse der Ansatzmessungen sind in Tab. 10 aufgeführt. Zur Orientierung sind ausserdem die relativen Veränderungen des Energie- und Proteinansatzes im Vergleich zur Kontrolle A in Abb. 8 und 9 aufgezeigt.

Analog zu den Ergebnissen der Wachstumsleistungen sind bei der Messung des Nährstoffansatzes sowohl tendenzielle als auch signifikante Unterschiede zwischen den Versuchsgruppen festzustellen (Tab. 10). Das niedrigste Niveau des Energie-, Protein-, Fett- und Rohascheansatzes liegt in der Gruppe H vor. Demgegenüber zeigte Gruppe E den höchsten Energie- und Proteinansatz. Die Ansatzwerte in der Gruppe H sind im Vergleich zu den anderen Versuchsgruppen A, B C, D, E und F signifikant vermindert und fallen mit der höchsten relativen Trypsininhibitoraktivität in der Futtermischung zusammen. Infolge einer zusätzlichen Dampfzufuhr und eines erhöhten Energieeintrags kann jedoch der Einfluss der Trypsininhibitoraktivität weiter reduziert werden. Deshalb verbesserte sich insbesondere der Proteinansatz bei den Gruppen I und K signifikant im Vergleich zur Gruppe H. Demgegenüber war der Energieansatz zwischen den Gruppen H und I bzw. K nur in der Tendenz verändert. Zwischen den Gruppen C und F sowie D und G besteht ebenfalls kein signifikanter Unterschied. Somit haben die Zerkleinerungsverfahren eine geringere Bedeutung, um antinutritive Substanzen zu reduzieren und dadurch Einfluss auf den Nährstoffansatz im Broilergesamtkörper auszuüben. 
Tab. 10: Täglicher Energie- und Nährstoffansatz im Ganzkörper

\begin{tabular}{|c|c|c|c|c|}
\hline Gruppe* & $\begin{array}{r}\text { Energie } \\
(\mathbf{k J} / \mathbf{d})\end{array}$ & $\begin{array}{c}\text { Protein } \\
\text { (g/d) }\end{array}$ & $\begin{array}{l}\text { Fett } \\
(\mathrm{g} / \mathrm{d})\end{array}$ & $\begin{array}{c}\text { Rohasche } \\
\text { (g/d) }\end{array}$ \\
\hline $\mathbf{A}$ (WS, kond. für $40 \mathrm{~min}$.) & $\begin{array}{l}429^{a b} \\
\pm 32\end{array}$ & $\begin{array}{l}8,9^{\mathrm{ab}} \\
\pm 0,5\end{array}$ & $\begin{array}{l}5,4^{\mathrm{ab}} \\
\pm 0,8\end{array}$ & $\begin{array}{l}1,4^{\mathrm{a}} \\
\pm 0,1\end{array}$ \\
\hline B (WS, kond. für $40 \mathrm{~min} .+$ flockiert) & $\begin{array}{l}409^{\mathrm{ab}} \\
\pm 22\end{array}$ & $\begin{array}{l}8,3^{b} \\
\pm 0,5\end{array}$ & $\begin{array}{l}5,3^{\mathrm{ab}} \\
\pm 0,7\end{array}$ & $\begin{array}{l}1,2^{\mathrm{a}} \\
\pm 0,1\end{array}$ \\
\hline $\mathbf{C}$ (WS, kond. für $10 \mathrm{~min}$.) & $\begin{array}{l}428^{\mathrm{ab}} \\
\pm 23\end{array}$ & $\begin{array}{l}8,9^{\mathrm{ab}} \\
\pm 0,4\end{array}$ & $\begin{array}{l}5,4^{\mathrm{ab}} \\
\pm 0,6\end{array}$ & $\begin{array}{l}1,3^{\mathrm{a}} \\
\pm 0,1\end{array}$ \\
\hline $\begin{array}{l}\text { D (WS, kond. für } 10 \text { min. }+ \text { exp., } 20 \\
\qquad \mathrm{kWh} / \mathrm{t} \text { ) }\end{array}$ & $\begin{array}{l}418^{a b} \\
\pm 37\end{array}$ & $\begin{array}{l}8,7^{\mathrm{ab}} \\
\pm 0,7\end{array}$ & $\begin{array}{l}5,3^{\mathrm{ab}} \\
\pm 0,6\end{array}$ & $\begin{array}{l}1,3^{\mathrm{a}} \\
\pm 0,1\end{array}$ \\
\hline $\begin{array}{l}\mathbf{E} \text { (HM, kond. für } 10 \text { min. + extr., } 15 \\
\text { kWh) }\end{array}$ & $\begin{array}{l}470^{\mathrm{a}} \\
\pm 47\end{array}$ & $\begin{array}{l}9,2^{\mathrm{a}} \\
\pm 0,3\end{array}$ & $\begin{array}{l}6,3^{\mathrm{a}} \\
\pm 1,3\end{array}$ & $\begin{array}{l}1,4^{\mathrm{a}} \\
\pm 0,1\end{array}$ \\
\hline F (HM, kond. für $10 \mathrm{~min})$. & $\begin{array}{l}427^{\mathrm{ab}} \\
\pm 47\end{array}$ & $\begin{array}{l}8,6^{\mathrm{ab}} \\
\pm 0,3\end{array}$ & $\begin{array}{l}5,6^{\mathrm{ab}} \\
\pm 1,1\end{array}$ & $\begin{array}{l}1,3^{\mathrm{a}} \\
\pm 0,1\end{array}$ \\
\hline $\begin{array}{l}\text { G (HM, kond. für } 10 \text { min. + exp., } 20 \\
\qquad \mathrm{kWh} / \mathrm{t})\end{array}$ & $\begin{array}{l}392^{b c} \\
\pm 40\end{array}$ & $\begin{array}{l}8,3^{\mathrm{ab}} \\
\pm 0,8\end{array}$ & $\begin{array}{l}4,9^{\mathrm{ab}} \\
\pm 0,8\end{array}$ & $\begin{array}{l}1,2^{\mathrm{a}} \\
\pm 0,2\end{array}$ \\
\hline $\mathbf{H}(\mathrm{HM}+\exp ., 20 \mathrm{kWh} / \mathrm{t})$ & $\begin{array}{l}341^{\mathrm{c}} \\
\pm 28\end{array}$ & $\begin{array}{l}6,7^{\mathrm{c}} \\
\pm 0,2\end{array}$ & $\begin{array}{l}4,5^{\mathrm{b}} \\
\pm 0,6\end{array}$ & $\begin{array}{l}1,0^{\mathrm{b}} \\
\pm 0,0\end{array}$ \\
\hline I (HM + exp., $15 \mathrm{kWh} / \mathrm{t}+$ Dampf) & $\begin{array}{l}405^{\mathrm{bc}} \\
\pm 33\end{array}$ & $\begin{array}{l}8,2^{b} \\
\pm 0,2\end{array}$ & $\begin{array}{l}5,2^{\mathrm{ab}} \\
\pm 0,8\end{array}$ & $\begin{array}{l}1,2^{\mathrm{a}} \\
\pm 0,1\end{array}$ \\
\hline $\mathbf{K}(\mathrm{HM}+$ exp., $40 \mathrm{kWh} / \mathrm{t})$ & $\begin{array}{l}400^{b c} \\
\pm 14\end{array}$ & $\begin{array}{l}8,0^{b} \\
\pm 0,3\end{array}$ & $\begin{array}{l}5,2^{\mathrm{ab}} \\
\pm 0,5\end{array}$ & $\begin{array}{l}1,2^{\mathrm{a}} \\
\pm 0,0\end{array}$ \\
\hline
\end{tabular}

Unterschiedliche Hochbuchstaben innerhalb einer Spalte bedeuten signifikante Differenzen $(\mathrm{P} \leq 0,05)$,

*) vgl. Tab. 3 


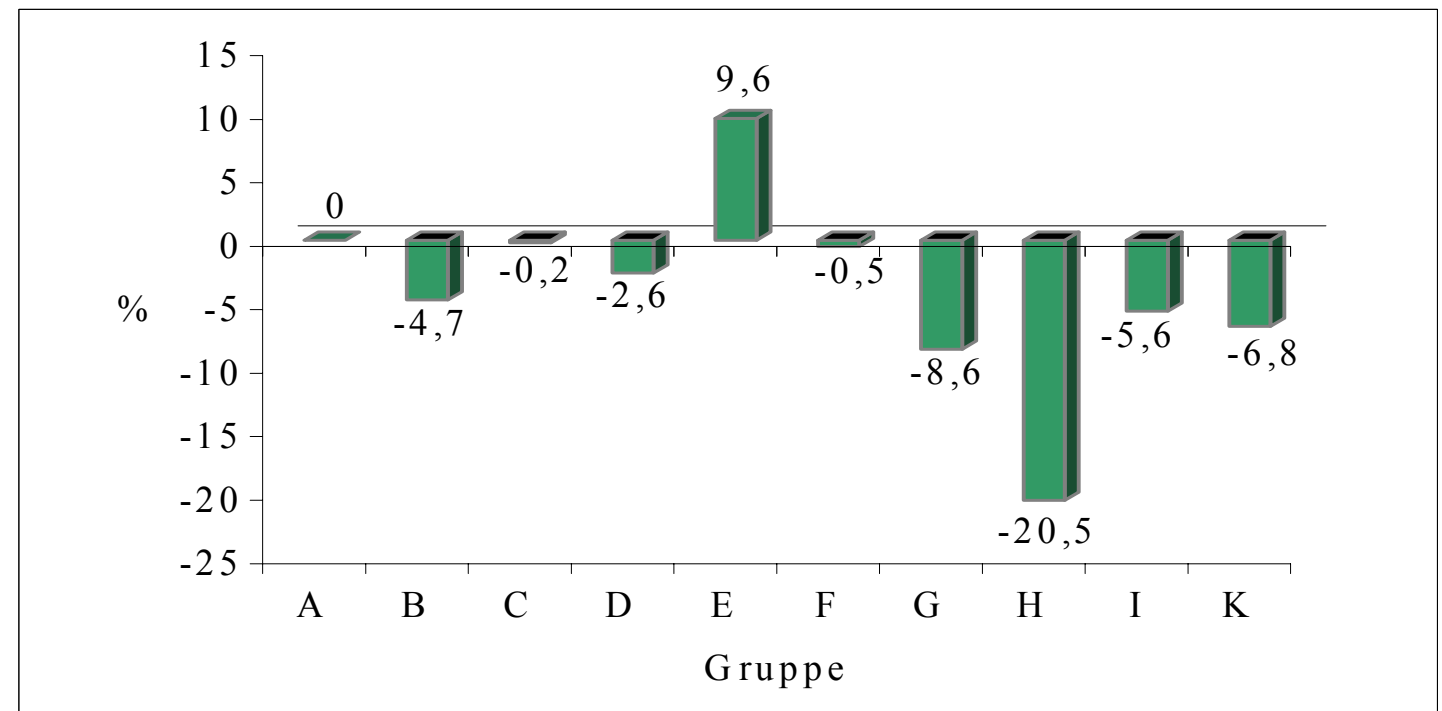

Abb. 8: Relative Veränderungen des Energieansatzes der Gruppen $B$ - K gegenüber der Kontrolle A

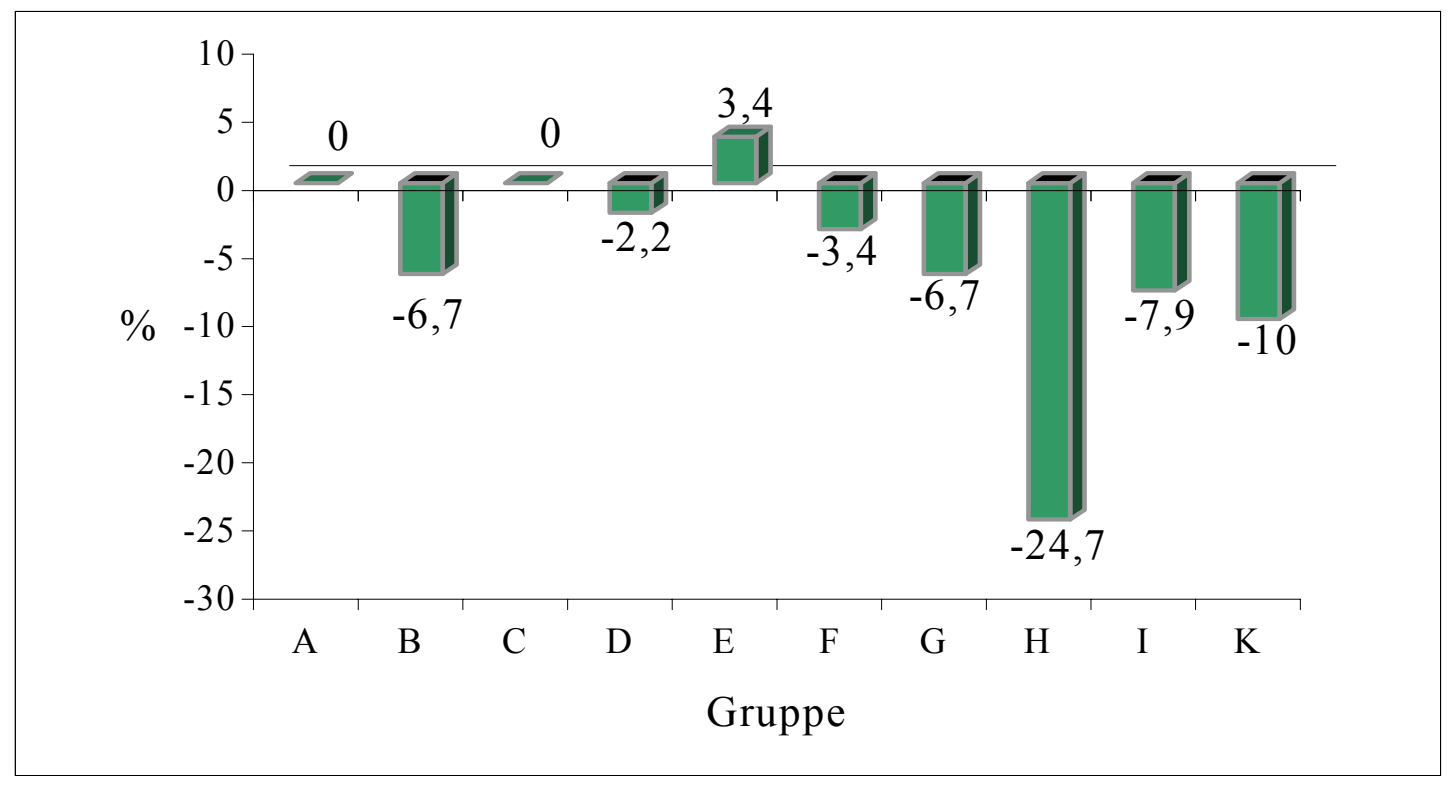

Abb. 9: Relative Veränderungen des Proteinansatzes der Gruppen $B$ - K gegenüber der Kontrolle A 


\subsection{Umsetzbare Energie}

Die Ergebnisse der Messung der N-korrigierten scheinbar umsetzbaren Energie (MEn) in den Futtermischungen sind in Tab. 11 zusammengefaßt.

Tab. 11: N-korrigierte scheinbar umsetzbare Energie

\begin{tabular}{lcc}
\hline Gruppe* $^{*}$ & $\begin{array}{c}\mathbf{M E}_{\mathbf{n}} \\
(\mathbf{M J} / \mathbf{k g} \mathbf{T})\end{array}$ & $\mathbf{s}$ \\
\hline A (WS, kond. für 40 min.) & $13,96^{\mathrm{c}}$ & $\pm 0,35$ \\
B (WS, kond. für 40 min. + flockiert) & $14,87^{\mathrm{a}}$ & $\pm 0,21$ \\
C (WS, kond. für 10 min.) & $14,31^{\mathrm{abc}}$ & $\pm 0,36$ \\
D (WS, kond. für 10 min. + exp., 20 kWh/t) & $14,27^{\mathrm{abc}}$ & $\pm 0,40$ \\
E (HM, kond. für 10 min. + extr., 15 kWh/t) & $14,07^{\mathrm{bc}}$ & $\pm 0,38$ \\
F (HM, kond. für 10 min.) & $14,25^{\mathrm{abc}}$ & $\pm 0,38$ \\
G (HM, kond. für $10 \mathrm{~min} .+$ exp., 20 kWh/t) & $14,70^{\mathrm{ab}}$ & $\pm 0,13$ \\
H (HM + exp., 20 kWh/t) & $14,28^{\mathrm{abc}}$ & $\pm 0,31$ \\
I (HM + exp., 15 kWh/t + Dampf) & $14,47^{\mathrm{abc}}$ & $\pm 0,18$ \\
K(HM + exp., 40kWh/t) & $14,15^{\mathrm{bc}}$ & $\pm 0,45$
\end{tabular}

Unterschiedliche Hochbuchstaben innerhalb einer Spalte bedeuten signifikante Differenzen $\left.(\mathrm{P} \leq 0,05),{ }^{*}\right)$ vgl. Tab. 3

Die relativen Veränderungen der umsetzbaren Energie der Futtermischungen $\mathrm{B}-\mathrm{K}$ sind außerdem in Abb. 10 gegenüber der Kontrolle A dargestellt. Der Gehalt an umsetzbarer Energie in den Futtermischungen B und G ist signifikant höher als bei der Kontrolle A. Die Ursache kann in der zusätzlichen Flockierung und Expandierung der Sojabohnen liegen. Zwischen den Gruppen H, I und K sowie D und G ergibt sich kein signifikanter Unterschied. Somit hatten in den vorliegenden Untersuchungen zusätzliche Dampfzufuhr, Energieeintrag und Zerkleinerungsart eine geringere Wirkung auf den Gehalt an umsetzbarer Energie. 


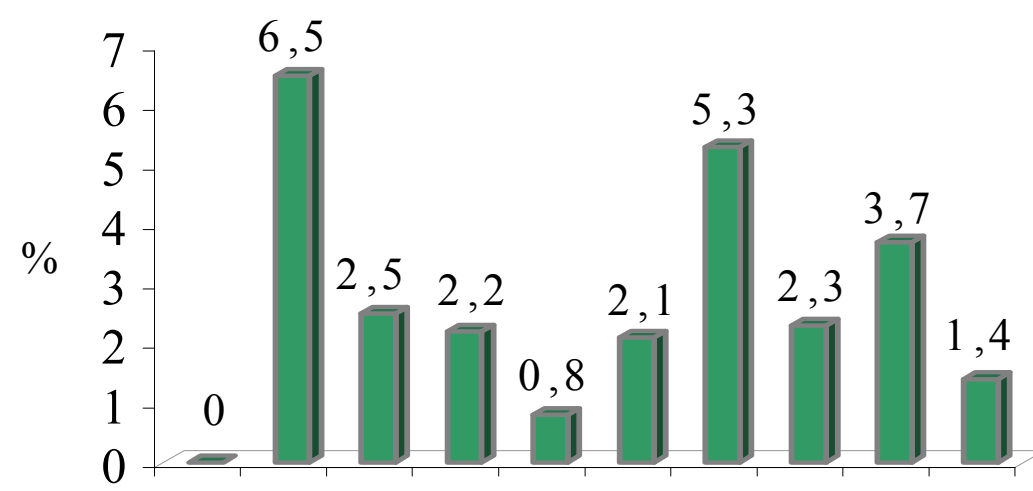

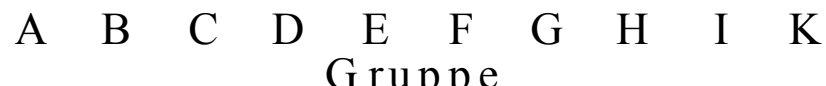

\section{Abb. 10: Relative Veränderungen der N-korrigierten scheinbar umsetzbaren Energie der Futtermischungen der Gruppen B - K gegenüber der Kontrolle A}

\subsection{N-Stoffwechselparameter}

\subsubsection{N-Bilanzmessung, Physiologischer Nutzwert und N-Verdaulichkeit}

Die Resultate der N-Bilanzmessungen und der daraus abgeleitete Physiologische Nutzwert $\left(\mathrm{PNu}_{3500}\right)$ sind in Tab. 12 zusammengefaßt. Die Ergebnisse der N-Verdaulichkeitsmessung ( $\alpha$ amino-N-Methode) sind Tab. 13 zu entnehmen.

Im vorangegangenen Abschnitt wurden bereits die signifikant niedrigeren Wachstumsparameter für die Gruppe H infolge der höchsten Restaktivität des TI in der Sojabohne dargestellt. Der Einfluss des TI auf N-Aufnahme und N-Ausscheidung sowie N-Bilanz war jedoch weniger deutlich erkennbar. Obwohl die Mischungen der Gruppen F, I und K im Vergleich zur Gruppe H eine niedrigere TIA aufwiesen, war eine höhere N-Auscheidung zu erkennen. Andererseits zeigten die Fütterungsgruppen F, I und K gegenüber B eine signifikant höhere N-Ausscheidung. Bezüglich N-Bilanz und Physiologischem Nutzwert $(\mathrm{PNu})$ zeigte sich kein signifikanter Unterschied zwischen den Gruppen. Dieses Ergebnis ist überaschend, da die PNu-Werte standardisiert waren und somit im Gegensatz zur N-Ausscheidung sowie N-Bilanz nicht durch Unterschiede in der N-Aufnahme überlagert wurden. Unter den restriktiven Fütterungsbedingungen des Bilanzversuches ergab sich nur für das flockierte Futter der Gruppe 
B ein Hinweis auf eine geringere N-Bilanz, jedoch ausschließlich bedingt durch eine etwas geringere N-Aufnahme und ohne Auswirkung auf die Höhe des PNu.

Tab. 12: Ergebnisse des N-Bilanzversuches

\begin{tabular}{|c|c|c|c|c|}
\hline Gruppe* & $\begin{array}{l}\text { N-Aufnah- } \\
\text { me/LM }_{\text {kg }}^{0,67} \\
\text { (mg/d) }\end{array}$ & $\begin{array}{l}\text { N-Ausschei- } \\
\text { dung/LM } \mathbf{k g}^{0,67} \\
\text { (mg/d) }\end{array}$ & $\begin{array}{l}\text { N-Bilanz/LM } \mathbf{k g}^{0,67} \\
(\mathrm{mg} / \mathrm{d})\end{array}$ & $\begin{array}{c}\mathrm{PNu}_{3500} \\
(\%)\end{array}$ \\
\hline A (WS, kond. für $40 \mathrm{~min}$.) & $\begin{array}{l}3448^{\mathrm{ab}} \\
\pm 83\end{array}$ & $\begin{array}{l}1478^{\mathrm{ab}} \\
\pm 132\end{array}$ & $\begin{array}{l}1971^{\mathrm{a}} \\
\pm 122\end{array}$ & $\begin{array}{l}71,12^{\mathrm{a}} \\
\pm 3,40\end{array}$ \\
\hline $\begin{array}{l}\text { B (WS, kond. für } 40 \mathrm{~min} .+ \\
\text { flockiert) }\end{array}$ & $\begin{array}{l}3096^{\mathrm{b}} \\
\pm 178\end{array}$ & $\begin{array}{l}1245^{\mathrm{a}} \\
\pm 175\end{array}$ & $\begin{array}{l}1851^{\mathrm{a}} \\
\pm 90\end{array}$ & $\begin{array}{l}71,56^{\mathrm{a}} \\
\pm 2,72\end{array}$ \\
\hline C (WS, kond. für $10 \mathrm{~min})$. & $\begin{array}{l}3374^{\mathrm{ab}} \\
\pm 245\end{array}$ & $\begin{array}{l}1432^{\mathrm{ab}} \\
\pm 199\end{array}$ & $\begin{array}{l}1942^{\mathrm{a}} \\
\pm 86\end{array}$ & $\begin{array}{l}71,14^{\mathrm{a}} \\
\pm 2,12\end{array}$ \\
\hline $\begin{array}{l}\text { D (WS, kond. für } 10 \mathrm{~min} .+ \\
\quad \text { exp., } 20 \mathrm{kWh} / \mathrm{t} \text { ) }\end{array}$ & $\begin{array}{l}3506^{\mathrm{a}} \\
\pm 142\end{array}$ & $\begin{array}{l}1488^{\mathrm{ab}} \\
\pm 75\end{array}$ & $\begin{array}{l}2018^{\mathrm{a}} \\
\pm 162\end{array}$ & $\begin{array}{l}71,95^{\mathrm{a}} \\
\pm 3,45\end{array}$ \\
\hline $\begin{array}{l}\mathbf{E} \text { (HM, kond. für } 10 \mathrm{~min} .+ \\
\quad \text { extr., } 15 \mathrm{kWh} / \mathrm{t})\end{array}$ & $\begin{array}{l}3374^{\mathrm{ab}} \\
\pm 72\end{array}$ & $\begin{array}{l}1454^{\mathrm{ab}} \\
\pm 149\end{array}$ & $\begin{array}{l}1920^{\mathrm{a}} \\
\pm 101\end{array}$ & $\begin{array}{l}70,45^{\mathrm{a}} \\
\pm 3,29\end{array}$ \\
\hline F (HM, kond. für 10 min.) & $\begin{array}{l}3588^{\mathrm{a}} \\
\pm 65\end{array}$ & $\begin{array}{l}1542^{b} \\
\pm 112\end{array}$ & $\begin{array}{l}2046^{\mathrm{a}} \\
\pm 130\end{array}$ & $\begin{array}{l}71,90^{\mathrm{a}} \\
\pm 3,48\end{array}$ \\
\hline $\begin{array}{l}\text { G (HM, kond. für } 10 \mathrm{~min} .+ \\
\quad \text { exp., } 20 \mathrm{kWh} / \mathrm{t})\end{array}$ & $\begin{array}{l}3368^{\mathrm{b}} \\
\pm 363\end{array}$ & $\begin{array}{l}1359^{\mathrm{ab}} \\
\pm 170\end{array}$ & $\begin{array}{l}2008^{\mathrm{a}} \\
\pm 199\end{array}$ & $\begin{array}{l}73,27^{\mathrm{a}} \\
\pm 1,80\end{array}$ \\
\hline $\mathbf{H}(\mathrm{HM}+$ exp., $20 \mathrm{kWh} / \mathrm{t})$ & $\begin{array}{l}3391^{\mathrm{ab}} \\
\pm 299\end{array}$ & $\begin{array}{l}1495^{\mathrm{ab}} \\
\pm 208\end{array}$ & $\begin{array}{l}1896^{\mathrm{a}} \\
\pm 104\end{array}$ & $\begin{array}{l}69,71^{\mathrm{a}} \\
\pm 1,37\end{array}$ \\
\hline $\begin{array}{l}\text { I }(\mathrm{HM}+\text { exp., } 15 \mathrm{kWh} / \mathrm{t}+ \\
\text { Dampf) }\end{array}$ & $\begin{array}{l}3494^{\mathrm{a}} \\
\pm 74\end{array}$ & $\begin{array}{l}1545^{\mathrm{b}} \\
\pm 43\end{array}$ & $\begin{array}{l}1949^{\mathrm{a}} \\
\pm 73\end{array}$ & $\begin{array}{l}70,05^{\mathrm{a}} \\
\pm 1,51\end{array}$ \\
\hline $\mathbf{K}(\mathrm{HM}+\exp ., 40 \mathrm{kWh} / \mathrm{t})$ & $\begin{array}{l}3614^{\mathrm{a}} \\
\pm 44\end{array}$ & $\begin{array}{l}1607^{b} \\
\pm 155\end{array}$ & $\begin{array}{l}2008^{\mathrm{a}} \\
\pm 147\end{array}$ & $\begin{array}{l}70,53^{\mathrm{a}} \\
\pm 4,27\end{array}$ \\
\hline
\end{tabular}

Unterschiedliche Hochuchstaben innerhalb einer Spalte bedeuten signifikante Differenzen $(\mathrm{P} \leq 0,05)$ *) vgl. Tab. 3

Gruppe H, mit der relativ höheren Trypsininhibitoraktivität in der Diät, weist einen tendenziell geringeren PNu von 69,71 \% auf. Den höchsten PNu zeigt Gruppe G (Vermahlung, Expander) in Höhe von 73,27 \%. Der Unterschied ist jedoch gegenüber der Kontrolle A sowie den weiteren Behandlungsgruppen nicht signifikant und kann aus der Restaktivität des Inhibitors nicht erklärt werden. Dabei ist zu berücksichtigen, dass die behandelten Sojabohnen als Rationsbestandteil geprüft wurden, also ein Verdünnungseffekt für den TI vorlag. 
Die N-Verdaulichkeit der Futtermischungen (Tab. 13) zeigte demgegenüber signifikante Unterschiede zwischen der Kontrolle A und der Gruppe B sowie zwischen der Gruppe H und den anderen Gruppen (außer K). Die signifikant verminderte N-Verdaulichkeit bei Gruppe H kann auf die Restaktivität des TI in den Sojabohnen zurückgeführt werden, während die signifikant niedrigere N-Verdaulichkeit bei der Kontrolle A gegenüber der Gruppe B offensichtlich andere Ursachen haben muß. Vermutlich hat die zusätzliche Flockierung der Behandlungsvariante B eine Verbesserung der N- Verdaulichkeit bewirkt.

Tab. 13: Ergebnisse der scheinbaren N-Verdaulichkeit

\begin{tabular}{lcc}
\hline Gruppe* $^{*}$ & N-Verdaulichkeit \\
& $(\mathbf{\%})$ & \\
\hline A (WS, kond. für 40 min.) & $80.92^{\mathrm{bc}}$ & $\pm 3,02$ \\
B (WS, kond. für 40 min. + flockiert) & $85,39^{\mathrm{a}}$ & $\pm 1,49$ \\
C (WS, kond. für 10 min.) & $81,44^{\mathrm{abc}}$ & $\pm 3,30$ \\
D (WS, kond. für 10 min. + exp., 20 kWh/t) & $83,89^{\mathrm{ab}}$ & $\pm 2,11$ \\
E (HM, kond. für 10 min. + extr., 15 kWh/t) & $82,87^{\mathrm{abc}}$ & $\pm 2,28$ \\
F (HM, kond. für $10 \mathrm{~min})$. & $81,66^{\mathrm{abc}}$ & $\pm 1,97$ \\
G (HM, kond. für $10 \mathrm{~min} .+$ exp., 20 kWh/t) & $84,53^{\mathrm{ab}}$ & $\pm 1,39$ \\
H (HM + exp., 20 kWh/t) & $75,75^{\mathrm{d}}$ & $\pm 2,21$ \\
I (HM + exp., 15 kWh/t + Dampf) & $82,66^{\mathrm{abc}}$ & $\pm 1,16$ \\
K (HM + exp., 40kWh/t) & $79,38^{\mathrm{cd}}$ & $\pm 2,54$ \\
\hline
\end{tabular}

Unterschiedliche Hochbuchstaben innerhalb einer Spalte bedeuten signifikante Differenzen $\left.(\mathrm{P} \leq 0,05),{ }^{*}\right)$ vgl. Tab. 3

Die höhere N- Verdaulichkeit bei Gruppe I bzw. K im Vergleich zu Gruppe H kann auf Grund der zusätzlichen Dampfzufuhr bzw. des erhöhten Energieeintrags entstanden sein, da durch diese Verfahren die Temperatur während des Behandlungsprozesses erhöht und dadurch die TIA in der Sojabohne weiter reduziert wurde.

\subsection{Ileale Aminosäureverdaulichkeit (Arg, Met +Cys, Thr, Lys) und Lysinwirksamkeit}

In Tab. 14 sind die Ergebnisse der scheinbaren ilealen Aminosäureverdaulichkeit ausgewählter Aminosäuren zusammengefasst 
Tab. 14: Scheinbare ileale Aminosäureverdaulichkeit (\%) ausgewählter Aminosäuren

\begin{tabular}{|c|c|c|c|c|}
\hline Gruppe* & Arginin & $\begin{array}{l}\text { Methionin } \\
+ \text { Cystin }\end{array}$ & Threonin & Lysin \\
\hline $\mathbf{A}$ (WS, kond. für $40 \mathrm{~min}$.) & $93,0^{\mathrm{abc}}$ & $74,2^{\text {bcd }}$ & $81,8^{\mathrm{abc}}$ & $87,9^{\mathrm{a}}$ \\
\hline $\begin{array}{l}\text { B (WS, kond. für } 40 \mathrm{~min} .+ \\
\text { flockiert) }\end{array}$ & $\begin{array}{l} \pm 1.0 \\
95,0 \mathrm{ab} \\
+0.1\end{array}$ & $\begin{array}{l} \pm 5.3 \\
76,4 \\
+2.8\end{array}$ & $\begin{array}{l} \pm 1.2 \\
83,9^{\mathrm{ab}} \\
\pm 1.3\end{array}$ & $\begin{array}{l} \pm 0.9 \\
89,9^{\mathrm{a}} \\
+1.0\end{array}$ \\
\hline C (WS, kond. für $10 \mathrm{~min}$.) & $\begin{array}{l}94,7^{\mathrm{ab}} \\
\pm 3,2\end{array}$ & $\begin{array}{l}84,0^{\text {ab }} \\
\pm 0,5\end{array}$ & $\begin{array}{l}85,7^{\text {ab }} \\
\pm 2,5\end{array}$ & $\begin{array}{l}90,3^{\mathrm{a}} \\
\pm 0,5\end{array}$ \\
\hline $\begin{array}{l}\mathbf{D} \text { (WS, kond. für } 10 \mathrm{~min} .+ \\
\quad \text { exp., } 20 \mathrm{kWh} / \mathrm{t})\end{array}$ & $\begin{array}{l}96,2^{\mathrm{a}} \\
\pm 1,2\end{array}$ & $\begin{array}{l}81,5^{\mathrm{ab}} \\
\pm 5,5\end{array}$ & $\begin{array}{l}86,0^{\mathrm{ab}} \\
\pm 2,3\end{array}$ & $\begin{array}{l}89,2^{\mathrm{a}} \\
\pm 1,9\end{array}$ \\
\hline $\begin{array}{l}\mathbf{E} \text { (HM, kond. für } 10 \mathrm{~min} .+ \\
\text { extr., } 15 \mathrm{kWh} / \mathrm{t} \text { ) }\end{array}$ & $\begin{array}{l}92,8^{\mathrm{abc}} \\
\pm 1,7\end{array}$ & $\begin{array}{l}83,7^{\mathrm{ab}} \\
\pm 7,3\end{array}$ & $\begin{array}{l}86,0^{a b} \\
\pm 2,1\end{array}$ & $\begin{array}{l}87,0^{\mathrm{a}} \\
\pm 0,5\end{array}$ \\
\hline $\mathbf{F}$ (HM, kond. für $10 \mathrm{~min})$. & $\begin{array}{l}87,9^{\mathrm{cd}} \\
\pm 3,1\end{array}$ & $\begin{array}{l}81,4^{\mathrm{ab}} \\
\pm 2,6\end{array}$ & $\begin{array}{l}82,0^{a b c} \\
\pm 2,1\end{array}$ & $\begin{array}{l}81,0^{b} \\
\pm 3,3\end{array}$ \\
\hline $\begin{array}{l}\text { G (HM, kond. für } 10 \mathrm{~min} .+ \\
\text { exp., } 20 \mathrm{kWh} / \mathrm{t})\end{array}$ & $\begin{array}{l}92,9^{\mathrm{abc}} \\
\pm 1,3\end{array}$ & $\begin{array}{l}83,3^{\mathrm{ab}} \\
\pm 2,0\end{array}$ & $\begin{array}{l}86,7^{\mathrm{a}} \\
\pm 1,4\end{array}$ & $\begin{array}{l}87,5^{\mathrm{a}} \\
\pm 1,3\end{array}$ \\
\hline $\mathbf{H}(\mathrm{HM}+\exp ., 20 \mathrm{kWh} / \mathrm{t})$ & $\begin{array}{l}83,5^{\mathrm{d}} \\
\pm 3,9\end{array}$ & $\begin{array}{l}69,0^{\mathrm{d}} \\
\pm 4,2\end{array}$ & $\begin{array}{l}72,1^{d} \\
\pm 4,3\end{array}$ & $\begin{array}{l}74,2^{\mathrm{c}} \\
\pm 3,4\end{array}$ \\
\hline $\begin{array}{l}\text { I (HM + exp., } 15 \mathrm{kWh} / \mathrm{t}+ \\
\text { Dampf) }\end{array}$ & $\begin{array}{l}90,3^{b c} \\
\pm 2,1\end{array}$ & $\begin{array}{l}75,0 \\
\pm 0,5\end{array}$ & $\begin{array}{l}77,7^{\mathrm{c}} \\
\pm 0,4\end{array}$ & $\begin{array}{l}86,0^{\mathrm{a}} \\
\pm 2,0\end{array}$ \\
\hline $\mathbf{K}(\mathrm{HM}+$ exp., 40kWh/t $)$ & $\begin{array}{l}91,9^{\mathrm{abc}} \\
\pm 1,1\end{array}$ & $\begin{array}{l}79,2^{\text {abc }} \\
\pm 1,7\end{array}$ & $\begin{array}{l}80,9^{\text {bc }} \\
\pm 1,7\end{array}$ & $\begin{array}{l}88,0^{\mathrm{a}} \\
\pm 1,4\end{array}$ \\
\hline
\end{tabular}

Unterschiedliche Hochbuchstaben innerhalb einer Spalte bedeuten signifikante Differenzen $\left.(\mathrm{P} \leq 0,05),{ }^{*}\right)$ vgl. Tab. 3

Zwischen den Gruppen A, B, C, D, E und K besteht in allen geprüften ilealen Aminosäureverdaulichkeiten kein signifikanter Unterschied. Obwohl unterschiedliche TIA in den behandelten Sojabohnen vorhanden waren, zeigten sich vergleichbare Effekte auf die ileale Aminosäureverdaulichkeit der entsprechenden Futtermischungen. Andererseits sind die ilealen Aminosäureverdaulichkeiten von Threonin und Lysin der Futtermischung H signifikant niedriger als in allen anderen Futtermischungen. Beim Vergleich der Argininverdaulichkeit der Futtermischung H gegenüber den anderen Futtermischungen (mit Ausnahme von Gruppe F) sind auch signifikante Unterschiede beobachtet worden. Hinsichtlich der Methionin + CystinVerdaulichkeit besteht zwischen Fütterungsgruppe H und A sowie B und K kein signifikanter Unterschied. Die verminderte Aminosäureverdaulichkeit bei der Gruppe H ist auf die höchste 
Restaktivität des TI in der Sojabohne zurückzuführen. Eine signifikant höhere Aminosäureverdaulichkeit ist bei den Fütterungsgruppen I und $\mathrm{K}$ gegenüber $\mathrm{H}$ zu beobachten. Dabei ist ein positiver Effekt des zusätzlichen Energieeintrags und einer Dampfzufuhr auf die Aminosäureverdaulichkeit der Futtermischungen (I und K) infolge der Senkung der TIA in den Sojabohnen anzunehmen.

Beim Vergleich der Gruppe C mit F zeigt Gruppe C eine signifikant bessere ileale Arginin- und Lysinverdaulichkeit. Dieser Unterschied ist jedoch zwischen beiden Gruppen für Methionin + Cystin und Threonin nur tendenziell feststellbar. Zwischen Gruppe D und G besteht kein signifikanter Unterschied in der Aminosäureverdaulichkeit. Somit ist kein Einfluss der unterschiedlichen Zerkleinerungsart auf die ileale Aminosäureverdaulichkeit erkennbar.

Betrachtet man die gesamten Ergebnisse der ilealen Aminosäureverdaulichkeit, so ist zu erkennen, dass es verschiedene Behandlungsalternativen gibt, um die unerwünschten Stoffe in der Sojabohne zu vermindern und dadurch die Nährstoffverdaulichkeit der Sojabohnen zu verbessern.

Aus Tab. 15 geht ein Ergebnisvergleich der ilealen Verdaulichkeit für Lysin und der Lysinwirksamkeit hervor. Zur besseren Orientierung sind in Abb. 11 die relativen Abweichungen der ilealen Lysinverdaulichkeit und Lysinwirksamkeit im Vergleich zur Kontrolle A dargestellt.

Auf Grund der höchsten Restaktivität in der Sojabohne zeigt die Fütterungsgruppe H eine signifikant niedrigere ileale Lysinverdaulichkeit gegenüber der Kontrolle A. Auch in der Futtermischung $\mathrm{F}$ ist eine signifikant niedrigere ileale Lysinverdaulichkeit gegenüber der Kontrolle A zu beobachten. Dies kann jedoch aus der Restaktivität des TI in den Sojabohnen nicht erklärt werden, weil die TIA in den behandelten Sojabohnen A und F auf vergleichbarem Niveau lagen (16\% bzw. $21 \%$ der unbehandelten Sojabohne).

Auf der Ebene der Lysinwirksamkeit ist zwischen den geprüften Futtermischungen kein signifikanter Unterschied $\mathrm{zu}$ ermitteln. Es wurde nur eine tendenziell niedrigere Lysinwirksamkeit bei Gruppe H gegenüber der Kontrolle A festgestellt. Somit ist der Einfluss der Restaktivität des TI in den behandelten Sojabohnen der Gruppe H auf die Lysinwirksamkeit im Vergleich zur Kontrolle A nicht deutlich erkennbar. Beim Vergleich der ilealen Lysinverdaulichkeit und der Lysinwirksamkeit ist ein Bewertungsunterschied für die Fütterungsgruppen $\mathrm{F}$ und $\mathrm{H}$ zu ersehen.

Die Lysinwirksamkeit bei $\mathrm{F}$ war im Vergleich zu A nahezu unverändert, die ileale Lysinverdaulichkeit dagegen signifikant reduziert. Die Lysinwirksamkeit bei $\mathrm{H}$ war tendenziell 
um $4 \%$ reduziert, die ileale Lysinverdaulichkeit dagegen signifikant vermindert und auf dem niedrigsten Niveau. Die Ursachen für diese differenzierte Bewertung bedürfen weiterer Klärung.

Tab. 15: Ergebnisvergleich der scheinbaren ilealen Lysinverdaulichkeit und Lysinwirksamkeit

\begin{tabular}{|c|c|c|c|c|}
\hline Gruppe* & $\begin{array}{l}\text { Lysin-VQ } \\
\quad(\%)\end{array}$ & $\begin{array}{c}\text { relativ } \\
(A=100)\end{array}$ & $\begin{array}{c}\text { Lysinwirksamkeit } \\
\qquad\left(\text { bc }^{-1}\right)\end{array}$ & $\begin{array}{r}\text { relativ } \\
(A=100)\end{array}$ \\
\hline A (WS, kond. für $40 \mathrm{~min}$.) & $\begin{array}{l}87,88^{\mathrm{a}} \\
\pm 0,91\end{array}$ & 100 & $\begin{array}{l}80,20^{\mathrm{a}} \\
\pm 7,73\end{array}$ & 100 \\
\hline $\begin{array}{l}\text { B (WS, kond. für } 40 \mathrm{~min} .+ \\
\text { flockiert) }\end{array}$ & $\begin{array}{l}89,86^{\mathrm{a}} \\
\pm 0,99\end{array}$ & 102 & $\begin{array}{l}81,06^{\mathrm{a}} \\
\pm 6,14\end{array}$ & 101 \\
\hline $\mathbf{C}$ (WS, kond. für $10 \mathrm{~min})$. & $\begin{array}{l}90,29^{\mathrm{a}} \\
\pm 0,48\end{array}$ & 103 & $\begin{array}{l}79,99^{\mathrm{a}} \\
\pm 4,80\end{array}$ & 100 \\
\hline $\begin{array}{l}\text { D (WS, kond. für } 10 \mathrm{~min} .+ \\
\text { exp., } 20 \mathrm{kWh} / \mathrm{t} \text { ) }\end{array}$ & $\begin{array}{l}89,15^{\mathrm{a}} \\
\pm 1,90\end{array}$ & 102 & $\begin{array}{l}82,13^{\mathrm{a}} \\
\pm 8,01\end{array}$ & 102 \\
\hline $\begin{array}{l}\mathbf{E} \text { (HM, kond. für } 10 \mathrm{~min} .+ \\
\quad \text { extr., } 15 \mathrm{kWh} / \mathrm{t})\end{array}$ & $\begin{array}{l}87,02^{\mathrm{a}} \\
\pm 0,48\end{array}$ & 99 & $\begin{array}{l}78,63^{\mathrm{a}} \\
\pm 7,16\end{array}$ & 98 \\
\hline F (HM, kond. für $10 \mathrm{~min})$. & $\begin{array}{l}81,01^{b} \\
\pm 3,33\end{array}$ & 92 & $\begin{array}{l}82,03^{\mathrm{a}} \\
\pm 8,04\end{array}$ & 102 \\
\hline $\begin{array}{l}\text { G (HM, kond. für } 10 \mathrm{~min} .+ \\
\text { exp., } 20 \mathrm{kWh} / \mathrm{t})\end{array}$ & $\begin{array}{l}87,51^{\mathrm{a}} \\
\pm 1,34\end{array}$ & 100 & $\begin{array}{l}85,02^{\mathrm{a}} \\
\pm 4,56\end{array}$ & 106 \\
\hline $\mathbf{H}(\mathrm{HM}+\exp ., 20 \mathrm{kWh} / \mathrm{t})$ & $\begin{array}{l}74,23^{\mathrm{c}} \\
\pm 3,38\end{array}$ & 85 & $\begin{array}{l}76,72^{\mathrm{a}} \\
\pm 2,99\end{array}$ & 96 \\
\hline $\begin{array}{l}\text { I (HM + exp., } 15 \mathrm{kWh} / \mathrm{t}+ \\
\text { Dampf) }\end{array}$ & $\begin{array}{l}86,00^{\mathrm{a}} \\
\pm 2,04\end{array}$ & 98 & $\begin{array}{l}77,47^{\mathrm{a}} \\
\pm 3,26\end{array}$ & 97 \\
\hline $\mathbf{K}(\mathrm{HM}+$ exp., 40kWh/t) & $\begin{array}{l}88,00^{\mathrm{a}} \\
\pm 1,40\end{array}$ & 100 & $\begin{array}{l}79,03^{\mathrm{a}} \\
\pm 9,12\end{array}$ & 99 \\
\hline
\end{tabular}

Unterschiedliche Hochbuchstaben innerhalb einer Spalte bedeuten signifikante Differenzen ( $\mathrm{P} \leq 0,05)$,

*) vgl. Tab. 3 


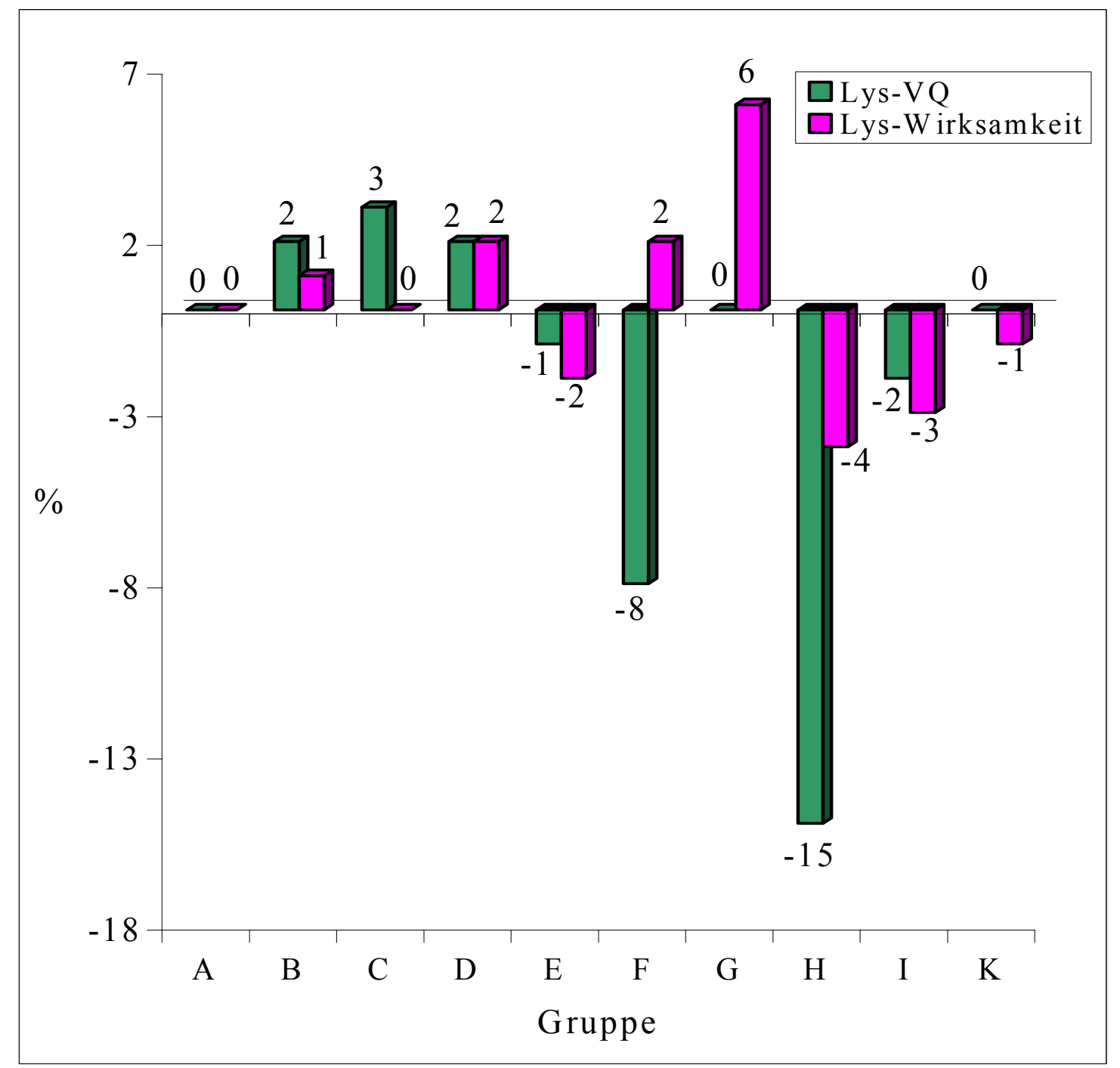

Abb. 11: Relative Veränderungen der scheinbaren ilealen Lysinverdaulichkeit und der Lysinwirksamkeit der Gruppen B - K gegenüber der Kontrolle A 


\section{Diskussion}

\subsection{Einflüsse einer unterschiedlichen Sojabohnenbehandlung auf Wachstumsparameter, Energie- und Nährstoffansatz}

Die futterwertverbessernde Wirkung der thermischen Behandlung von Sojabohnen wurde bereits bei Broilern, Schweinen und Ratten in zahlreichen Untersuchungen nachgewiesen. In den vorliegenden Untersuchungen wurden in Abhängigkeit von den Behandlungsverfahren differenzierte Einflüsse auf die geprüften Parameter festgestellt. Herauszustellen war insbesondere der signifikant geringere Futterverzehr bei Behandlungsgruppe H (Vermahlung, Expandierung), ebenso bei Behandlungsgruppe B (Walzenstuhl, Konditionierung und Flockierung). Im letztgenannten Fall stand diese Beobachtung auch mit der vorgenommenen Flockierung, die zur Verminderung der Futterdichte führt, in Verbindung. Die Schüttdichte der Sojabohnen lag nach der Flockierung (B) bei $0,42 \mathrm{~g} / \mathrm{cm}^{3}$, während bei den anderen behandelten Sojabohnen die Schüttdichte im Mittel $0,5 \mathrm{~g} / \mathrm{cm}^{3}$ betrug.

Der signifikant niedrigere Futterverzehr bei der Gruppe H läßt sich wahrscheinlich durch die höchste TIA erklären, was auch das geringere Wachstum der Tiere ausgelöst hat. Bei rohen und nicht ausreichend behandelten Sojabohnen kamen GERTLER et al. (1967) und WALDROUP et al. (1985) zu einem vergleichbaren negativen Einfluss auf den Futterverzehr.

Hinsichtlich der Lebendmassezunahme und Futterverwertung zeigte die Fütterungsgruppe H die gleiche Tendenz wie beim Futterverzehr (vgl. Tab. 9). Die Restaktivität des Trypsininhibitors in der Sojabohne verminderte das Wachstum im Vergleich zu der Gruppe A um $-27 \%$. Die Gruppe H realisierte einen Futteraufwand von 1,72, während der Futteraufwand der Kontrolle A bei 1,55 lag. Dies ist mit der erhöhten Trypsininhibitoraufnahme verbunden. Wenn die Behandlung der Sojabohne mit zusäzlicher Dampfzufuhr (I) oder mit Erhöhung des Energieeintrags durchgeführt wurde, sank die TIA weiter ab. Demzufolge erreichten die Gruppen I und K ein ähnliches Wachstumsniveau sowie eine vergleichbare Futterverwertung (1,57) wie die Kontrolle A (1,56). Zusätzliche Dampfzufuhr und zusätzlicher Energieeintrag führten zu einem weiteren Rückgang der TIA in der Sojabohne und damit $\mathrm{zu}$ einer Verbesserung der Wachstumsleistung und Futterverwertung. Eine Verminderung des Trypsininhibitors in der Sojabohne infolge der Erhöhung der Temperatur konnte auch in verschiedenen anderen Arbeiten nachgewiesen werden. GERTLER et al. (1967) fütterten Broiler mit einer Sojabohnendiät, die bei $25^{\circ} \mathrm{C}$ 
und $55^{\circ} \mathrm{C}$ entfettet wurde. Dabei fanden die Autoren signifikant niedrigere Wachstumsraten beim Einsatz einer bei $25{ }^{\circ} \mathrm{C}$ extrahierten Sojabohnendiät. FRIEDMAN et al. (1982) untersuchten die TIA in Rationen, die bei $25^{\circ} \mathrm{C}, 35^{\circ} \mathrm{C}, 45^{\circ} \mathrm{C}, 65{ }^{\circ} \mathrm{C}, 75{ }^{\circ} \mathrm{C}, 90{ }^{\circ} \mathrm{C}$ für 1 Stunde im Wasserbad behandeltes Sojaschrot enthielten. Dabei sank die Restaktivität des Trypsininhibitors nahezu linear auf $40 \%$ ab. ZHANG et al. (1993) konnten bei der Fütterung von Broilern (7.- 21. LT) mit Futterrationen, die mit $104{ }^{\circ} \mathrm{C}, 121{ }^{\circ} \mathrm{C}$ bzw. $138^{\circ} \mathrm{C}$ extrudierte Sojabohnen enthielten, eine von der Behandlungstemperatur abhängige Verbesserung der Lebendmassezunahme feststellen. Die tägliche LMZ lag in den Untersuchungsgruppen Extrusion $/ 104{ }^{\circ} \mathrm{C}$, Extrusion/ $121{ }^{\circ} \mathrm{C}$ und Extrusion/ $138{ }^{\circ} \mathrm{C}$ bei $17 \mathrm{~g} / \mathrm{d}, 18 \mathrm{~g} / \mathrm{d}$ und $20 \mathrm{~g} / \mathrm{d}$. Insgesamt zeigen die vorliegenden Ergebnisse, dass durch alleinige Expanderbehandlung der Sojabohne eine begrenzte Futterwertverbesserung erzielt wird. Deshalb ist für eine bessere Wirkung des Expandierens hinsichtlich der Futterwertsteigerung zusätzlich Dampfzufuhr oder ein höherer Energieeintrag notwendig.

Vergleicht man die Behandlungsverfahren C mit Kontrolle A, erzielte die 10-minütige Kondionierung der Sojabohne vergleichbare Wachstumsergebnisse und Futterverwertungsdaten wie die 40- minütige Konditionierung (Kontrolle A). Somit scheint es, dass eine10-minütige Konditionierung ausreichend ist, um die negativen Einflüsse des Trypsininhibitors auf die Wachstumsparameter zu vermindern. Diese Ergebnisse stehen im Widerspruch zu den Ergebnissen von HERKELMANN et al. (1990) beim Broiler, die ein Dampferhitzen der Sojabohnen bei $100{ }^{\circ} \mathrm{C}$ für $15 \mathrm{~min}$. für nicht ausreichend halten, um die TIA zu senken und deren Einflüsse auf die Wachstumsleistung und Futterverwertung einzuschränken. Ausgehend von ihren Untersuchungen empfehlen die Autoren, dass Sojabohnen mindestens für 20 min. mit Dampf erhitzt werden sollen, um die negative Wirkung des Trypsininhibitors bei den Monogastriern zu verhindern. Vermutlich können verschiedene Faktoren, wie technische Behandlungsbedingungen oder das verwendete Tiermaterial (Genotyp oder Herkunft der Tiere), die Ursache dafür sein, dass keine Übereinstimmung zwischen den vorliegenden Untersuchungen und der zitierten Arbeit bestand. Im Zusammenhang mit dem verwendeten Tiermaterial könnte die Empfindlichkeitsgrenze der Tiere gegenüber dem Trypsininhibitor unterschiedlich sein. QIN (1996) prüfte bei Ferkeln die Empfindlichkeit der Rassen „Landrace“ und „Min“ gegenüber dem TI bezüglich der Lebendmassezunahmen. Dabei wuchsen die „Landrace Ferkel“ schlechter als „Min Ferkel“, wenn die beiden Rassen mit einer Diät aus rohen Sojabohnen oder mit unter gleichen Bedingungen behandelten Sojabohnen gefüttert wurden. Der Autor 
kam zu dem Schluß, dass es notwendig ist, ein geeignetes Behandlungsverfahren unter Berücksichtigung der Empfindlichkeit der Tiere gegenüber dem TI zu entwickeln.

Beim Vergleich der Behandlungsverfahren $\mathrm{C}$ mit $\mathrm{F}$ sowie D mit G konnten keine großen Unterschiede in der Restaktivität des TI in den Sojabohnen festgestellt (Tab. 6) werden. Dabei führten die genannten Behandlungsstufen zu ähnlichen Restaktivitäten des Trypsininhibitors in den Sojabohnen. Dementsprechend ergaben sich zwischen Gruppe C und F sowie D und G keine signifikanten Unterschiede hinsichtlich Futteraufnahme, Wachstum und Futteraufwand. Die Ergebnisse weisen zugleich darauf hin, dass Vermahlungsart (Walzenstuhl und Hammermühle) hinsichtlich der Senkung des Trypsininhibitorgehaltes sowie der Einflussnahme auf Wachstumsparameter eine geringere Bedeutung hatten.

Die Ergebnisse aus den Körperanalysen belegen, dass eine höhere TI-Aufnahme mit dem Futter einen negativen Einfluss auf den Protein- und Energieansatz ausübte. Dies betrifft vor allem die Fütterungsgruppe $\mathrm{H}$, wobei die Sojabohnen nur mit dem Expander behandelt wurden. Die Tiere der Fütterungsgruppe H konnten Energie und Protein in einer Höhe von $341 \mathrm{~kJ} / \mathrm{d}$ bzw. 6,7 g /d ansetzen, während die höchsten täglichen Energie- und Proteinansätze in der Fütterungsgruppe E bei $429 \mathrm{~kJ} / \mathrm{d}$ bzw. 8,9 g/d lagen. Diese Differenz konnte statistisch gesichert werden. Eine Verbesserung des täglichen Energie- und Proteineinsatzes konnte bei Gruppe I um $+19 \%$ bzw. $+22 \%$ sowie bei Gruppe K um $+17 \%$ bzw. $+19 \%$ erreicht werden, nachdem eine Behandlung der Sojabohnen mit zusätzlichem Dampf und zusätzlichem Energieeinsatz durchgeführt wurde. Zusätzliche Dampfzufuhr oder ein Mehreintrag an Energie führte zu einem signifikant erhöhten Proteinansatz.

HERKELMAN et al. (1990) fanden bei Broilern, die mit rohen Sojabohnen, autoklavierten Sojabohnen oder Sojaschrot gefüttert wurden, einen Futteraufwand von 1,78; 1,51 bzw. 1,36. Die Autoklavierung war bei $110{ }^{\circ} \mathrm{C} / 120 \mathrm{~min}$. vorgenommen worden. Beim Vergleich mit vorliegenden Ergebnissen zeigten die Gruppen A, B, C, D und E, die mit ausreichend behandelten Sojabohnen gefüttert wurden, ähnliche Daten für den Futteraufwand wie die zitierten Untersuchungen. Der Futteraufwand lag in den Fütterungsgruppen A, B, C, D und E im Mittel bei 1,50. In der Fütterungsgruppe $H$ mit erhöhtem Futteraufwand $(1,75)$ wurden vergleichbare Resultate erzielt, wie beim Einsatz roher Sojabohnen $(1,78)$ in der Untersuchungen von HERKELMAN et al. (1990). 


\subsection{Einflüsse einer unterschiedlichen Sojabohnenbehandlung auf N-Bilanzparameter}

Eine erhöhte N-Ausscheidung sowie schlechtere Proteinverwertung infolge nicht ausreichend behandelter Sojabohnen wurde bei Schweinen, Ratten und Broilern mehrfach nachgewiesen. Hinsichtlich der N-Bilanz ergab sich in der vorliegenden Arbeit unter den restriktiven Fütterungsbedingungen eines Bilanzversuches nur für das flockierte Futter B ein Hinweis auf niedrigere Meßwerte, die mit der Restaktivität des Trypsininhibitors in der Sojabohne nicht erklärt werden konnten, weil die behandelten Sojabohnen der Gruppe B im Vergleich zu den anderen Behandlungsstufen die niedrigste TIA aufwiesen.

Obwohl die Restaktivität des Trypsininhibitors in den Sojabohnen in Gruppe H (Vermahlung und Expandierung) das höchste Niveau aufwies, exkretierten die Tiere der Fütterungsgruppe $\mathrm{H}$ im Mittel täglich $1495 \mathrm{mg} \mathrm{N} / \mathrm{LM}_{\mathrm{kg}}{ }^{0,67}$. Der Unterschied zur Kontrollgruppe A war nur tendenziell.

Die abgeleiteten Kennzahlen für den standardisierten physiologischen Nutzwert $\left(\mathrm{PNu}_{3500}\right)$ wiesen tendenziell geringere Werte für die Futtermischungen mit der höchsten Restaktivität des Inhibitors auf (H, I und K). Die Unterschiede zwischen den Restaktivitäten waren jedoch nur schwach ausgeprägt. In Verbindung mit dem Vorhandensein des Trypsininhibitors in der Ration, zeigen die Resultate der Untersuchung von KAKADE et al. (1973) eine signifikant schlechtere Proteinverwertung, wenn Ratten mit rohen Sojabohnen gefüttert werden. Die Autoren nutzten als Maßstab der Proteinverwertung die Kennzahl PER (Protein efficiency ratio). QIN et al. (1997) fütterten Schweine mit Sojabohnendiäten, die bei $100{ }^{\circ} \mathrm{C} / 40 \mathrm{~min}$., $118{ }^{\circ} \mathrm{C} / 5$ min. bzw. $136{ }^{\circ} \mathrm{C} / 1,5$ min. dampferhitzte Sojabohnen enthielten. Dabei ergaben sich keine signifikanten Unterschiede zwischen den geprüften Fütterungsgruppen in der Netto-Proteinverwertung (NPU). Die NPU lag bei den Gruppen $100^{\circ} \mathrm{C} / 40 \mathrm{~min}$. und $118{ }^{\circ} \mathrm{C} / 5$ min. bei 61,24 \% bzw. 56,02\%. Zusammenfassend konnte im vorliegenden Versuch gezeigt werden, dass die $\mathrm{N}-$ Verwertung, gemessen durch standardisierte $\mathrm{PNu}-$ Werte, infolge der unterschiedlichen Behandlungsverfahren von Vollfettsojabohnen keiner starken Veränderung unterlag. Dabei ist jedoch zu berücksichtigen, dass die differenziert behandelten Sojabohnen in Mischungen mit weiteren Futterkomponenten eingesetzt waren, also Verdünnungseffekte für den TI vorlagen. 


\subsection{Einflüsse einer unterschiedlichen Sojabohnenbehandlung auf die N-Verdaulichkeit}

In Kapitel 5.1 wurden geringere Werte für Futterverzehr, Lebendmassezunahme und Futteraufwand der Gruppe H gezeigt. Dies konnte ebenfalls durch die N-Verdaulichkeitswerte (Tab. 13) bestätigt werden. Dabei zeigte die Fütterungsgruppe $\mathrm{H}$ eine signifikant niedrigere N-Verdaulichkeit von $76 \%$ gegenüber der Kontrolle A mit $81 \%$ sowie den anderen Gruppen B, C, D, F und G. Die Ursache der herabgesetzten N-Verdaulichkeit bei Fütterungsgruppe H fällt mit der höchsten TIA im Sojaschrot zusammen, da der Trypsininhibitor höhere NVerluste über endogene und exogene Ausscheidungen hervorruft (BARTH et al., 1993).

Die scheinbare N-Verdaulichkeit bei Gruppe H (76 \%) konnte jedoch durch zusätzliche Dampfzufuhr (I) und zusätzlichen Energieeintrag (verbunden mit einer weiteren Senkung der TIA in der Sojabohne) um 7 bzw. 4 Verdaulichkeitseinheiten weiter verbessert werden. Beim Schwein kamen QIN et al. (1997) und HANOCK et al. (1990) zu vergleichbaren Ergebnissen, denn sie konnten die N-Verdaulichkeit beim Schwein durch Erhöhung der Behandlungstemperatur (von $118^{\circ} \mathrm{C}$ auf $136{ }^{\circ} \mathrm{C}$ ) um $4 \%$ erhöhen. Auch HANOCK et al. (1990) stellten nach Fütterung einer autoklavierten Sojabohnen/Mais Diät (10 min. bzw. 20 min. bei $120{ }^{\circ} \mathrm{C}$ ) beim Schwein eine N-Verdaulichkeit von $72,7 \%$ bzw. 80,7 \% fest. In dem vorliegenden Versuch wurde bei den Behandlungsvarianten $\mathrm{H}$, I und $\mathrm{K}$ auf $120{ }^{\circ} \mathrm{C}, 130{ }^{\circ} \mathrm{C}$ bzw. $135{ }^{\circ} \mathrm{C}$ erhitzt. Ausgehend davon läßt sich schlußfolgern, dass eine Erhöhung der Temperatur im Expander über Dampfzufuhr oder Energieeintrag einen positiven Effekt auf die N-Verdaulichkeit ausüben kann. Mögliche Schädigungen einzelner Aminosäuren müssen dabei aber einer Kontrolle unterliegen.

Vergleicht man die Werte der N-Verdaulichkeit zwischen Behandlungsverfahren I und K mit der Kontrolle A (Tab. 13) so wird ersichtlich, dass die N-Verdaulichkeit der Gruppen I und K trotz ihrer höheren Restaktivität des Trypsininhibitors mit Gruppe A vergleichbar war. VAN DER GRIFT et al. (1983) stellten in ihren Untersuchungen fest, dass wachsende Schweine ohne gesteigerte N-Verluste oder schlechtere AS-Vedaulichkeiten eine Sojaflockendiät tolerieren können, die eine TIA von $6,2 \mathrm{mg} \mathrm{TI} / \mathrm{g}$ in den Sojaflocken enthält. In der voliegenden Untersuchung wiesen die Sojabohnen der Futtermischungen I und $\mathrm{K}$ eine Trypsininhibitoraktivität im Mittel von $8 \mathrm{mg}$ TIA/g auf. Diese Werte näherten sich der von den Autoren festgestellten Empfindlichkeitsgrenze der Tiere. Deshalb könnte dies eine 
Erklärung dafür sein, dass die N-Verdaulichkeit der Fütterungsgruppen I, K und der Kontrolle A miteinander vergleichbar war.

Daneben wurde eine signifikant verbesserte N-Verdaulichkeit beim Behandlungsverfahren B gegenüber A festgestellt. Dabei wiesen die behandelten Sojabohnen A (100 ${ }^{\circ} \mathrm{C} / 40 \mathrm{~min}$.) und $\mathrm{B}\left(100{ }^{\circ} \mathrm{C} / 40\right.$ min., Flockierung) ähnliche Restaktivitäten des Trypsininhibitors auf. Deshalb kann der signifikante Unterschied in der N-Verdaulichkeit zwischen den beiden Fütterungsgruppen nicht durch die TIA erklärt werden, sondern muß mit der zusätzlichen Flockierung der Sojabohnen bei der Fütterungsgruppe B in Verbindung stehen. Demzufolge könnte die Kombination von thermischen und mechanischen Behandlungsverfahren wie Flockierung, Extrusion und Expandierung Vorteile hinsichtlich Futterwertverbesserung der Sojabohnen bieten. Dies könnte auch eine Erklärung dafür sein, warum sich die NVerdaulichkeit bei der Fütterungsgruppe B erhöht hatte. Auch BENGALA et al. (1991) stellten vergleichbare Effekte der mechanischen Behandlungsverfahren auf die NVerdaulichkeit fest. Dabei wurde die N-Verdaulichkeit nach der Fütterung mit extrudierten Erbsen an Schweine um 13 \% erhöht. Ausgehend von ihren Ergebnissen vermuten die Autoren, dass der Vorteil einer Extrusion in der Verbesserung der N-Verdaulichkeit bei gleichzeitiger Modifizierung der Stärkestruktur und dadurch bedingt verbesserter Stärkeverdaulichkeit liegen könnte. Nach Meinung der Autoren kann die verbesserte Särkeverdaulichkeit eine Veränderung der mikrobiellen Aktivität im Verdauungstrakt bewirken, die zu einer Modifizierung der endogenen N-Ausscheidungen aus der mikrobiellen Fermentation führt.

Insgesamt zeigte die N-Verdaulichkeit der Gruppen A, C, D, E und I vergleichbare Werte wie von RODHOUSE et al. (1992), die bei der Fütterung von nicht extrudiertem und extrudiertem Sojaextraktionsschrot an Broiler eine N-Verdaulichkeit im Mittel von 81,7 \% bzw. 82,3\% feststellten.

\subsection{Einflüsse einer unterschiedlichen Sojabbohnenbehandlung auf $\mathbf{N}$-korrigierte umsetzbare Energie und Trypsinaktivität im Chymus}

Zur Verbesserung der Umsetzbarkeit der Energie in Futtermischungen durch unterschiedliche Behandlungsverfahren liegen in der Literatur wenige Arbeiten vor. Allerdings gibt es einige 
Untersuchungen, die darauf hinweisen, dass sich der Gehalt an umsetzbarer Energie des Futters je nach dem Behandlungsverfahren variieren läßt.

In der vorliegenden Untersuchung wurde der Gehalt an umsetzbarer Energie mit Hilfe eines Stoffwechselversuchs bestimmt. Wie aus der Abb. $12 \mathrm{zu}$ sehen ist, wurde die scheinbar umsetzbare Energie infolge der höchsten TIA in der Futtermischung H nicht beeinflusst.

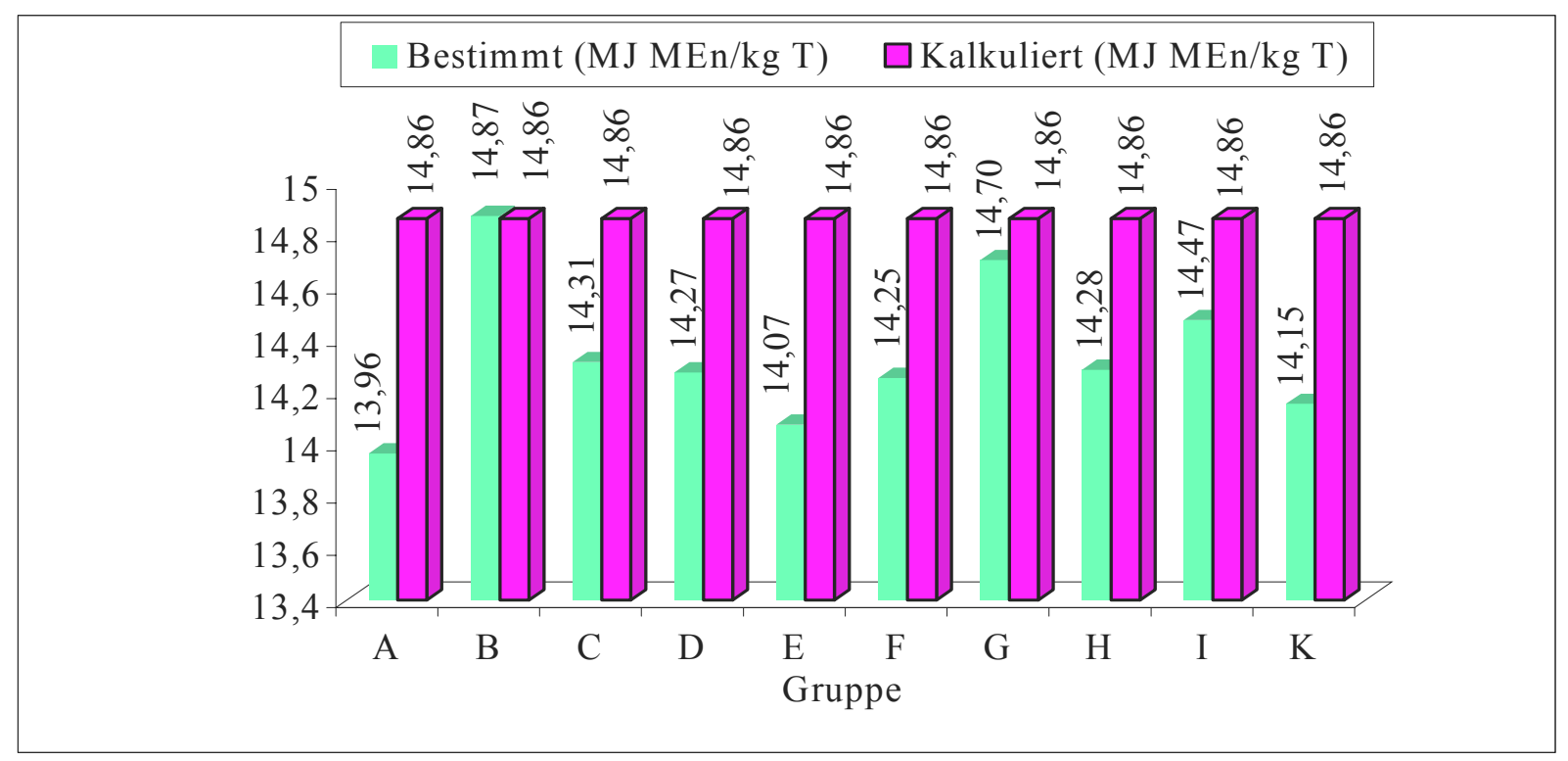

Abb.12: N-korrigierte scheinbar umsetzbare Energie

Die Gehalte an umsetzbarer Energie in den Futtermischungen B $(14,9 \mathrm{MJ} / \mathrm{kg} \mathrm{T})$ und F (14,70 MJ/kg T) sind signifikant höher als bei der Kontrolle A (13,96 MJ/ kg T). Der Grund für die Steigerung der umsetzbaren Energie bei $\mathrm{B}$ und $\mathrm{F}$ sowie bei $\mathrm{H}$ kann dabei an den Behandlungsverfahren Flockierung und Expander liegen. Diese Ergebnisse werden durch ältere Befunde von CAREW et al. (1962) unterstützt, wobei die Autoren bedingt durch die Intensität der Behandlungsverfahren eine signifikant bessere Fettverdaulichkeit von $92 \%$ bzw. $82 \%$ für die flockierten bzw. expandierten Sojabohnen im Vergleich zu einfach zerkleinerten Sojabohnen (62\%) beim Broiler fanden. NOLAND et al. (1976) machten in ihrer Untersuchung an Schweinen die Beobachtung, dass die Erhöhung der umsetzbaren Energie bei der extrudierten Sojabohnendiät höher liegt als bei der gekochten Sojabohnendiät bzw. bei der nicht behandelten Sojaextraktionsschrotdiät. Die Autoren vermuten dabei, dass das Extrusionsverfahren die Zellstrukturen des Futters effektiver zerstört und Fett im Futter 
dadurch besser freigesetzt und absorbiert wird, so dass ein höherer Gehalt an umsetzbarer Energie in der Futtermischung resultiert.

Andererseits konnten bei Erhöhung der Temperatur von $120{ }^{\circ} \mathrm{C}$ auf $130{ }^{\circ} \mathrm{C}$ und $135{ }^{\circ} \mathrm{C}$ keine temperaturabhängigen signifikanten Effekte hinsichtlich der umsetzbaren Energie beobachtet werden (vgl. H vs I und K). Im Gegensatz hierzu zeigte LIEBERT (1994) eine tendenzielle Verbesserung der scheinbar umsetzbaren Energie von 13,23 MJ/kg T auf 13,45 MJ/kg T, wenn die Expandierung der Futtermischung (Sojaschrot/Weizen) für Broiler bei $85{ }^{\circ} \mathrm{C} \mathrm{bzw}$. $120{ }^{\circ} \mathrm{C}$ durchgeführt wurde. Ausgehend von vorliegenden Ergebnissen und der Befunde von oben zitierten Autoren ist insgesamt anzunehmen, dass die Kombination der mechanischen und thermischen Behandlungsverfahren bei der Verbesserung der Umsetzbarkeit der Energie eine positive Rolle spielt. Dieses bedarf weiterer Abklärung, um zuverlässige Vorhersagen bezüglich der zu erwartenden Wirkungen zu ermöglichen.

Hinsichtlich der Trypsinaktivität im Chymus trat eine der TIA entsprechende Veränderung ein. Die Trypsinaktivität war insbesondere bei $\mathrm{H}$ und $\mathrm{K}$ im Vergleich zu Kontrolle A um $88 \%$ bzw. $81 \%$ abgesunken, während bei anderen Behandlungsvarianten die Aktivitätsmessung gegenüber der Kontrolle A vergleichbare Werte ergab. Wie in Tab. 7 dargestellt wurde, war die TIA in den Behandlungsgruppen $\mathrm{H}$ und $\mathrm{K}$ relativ höher als in der Kontrolle A. Deshalb steht die verminderte Trypsinaktivität direkt mit erhöhten TIAufnahmen in Beziehung. Diese Ergebnisse unterstreichen, übereinstimmend mit anderen Befunden (GERTLER et al., 1967, GERTLER und NITSAN 1970, LIEBERT et al., 1996), dass bei der Fütterung von Broilern und Laborratten mit TI-reichem Futter eine empfindliche Reaktion auf diesen antinutritiven Faktor im Gastrointestinaltrakt eintritt.

Zusammenfassend steht die verminderte Trypsinaktivität im Chymus des Jejunums bei H und $\mathrm{K}$ in direktem Zusammenhang mit den Verdaulichkeitsmessungen (vgl. Tab. 8 und 13). Deshalb ist anzunehmen, dass die alleinige Expanderbehandlung nicht geeignet war, um den negativen Einfluss des Trypsininhibitors auf die Trypsinaktivität im Chymus des Jejunums ausreichend $\mathrm{zu}$ vermindern. Eine Erhöhung des Energieeinsatzes oder zusätzliche Dampfzufuhr erscheint deshalb notwendig. 


\subsection{Einfluss einer unterschiedlichen Sojabohnenbehandlung auf die scheinbare ileale Verdaulichkeit ausgewählter Aminosäuren}

Im vorangegangenen Abschnitt wurde der Einfluss einer unterschiedlichen TIA in Abhängigkeit von den Behandlungsverfahren auf den Futterwert der behandelten Sojabohnen bezüglich einiger Wachstumsparameter, der Proteinverwertung und Nährstoffverdaulichkeit beschrieben. Nach KOEHLER et al. (1988) ist die Verbesserung des Futterwertes stark mit der Verdaulichkeit der Aminosäuren verbunden. Ausgehend davon war es von Interesse, den Einfluss der unterschiedlich behandelten Sojabohnen in den Diäten auf die scheinbare ileale Aminosäureverdaulichkeit beim Broiler zu untersuchen. Außerdem liegen in der Literatur zum Einfluss eines TI auf die ileale Aminosäureverdaulichkeit beim Broiler nur wenige Ergebnisse vor.

Die vorliegenden Daten zeigen in vielen Fällen eine Überlegenheit der ausreichend behandelten Sojabohnen gegenüber nicht ausreichend behandelten Sojabohnen. Es wurde gezeigt, dass die Aminosäureverdaulichkeitswerte nur bei den mit dem Expander behandelten Sojabohnen $(\mathrm{H})$ gegenüber der Kontrolle A deutliche Unterschiede aufweisen (Tab. 14). Insbesondere signifikant vermindert waren die Arginin-, Threonin- und Lysinverdaulichkeiten bei der Versuchsgruppe H. Die Befunde waren auf eine höhere TI-Restaktivität in der Sojabohne zurückzuführen. Die niedrigere Aminosäureverdaulichkeit bei $\mathrm{H}$ konnte jedoch infolge der weiteren Senkung der Restaktivität verbessert werden, wenn die Sojabohnen entweder durch zusätzliche Dampfzufuhr (I) oder einen erhöhten Energieeintrag (K) expandiert wurden. Dabei wurde die scheinbare ileale Aminosäureverdaulichkeit (Arginin, Methionin + Cystin und Threonin) von $74 \%$ (Gruppe H ) auf $82 \%$ (I) bzw. $85 \%$ (K) gesteigert. Dieser Effekt der Behandlungsverfahren $\mathrm{I}$ und $\mathrm{K}$ war auch in den Wachstumsergebnissen und der N-Verdaulichkeit erkennbar, wobei die tägliche LMZ, Futterverwertung und N-Verdaulichkeit durch den Einsatz der genannten Behandlungsvarianten verbessert wurden.

Trotz der relativ höheren TI-Restaktivität in den Sojabohnen der Fütterungsgruppen I und K im Vergleich zur Kontrolle A und den Gruppen B, C, D und E bewirkte deren TI-Restaktivität (Tab. 7) hinsichtlich der geprüften ilealen Aminosäureverdaulichkeiten mit Ausnahme von Threonin geringfügige Veränderungen. Der Unterschied zwischen den geprüften Fütterungsgruppen war dabei nicht signifikant. CHANG et al. (1987) fanden auch bei der Fütterung von Sojaextraktionsschrot an wachsende Schweine mit 5,3; 4,0 und 1,8 mg TI/g 
eine ähnliche Aminosäureverdaulichkeit zwischen den geprüften Gruppen. Dies könnte daran liegen, dass die TIA in den Fütterungsgruppen in einem Grenzbereich liegen, in dem die Tiere den Einfluss der TI-Restaktivität noch tolerieren können. Wie vorher erwähnt wurde, liegt der Grenzbereich des TI für monogastrische Tiere, ohne einen Einfluss auf ernährungsphysiologische Parameter zu haben, vermutlich im Bereich etwa von $6 \mathrm{mg} / \mathrm{g}$ (VAN DER GRIFT et al., 1983).

Die Gruppen A, B, C, D und E zeigten hinsichtlich der scheinbaren Arginin-, Threonin- und Lysinverdaulichkeit vergleichbare Ergebnisse, die im Mittel bei $92 \%, 84 \%$ und $88 \%$ lagen. Diese Ergebnisse sind mit der Untersuchung von HAN und PARSONS et al. (1991) beim Broiler vergleichbar . Die Autoren ermittelten für eine ausreichend erhitzte Sojabohnendiät eine ileale Arginin-, Threonin- Lysinverdaulichkeit von 90 \%, 84 \% bzw. 86,9\%. PARSONS et al. (1992) stellten auch eine scheinbare ileale Aminosäureverdaulichkeit für Arginin, Threonin und Lysin von $91 \%, 83$ \% bzw. 88 \% für Sojaextraktionsschrot beim Broiler fest. Deshalb läßt sich schlußfolgern, dass alle Behandlungsverfahren außer $\mathrm{H}$ geeignete Behandlungsverfahren waren, um die Aminosäureverdaulichkeit positiv zu beeinflussen.

Beim Vergleich der Fütterungsgruppe $\mathrm{C}$ mit $\mathrm{F}$ sowie von D mit $\mathrm{G}$ wurden hinsichtlich der Aminosäureverdaulichkeit keine signifikanten Unterschiede beobachtet. Deshalb ist die Bedeutung der Vermahlungsart hinsichtlich der Senkung des TI und der Verbesserung der Aminosäureverdaulichkeit offensichtlich von geringerfügigem Einfluss. Da der Energieverbrauch bei der Zerkleinerung des Futtermittels durch Walzenstuhl niedriger als durch Hammermühle ist (FRIEDRICH, 1977), empfiehlt es sich für die Praxis, die Konditionierung oder das Expandieren mit dem Walzenstuhl zu kombinieren.

Obwohl bei der Gruppe H die Lysinverdaulichkeit im Vergleich zu der Gruppe K durch die TI-Restaktivität signifikant beeinflusst wurde, konnten keine signifikanten Unterschiede auf der Ebene der Lysinwirksamkeit festgestellt werden. Insgesamt reagierten die Werte der Lysinwirksamkeit nur tendenziell. Diese Beobachtung bedarf weiterer Überprüfung und ernährungsphysiologischer Bewertung. 


\section{Zusammenfassung und Schlußfolgerung}

Ziel der vorliegenden Arbeit war es, den Einfluss von unterschiedlich behandelten Sojabohnen in einer Broilerration (Mais und behandeltes Soja) auf die ernährungsphysiologischen Parameter beim wachsenden Küken zu prüfen.

Unter Berücksichtigung der Einflussgrößen (z. B. Zeit, mechanischer Energieeinsatz und Futterstruktur), die die Effektivität der Futterbearbeitungsverfahren beeinflussen, wurde zunächst die Behandlung einer einheitlichen Charge von Vollfettsojabohnen unter folgenden technische Bedingungen vorgenommen:

A: Walzenstuhl (WS) + Konditionierung (40 min./100 ${ }^{\circ} \mathrm{C}$, Standardverfahren); B: WS + Konditionierung (40 $\left.\mathrm{min} . / 100{ }^{\circ} \mathrm{C}\right)+$ Flockierung; C: WS + Konditionierung $\left(10 \mathrm{~min} . / 100{ }^{\circ} \mathrm{C}\right)$; D: WS + Konditionierung $\left(10 \mathrm{~min} . / 100{ }^{\circ} \mathrm{C}\right)+$ Expandieren $(20 \mathrm{kWh} / \mathrm{t})$; E: Hammermühle $(\mathrm{HM})+$ Konditionierung $\left(10 \mathrm{~min} . / 100^{\circ} \mathrm{C}\right)+$ Extrusion $(15 \mathrm{kWh} / \mathrm{t}) ; \mathbf{F}$ : HM + Konditionierung $\left(10 \mathrm{~min} . / 100{ }^{\circ} \mathrm{C}\right)$, G: $\mathrm{HM}+$ Konditionierung $\left(10 \mathrm{~min} . / 100{ }^{\circ} \mathrm{C}\right)+$ Expandieren $(20 \mathrm{kWh} / \mathrm{t}) ; \mathbf{H}: \mathrm{HM}+$ Expandieren $(20 \mathrm{kWh} / \mathrm{t}) ; \mathbf{I}: \mathrm{HM}+$ Expandieren (20 kWh/t) mit Dampfzufuhr; K: HM + Expandieren $(40 \mathrm{kWh} / \mathrm{t})$.

Mit $6 \times 10$ männlichen Broilern der Herkunft Cobb wurde im Zeitraum vom 7. - 28 . Lebenstag (LT) je Behandlung ein Wachstumsversuch durchgeführt. Während des Wachstumsversuchs wurden Daten zum Futterverzehr, Lebendmassezuwachs und Futteraufwand sowie Energie- und Proteinansatz über Körperanalyse erfaßt.

Die ileale Aminosäureverdaulichkeit der einzelnen Mischungen wurde in jeweils 4 gepoolten Chymusproben (9 Tiere / gepoolte Probe) mit Hilfe eines Indikators (HCl-unlösliche Rohasche, Zusatz von $1 \%$ Celite) nach Verfütterung vom 21. - 28. LT bestimmt.

Parallel zum Wachstumsversuch wurde ein Stoffwechselversuch (6 männliche Küken der Herkunft Cobb je Behandlungsstufe) im Zeitraum vom 15. - 21. LT bei Fütterung der Versuchsmischung durchgeführt. Dabei erfolgte 3-mal täglich eine quantitative Exkrementsammlung. Neben der N- Bestimmung in den Exkrementen der Basis für die NBilanzmessung wurde der Bruttoenergiegehalt erfaßt und auf dieser Grundlage der Gehalt an N-korrigierter umsetzbarer Energie (MEn) in den Futtermischungen bestimmt. Weiterhin wurde aus den Daten der Bilanzmessungen der physiologische Nutzwert (PNu) als Kriterium der Proteinqualitätsbeurteilung sowie die Lysinwirksamkeit abgeleitet. Am Ende des Stoffwechselversuchs wurden die Tiere geschlachtet und die Trypsinaktivität im Chymus des Jejunums bestimmt. 


\section{Die Ergebnisse lassen sich folgendermaßen zusammenfassen:}

1. In Abhängigkeit von den gegebenen Bedingungen der Futterbehandlungsverfahren konnten unterschiedliche Trypsininhibitoraktivitäten (TIA) in den behandelten Sojabohnen erzielt werden. Eine starke Reduzierung des TIA war insbesondere bei den behandelten Sojabohnen A bis G erkennbar. Die relative Restaktivität lag bei diesen Gruppen (im Vergleich zur rohen Sojabohne) bei 16-27\%. Im Gegensatz dazu wurde eine höhere relative Restaktivität in den behandelten Sojabohnen H, I und K in Höhe von $75 \%, 32 \%$ und $48 \%$ festgestellt .

2. Die Futteraufnahme, Lebendmassezunahme und Futterverwertung waren bei der Gruppe $\mathrm{H}$ infolge der höchsten Restaktivität des Trypsininhibitors signifikant niedriger als bei der Kontrolle A und anderen Gruppen (B, C, D, E, F, G, I und K). Analog dazu führte die höchste TIA in den Sojabohnen $\mathrm{H}$ ebenfalls zu einem signifikant verminderten Nährstoffansatz im Ganzkörper. Der Einfluss der höchsten Restaktivität des Trypsininhibitors auf den $\mathrm{PNu}$ war bei Gruppe $\mathrm{H}$ wenig ausgeprägt.

3. Die N-korrigierte umsetzbare Energie in den Futtermischungen B $(14,87 \mathrm{MJ} / \mathrm{kg} \mathrm{T})$ und $\mathrm{F}$ $(14,70 \mathrm{MJ} / \mathrm{kg} \mathrm{T})$ war signifikant höher als bei der Kontrolle A (13,96 MJ $/ \mathrm{kg})$. Der Grund für die Steigerung der N-korrigierten umsetzbaren Energie bei B und F kann dabei in der möglichen Verbesserung der Energieverfügbarkeit durch die Behandlungsverfahren Flockierung und Expander liegen.

4. Aufgrund der höchsten Restaktivität des Trypsininhibitors wurde bei der Gruppe H eine verminderte ileale Aminosäure- und Stickstoffverdaulichkeit im Vergleich zu Kontrolle A und den anderen Gruppen (B, C, D un E) festgestellt. Durch zusätzliche Dampfzufuhr und Erhöhung des Energieeintrages in den Gruppen I bzw. K konnten die antinutritiven Faktoren in den Sojabohnen reduziert werden und demzufolge die ileale Aminosäure- und Stickstoffverdaulichkeit bei den Gruppen I und K gegenüber der Gruppe H signifikant verbessert werden. Obwohl bei der Gruppe H die ileale Lysinverdaulichkeit gegenüber der Kontrolle A signifikant niedriger lag, wurde in Bezug auf die Lysinwirksamkeit kein signifikanter Unterschied zwischen den Gruppen H und der Kontrolle A festgestellt.

5. Die Trypsinaktivität im Chymus wurde auch in Abhängigkeit von der Restaktivität des Trypsininhibitors in den Sojabohnen unterschiedlich beeinflusst. Eine signifikant 
verminderte Trypsinaktivität im Chymus war insbesondere bei den Gruppen H sowie K feststellbar.

\section{Die vorliegenden Ergebnisse lassen folgende Schlußfolgerungen zu:}

Wie aus den Werten der Trypsininhibitoraktivität und der Proteinlöslichkeit hervorgeht, ist bei gleichzeitiger Betrachtung des Energieverbrauches und der daraus resultierenden Bearbeitungseffektivität eine zehnminütige Konditionierung von Vollfettsojabohnen einer vierzigminütigen vorzuziehen.

Beim Vergleich der Behandlungsverfahren zeigte sich, dass im Hinblick auf die untersuchten Parameter Behandlungsalternativen für Sojabohnen bestehen. Das Bearbeitungsverfahren (nur mit dem Expander) mit geringerem Energieeinsatz $(20 \mathrm{kWh} / \mathrm{t})$ hatte keinen großen Effekt auf die Verbesserung der Futterwerte. Deshalb sollte das Expandieren der Sojabohnen für die Verbesserung der Futterwerte mit zusätzlichem Energieeintrag (40 kWh/t) oder Dampfzufuhr kombiniert werden (s. K bzw. I)

Das Zerkleinerungsverfahren blieb hinsichtlich der Veränderung der TIA und des Futterwertes von untergeordneter Bedeutung, denn die geprüften Parameter wiesen keine statistisch absicherbaren Unterschiede auf (vgl. D und G sowie C und F). Aufgrund des geringeren Energieverbrauches des Zerkleinerungsverfahrens mit Walzenstuhl ist zu empfehlen, sowohl die Konditionierung als auch das Expandieren mit dem Walzenstuhl zu kombinieren.

Die positive Wirkung des Flockierungsverfahrens auf die Energieverfügbarkeit und NVerdaulichkeit bedarf weiterer Abklärung.

Beim Vergleich der relativen Einordnung der Lysinverfügbarkeit durch ileale Lysinverdaulichkeit und Lysinwirksamkeit auf Basis der Gesamtverwertung im NBilanzversuch zeigten sich klare Bewertungsunterschiede in den Gruppen F und H. Aus diesen wiederholten Beobachtungen (AMAD und LIEBERT, 2000) ist abzuleiten, dass weitere klärende Untersuchungen zur Eignung von ilealen Verdaulichkeitsmessungen für die notwendigerweise an der Leistung (Gesamtverwertung) orientierte Bewertung nutzbarer Anteile der Futteraminosäuren erforderlich sind. 


\section{Summary and Conclusion}

The objective of the present study was to evaluate the effects of differently treated soybeans on nutrition-physiological parameters in diets (Corn and differently treated soybean) for growing chicken. Considering the factors which influence the effectivity of the treatment process on feed value such as time, mechanical energy and feed structure, one batch of full fat soybean was treated in this present investigation under the following technical conditions:
A: Roller mill (RM) + Conditioning (40 min.); B: RM + Conditioning (40 min.) + flaking;
C: RM + Conditioning (10 min.); D: RM + Conditioning (10 min.) + Expander (20 kWh/t);
E: Hammer mill (HM) + Conditioning (10 min.) + Extruder; F: HM + Conditioning (10 min.); G: HM + Conditioning (10 min.) + Expander $(20 \mathrm{kWh} / \mathrm{t}) ; \mathbf{H}: \mathrm{HM}+$ Expander (20 $\mathrm{kWh} / \mathrm{t}) ; \mathbf{I}: \mathrm{HM}+$ Expander $(15 \mathrm{kWh} / \mathrm{t})+$ Steam; K: HM + Expander $(40 \mathrm{kWh} / \mathrm{t})$.

In a growth trial (day 7-28) with male chickens (genotype Cobb) daily feed intake, average daily gain (ADG), feed conversion ratio (FCR), energy and protein depositions (PD) were examined. After feeding the animals with experimental diets from day 21 to 28, the apparent ileal amino acid digestibility of some amino acids in the diets was determined in 4 pooled chyme samples ( 9 animals/pooled sample) using acid insoluble ash marker ( $\mathrm{HCl}$ insoluble crude ash, $1 \%$ celite added in each test diet).

Further to the growth trial, a metabolism bioassay (6 male chickens genotype Cobb/treatment) was conducted from day 15 to 21 which consisted of a 6-day collection period, after a 5-day adaptation period. The excrements were collected 3 times a day. Besides the nitrogen determination in the excrements which was the basis for the N-balance measurement, the gross energy content was measured for determining the $\mathrm{N}$-corrected metabolizable energy $(\mathrm{MEn})$ in the feed mixture. Furthermore, the physiological protein value $(\mathrm{PNu})$ as a criterion for evaluating protein quality and the lysine efficiency were derived from the data of the balance measurements. At the end of the metabolism bioassay, the animals were killed and the trypsin avtivity in the collected chyme of the jejunum was determined.

\section{The results of this experiment can be summerized as follows:}

1. Depending on the given conditions of feed treatments, different trypsin inhibitor activities (TIA) could be detected in the treated soybeans. A high reduction of the TIA was found particularly in treated soybeans A, B, C, D, E, F and G. The relative remaining activity of trypsin-inhibitors in these groups varied from 16 to $27 \%$ compared to untreated soybean. In 
contrast, the remaining trypsin inhibitor activity in the treated soybeans $\mathrm{H}, \mathrm{I}$ and $\mathrm{K}$ was relatively high, resulting in a value of $75 \%, 32 \%$ and $48 \%$ resp., compared to untreated soybean.

2. The daily feed intake, average daily gain and feed utilization of diet group $H$ were, due to the highest activity of the trypsin inhibitor, lower than the control A and those of other diet groups (B, C, D, E, F, G and K). Similarly, the highest TIA in the soybean $\mathrm{H}$ led to a significantly reduced nutrient deposition. However, the influence of highest remaining activity of trypsin inhibitor in the $\operatorname{diet} \mathrm{H}$ on $\mathrm{PNu}$ was insignificant.

3. The N-corrected metabolizable energy in the diets $\mathrm{B}(14,87 \mathrm{MJ} / \mathrm{kg} \mathrm{DM})$ and $\mathrm{F}(14,70 \mathrm{MJ} / \mathrm{kg} \mathrm{DM})$ was significantly higher than that of the control A $(13,96 \mathrm{MJ} / \mathrm{kg} \mathrm{DM})$. The reason for an increase in metabolizable energy in the diets $\mathrm{B}$ and $\mathrm{F}$ can be due to the possible improvement of nutrient availability through flaking and expander treatments (The improvement of oil availablity as a result of damaging the cell structure of seeds could be responsible for the increasing metabolizable energy in the diets $\mathrm{B}$ and F).

4. Due to the relatively higher TIA, both reduced ileal apparent amino acid and nitrogen digestibility were observed in the diet $\mathrm{H}$ compared to control $\mathrm{A}$ and the other diets $(\mathrm{B}, \mathrm{C}, \mathrm{D}$ and E). However, further steam input and an additional energy supply in treated soybeans I and $\mathrm{K}$ resp., reduced the antinutritional factors in the soybeans. Thus significantly improving the ileal apparent amino acid and nitrogen digestibility in these groups (I und K) as compared to the group H. Despite its lower ileal apparent lysine digestibility in the diet group $\mathrm{H}$ compared to the control A, lysine efficiency of both groups was not significantly different.

5. Depending on the activity of the trypsin inhibitor in the treated soybeans, the trypsin activity in the chyme was influenced differently. A significantly reduced trypsin activity in the chyme was particularly observed in the diets $\mathrm{H}$ and $\mathrm{K}$.

\section{Conclusion}

From the results of trypsin inhibitor activity, protein solubility and from considering energy consumption for heat treatment and its effectiveness on feed value, a ten min. conditioning of full fat soybean is to be preferred compared to a $40 \mathrm{~min}$. conditioning. 
The comparison of the experimental groups regarding the parameters examined showed that alternative heat treatments for soybeans exist. However, the expander treatment with low energy supply $(20 \mathrm{kWh} / \mathrm{t})$ did not have a significant effect on the improvement of feed value. Therefore, the treatment of soybeans with expander for improving feed value should be combined either with high energy supply $(40 \mathrm{kWh})$ or steam addition.

The type of milling in the present experiment is of little importance concerning an influence on the TIA and the feed value of the diets, as the tested parameters did not show statistically relevant differences (Comparing $\mathrm{D}$ with $\mathrm{G}$ and $\mathrm{C}$ with $\mathrm{F}$ ). Based on the results of the present experiment, it is suggested to combine conditioning as well as expander procedure with RM, because the energy consumption of RM mill is lower than HM.

The positive effect of flaking on the energy availability and N-digestibility requires further clarification.

Comparing the results of relative lysine availability taken from the data of lysine digestibility and lysine efficiency from the balance trial, it can be stated that there was a clear difference in the evaluation of groups $\mathrm{F}$ and $\mathrm{H}$, regarding the total lysine utilization. These recurring observations (AMAD and LIEBERT, 2000), suggest that further investigations which clarify the use of measuring of ileal amino acid digestibility are required. Such measurements should focus on the utilizable part of feed amino acids. 


\section{Literaturverzeichnis}

ABBEY B. W.; NEALE, R. J.; NORTON, G., 1979a: Nutritional effects of fieldbean (Vicia faba L.) proteinase inhibitors fed to rats. Br. J. Nutr. 41, 31-38.

ABBEY, B. W.; NORTON, G.; NEALE, R. J., 1979b: Effects of dietary proteinase inhibitors from field-bean (Vicia faba L.) and field bean meal on pancreatic function in the rat. Br. J. Nutr. 41, 39-45.

ALETOR, K. A.; OJO, O.-J., 1989: Changes in differently processed soybean (Glycine max.) and Limabean (Phaseoulus lunatus) with particular reference to their chemicalcomposition and their mineral and some inherent antinutritional constituents. Nahrung 33, 1009-1016.

AMAD, A.; LIEBERT, F., 2000: Einfluss unterschiedlicher Behandlungen und Futterzusätze in Weizen-Sojaschrot-Mischungen auf ileale Lysinverdaulichkeit und Lysinwirksamkeit beim Broiler. Proc. Soc. Physiol. 9, 112.

ASHTON, W.M.; EVANS, C., 1962: Phosphorus compounds of oats. 3. Composition of phytin from oats and other cereals. J. Sci. Food Agric. 13, 168-174.

BARRE und HOUT, 1965: zit. n. O'DELL und DE BOLAND, 1976.

\section{BARRIER, G.B.; CASTAING, J.; PEYRONNET, C.; LUCBERT, J., 1992:}

Comparison of pea varieties (Pisum sativum) varying in their trypsin inhibitor activity on broiler performance. In: Proceedings of the $1^{\text {st }}$ Eurpean Conf. on Legume Seeds. 1-3 june 1991. Angers, France, 392-527.

BARTH, C. A.; LUNDIG, B.; SCHMITZ, M.; HAGEMEISTER, H., 1993: Soybean trypsin inhibitor (s) reduce absorption of exogenous and increase loss of endogenous protein in miniature pigs. J. Nutr. 123, 2195-2200.

BECKER, M. (1950): Phytin in der Tierernährung. Landw. Forsch. 2, 64-72. 
BEHNKE, C.K., 1996: Feed manufacturing technology : current issues and challenges. Anim. Feed Sci. Technol. 62, 49-57.

BengalA, F. J; AUMAîTRE, A; PEINIAU, J., 1991: Effect of feeding raw extruded peas on ileal digestibility, pancreatic enzymes and plasma glucose and insulin in early weaned pigs. J. Anim. Physiol. a. Anim. Nutr. 65, 154-164.

BIRK, Y., 1985: The Bowman-Birk inhibitor. Trypsin- and chymotrypsin-inhibitor from soybeans. Int. J. Pept. Prot. Res. 25, 113-131.

BIRK, Y.; SMIRNOFF, P., 1992: Protein protease inhibitors from legume seeds and their significance in nutrition, pest control and medicine. Proceedings of the $1^{\text {st }}$ European Conference on Legume Seeds. 1-3 june 1991, Angers, France, 391-392.

BLUM, E., 1989: Einfluss von Nahrungsproteinen verschiedenen Trypsin-Inhibitorgehaltes auf das exokrine Pankreas des Miniaturschweines. Ein Vergleich von Casein mit zwei Sojaprodukten. Diss. agr. Kiel.

BRUNE, H., 1956: Experimentelle Untersuchungen über die Wirkung oraler Saponingaben beim Wiederkäure. Z. Tierernährg. u. Futtermittelkde. 11, 259-322.

CAMORE, A. L.; CLYDESDALE, F. M., 1981: Effect of $\mathrm{pH}$ and heat treatment on the binding of calcium, magnesium, zinc and iron to wheat bran and fractions of dietary fiber. J. Food Sci. 46, 548-554

CAREW, L. B. Jr.; NESHEIM, M. C., 1962: The effect of pelleting on the nutritional value of ground soybeans for the chick. Poultry Sci. 41, 161-164.

CARRÉ, B.; CONAN, L., 1989: Relationship between trypsin-inhibitor content of pea seeds and pea protein digestibility in poultry. In: HUISMAN, J.; VAN DER POEL, A.F.B. VAN DER; LIENER, I. E.(Eds.): Recent advances of research in antinutritional factors in legume seeds. Pudoc, Wageningen, The Netherlands, 103-106.

CHAMPAGNE, E.T.; PHILLIPPY, B.Q., 1989: Effekts of pH on calcium-, zinc- and 
phytate solubilities and complexes following in vitro digestions of soy protein isolate.

J. Food Sci. 54, 587-592.

CHANG, C. L.; TANSKLEY, T. D.; KNABE, D. A..; ZEBROWSKA, T., 1987:

Effect of different heat treatments during processing on nutrient digestibilities of soybean meal by growing swine. J. Anim. Sci. 65, 1273-1282.

CHERYAN, M., 1980: Phytic acid interactions in food systems. CRC. Crit. Rev Food Sci. Nutr. 13, 297-335.

COSGROVE, D.J., 1980: Inositol phosphates: Their chemistry, biochemistry and physiology. Elsevier Sci. Publ., New York, 85-88.

DAVIES, N.T.; FLETT, A.A., 1978: The similarity between alkaline phosphatase and phytase activities in rat intestine and their importance in phytate induced zinc deficiency. Br. J. Nutr. 39, 307-316.

DE BOLAND, A.R., CARNER, G.B. and O'DELL, B.L., 1975: Identification and properties of phytate in cereal grains and oilseed products.

J. Agric. Food Chem. 23, 1186.-1189.

EDWARDS, H. M. JR.; CARLOS, A. B.; KASIM, A. B.; TOLEDO, R. T., 1999: Effects of steam pelleting and extrusion of feed on phytate phosphorus utilization in broiler chickens. Poultry Sci. 78, 96-101.

FABER, J. L. ; ZIMMERMAN, D. R.; 1973: Evaluation of infrared and extruder processed soyabeans in baby pig diets. J. Anim. Nutr. 36, 902-907.

FALBE, J.; REGITZ, M., 1990: Chemie Lexikon, 9. Auflage Band 3 H-L

FAUDEMAY, F.; LAPORTE, J. C.; TREMOLIÈRES, J., 1973: Passage des inhibiteurs trypsiques à travers la paroi intestinale de rat in vitro. Nutr. Metab. 15, 213-217. 
FRANKE, G., 1975: Nutzpflanzen der Tropen und Subtropen. Band I, S. Hirzel Verlag, Leipzig, 274-285.

FRIEDMAN, M.; GROSJEAN, O. K.; ZAHNLEY, J. C., 1982: Inactivation of soybean trypsin inhibitors by thiols. J. Sci. Food Agric. 33, 165-172.

FRIEDRICH, W., 1977: Futtermitteltechnologie. In: WÖHLBIER, W. (Hrsg.), Handelsfuttermittel, Band 1, Verlag. Eugen Ulmer, Stuttgart. 113-143.

GALLAHER, D.; SCHNEEMAN, B. O., 1986: Nutritional and metabolic response to plant inhibitors of digestive enzymes. In: M. FRIEDMAN (Ed.): Nutritional and toxicological significance of enzyme inhibitors in food. Plenum Press, New York, 167-184.

GDALA, J.; BURACZEWSKA, L.; GRELA, W., 1992: The chemical composition of different types and varieties of peas and the digetion of their protein in pigs. J. Anim. Feed Sci. 1, 71-79.

GEBHARDT, G., 1966: Die Bewertung der Eiweissqualität von Nahrungs- und Futtermittteln mit Hilfe des N-Bilanzversuches. In: HOCK, A. (Ed.): Vergleichende Ernährungslehre des Menschen und seiner Haustiere, Verlag Gustav Fischer, Jena, 328-348.

GERTLER, A.; BIRK, Y.; BONDI, A., 1967: A comparative study of the nutritional and physiological significance of pure soybean trypsin inhibitors and of ethanol extracted soybean meals in chicks and rats. J. Nutr. 91, 358-370.

GERTLER, A.; NITSAN, Z., 1970: The effect of trypsin inhibitors on pancreatopeptidase E, trypsin and chymotrypsin and amylase on the pancreas and intestinal tract of chicks receiving raw and heated soya-bean diets. Br. J. Nutr. 24, 893-904.

GESTETNER, B.; BIRK, Y; TENCER, Y., 1968: Soybean saponins. Fate of ingested soybean saponins and the physiological aspect of their hemolytic activity.

J. Agric. Food Chemistry 16, 1031-1035. 
GOIHL, J., 1995: Effect of mill type, particle size on finishing pigs growth evaluated. Feedstuffs 67, October 23, 13.

GRAF, E., 1986: Chemistry and applications of phytic acid. Pilatus Press, Minneapolis, 1-21.

GRANT, G.; GREER, F.; McKENZIE, N. H.; PUSZTAI, A., 1985: Nutritional response of mature rats to kidney bean (Phaseolus vulgaris) lectins. J. Sci. Food Agric. 36, $409-414$.

GREEN, G . M.; LYMAN, R. L., 1971: Chymotrypsin inhibitor stimulation of pancreatic enzyme secretion in the rat. Proc. Soc. Exp. Biol. Med. 136, 649 -654.

GREEN, G. M.; VAN LEVAN, H.; LIDDLE, R. A., 1986: Interactions of dietary protein and trypsin inhibitors on plasma cholecystokinin and growth in rats. Adv. Exp. Med. Biol. 199, 123-132.

GUBMANN, M. R.; DUGAN, G. M.; SPANGLER, W.L.; BAKER, E. C.;

RACKIS, J. J., 1989: Pancreatic response in rats and mice to trypsin inhibitors from soy and potato after short- and long- term dietary exposure. J. Nutr. 119, 1598-1609.

GÜNTER, F., 1988: How to improve the quality of full-fat soya beans and other legumes by hydrothermal treatment. Feed Magazine, Nov./Dec. 1988.

HAFEZ, Y. S.; SINGH, G.; MCLELLAN, M.E.; MONROE, L.L, 1983: Effects of microwave heating on nutritional quality of soybeans. Nutr. Rep. Int. 28, 413-421.

HAFEZ, Y. S.; MOHAMMAD, A. I; PERERA, P. A.; SINGH, G.; HUSSAIN, A. S., 1989: Effects of microwave heating and irradiation on phytate and phospholipid contents of soybean. J. Food Sci. 54, 958-962.

HAN, Y.; PARSONS, C. M., 1991: Nutritional evaluation of soybeans varying in trypsin inhibitor content. Poultry Sci. 70, 896-906. 
HANCOCK, J.D.; PEO, E. R. Jr.; LEWIS, A. J.; CRENSHAW, J. D., 1990: Effekts of ethanol extraktion and duration of heat treatment of soybean flakes on the utilization of soybean protein by growing rats and pigs. J. Anim. Sci. 68, 3233-3243.

HANCOCK, J.D., 1998: Experience with expanded feed in pigs. In: $4^{\text {th }}$ Intenational KahlSymposium. future aspects in animal nutrition and compound feed Technology. February $16^{\text {th }}-17^{\text {th }}$, Reinbek, $1-14$.

HARWOOD, J. P.; AUSMAN, L. M.; KING, N. W.; SEHGAL, P. K.;

NICOLOSI, R. J.; HASDAI, A; LIENER, I. E. 1983: Growth, digestibility, and enzyme activities in the pancreas and intestines of hamsters fed raw and heated soy flour. J. Nutr. 113, 662-668.

HASDAI, A.; LIENER; I. E, 1983: Growth, digestibility and enzyme activities in the pancreas and intestines of hamsters fed raw and heated soy flour. J. Nutr. 113, 662-668.

HASDAI, A.; NITSAN, Z.; VOLCANI, R., 1989: Growth, digestibility, and enzyme activities in the pancreas and intestines of guinea-pigs fed on raw and heated soybean flour. Br. J. Nutr. 62, 529-537.

HERKELMAN, K.L.;. CROMWELL, G.L.; STAHLY, T.S., 1990: Effect of heating time on the nutritional value of full-fat soybeans for chicks. J. Anim. Sci. 68 (Suppl. 1.)

HERKELMAN, K.L.; CROMWELL, G.L.; STAHLY, T.S., 1992: Apparent digestibility of amino acids in raw and heated conventional and low trypsin inhibitor soybeans for pigs. J. Anim. Sci. 70, 818-826.

HEIDENREICH, E., 1996: Problemlösung für die Erfüllung hygienischer Forderungen. Kraftfutter 80, 506-510

\section{HUISMAN, J.; LE GUEN, M. P.; BÉROT, S.; VAN WEERDEN, E. J., 1990:}

Digestive response of piglets to isolated fractions from peas. 2. Investigation into factors responsible for negative effects on performance of piglets fed high levels of peas: Carbohydrates and antinutritional factors. PhD Thesis, Agricutural, Wageningen, 
The Netherlands, 99-112.

ISHAAYA, I.; BIRK, Y.; BONDI, A.; TENCER, Y., 1969: Soybean saponins. IX. Studies of their effects on birds, mammals and cold-blooded organisms.

J. Sci. Food Agric. 20, 433-436.

JANSEN, H. D.; FRIEDRICH, W., 1975: Verfahrenstechnische Möglichkeiten zur Veränderung der Futterqualität. Kraftfutter 58, 98-102.

JEROCH, H.; FLACHOWSKY, G.; WIEßBACH, F., 1993: Futtermittelkunde. Gustav Fischer Verlag Jena.

JOHNSON, I. T.; GEE, I. M.; PRICE, K.; CURL, C.; FENWICK, G. R., 1986: Influence of saponins on gut permeability and active nutrient transport in vitro. J. Nutr. 116, 2270-2277.

JOHNSTON, S.L.; TRAYLOR, S.L.; HINES, R.H.; HANCOCK, J.D.; BEHNKE, K.C.; SORRELL, S.P.; KENNEDY, G.A., 1997: Conditioning (conventional, long-term and expander) effects on pellet quality and growth performance in finishing pigs. J. Anim. Sci. 75 (Suppl. 1), 65.

JONDREVILLE, C.; GROSJEAN, F.; BURON, G.; PEYRONNET, C.; BENEYTOUT, J. L.,1992: Comparison of four pea varieties in pig feeding through digestibility and growth performance results. J. Anim. Physiol. a. Anim. Nutr. 68, 113- 122.

KAI, H.; TAJIRI, H.; LEE, P. C.; LEBENTHAL, E., 1984: Induction of enterokinase in the rat small intestine following hypersecretion of trypsinogen by chronic trypsin inhibitor feeding. J. Pediat. Gastroent. Nutr. 3, 328-335.

KAKADE, M. L.; HOFFA, D. E.; LIENER, I. E., 1973: Contribution of trypsin inhibitor to the deleterious effects of unheated soybeans fed to rats. J. Nutr. 103, 1772-1779.

KAKADE, M. L.; THOMPSON, R. D.; ENGELSTAD, W. E.; BEHRENS, G. C.; 
YODER, R. D.; CRANE, F. M., 1976: Failure of soybean trypsin inhibitor to exert deleterious effects in calves. J. Dairy Sci. 59, 1484-1489.

KENNEDY, A.R; BEAZER, B.Y.; KINZLER, K.W.; NEWBERNE, P.M.,1996:

Suppression of carcinogenesis in the intestines of Min mice by the soybean derived Bowman Birk inhibitor. Cancer Research 56, 679-682.

KHAYAMBASHI, H.; LYMAN, L., 1966: Growth depression and pancreatic and intestinal changes in rats force-fed amino acid diets containing soybean trypsin inhibitor. J. Nutr. 89, 455-464.

KIRCHGESSNER, M. (1992): Tierernährung. 8. Auflage DLG-Verlag, Frankfurt(Main) $67-72$

KNUCKLES, B. E.; KUZMICKY, D. D; BETSCHART, A. A, 1985: Effect of phytate and partially hydrolyzed phytate on in vitro protein digestibility. J. Food Sci. 50, 1080-1082.

KOEHLER, D. D.; CORNELIUS, S. G.; MOSER, R. L.; PETTIGREW, J. E., 1988 : Apparent ileal amino acid digestibilities of standard and low trypsin inhibitor raw soybeans in swine diets. J. Anim. Sci. 66 (Suppl. 1), 133.

KONIJN, A. M.; BIRK, Y.; GUGGENHEIM, K., 1970a: Pancreatic enzyme pattern in rats as affected by dietary soybean flour. J. Nutr. 100, 361-368.

KONIJN, A. M.; BIRK, Y.; GUGGENHEIM, K., 1970b: In vitro synthesis of pancreatic enzymes: effect of soybean trypsin inhibitor. Am. J. Physiol. 218, 1113-1117.

KRATZER, F. H.; ALLRED, J. B.; DAVIS, P. N.; MARSHALL, B. J.; VOHRA, P., 1959: The effect of autoclaving soybean protein and the addition of ethylendiaminetetraacetate on the biological availability of dietary zinc for turkey poults. J. Nutr. 68, 313-317.

LANTZSCH, H.-J., 1990: Untersuchungen über ernährungsphysiologische Effekte des 
Phytats bei Monogastriern (Ratte, Schwein). Übers. Tierernährung. 18, 197-212.

LANTZSCH, H.-J.; WIJST, S.; DROCHNER, W., 1995: The effect of dietary calcium on the efficacy of microbial phytase in rations for growing pigs. J. Anim. Physiol. a. Anim. Nutr. 73, 19-26.

LEASE, J. G., 1966: The effect of autoclaving sesame meal on its phytic acid content and on the availability of its Zn to the chick. Poultry Sci. 45, 237-242.

LE GUEN, M. P.; BIRK, Y., 1993: Protein protease inhibitors from legume seeds: nutritional effects, mode of action and structure-function relationship. In: van der POEL, A. F. B.; HUISMAN, J.; SAINI, H. S. (Eds.): Recent advances of research in antinutritional factors in legume seeds. Pudoc, Wageningen, The Netherlands, 157-170.

LE GUEN, M. P.; HUISMAN, J.; MAKKINK, C. A., 1991: Effects of peas and pea isolates on protease activities in pancreatic tissue of piglets. In: VERSTEGEN, M. W.A.; HUISMAN, J.; DEN HARTOG, L. A. (Eds.): Proceedings of the $5^{\text {th }}$ international symposium on digestive physiology in pigs. Wageningen, The Netherlands, 207-210.

LEPKOVSKY, S.; FURUTA, F.; OZONE, K.; KOIKE, T., 1966: The proteases, amylases and lipases of the pancreas and intestinal contents of germ-free and conventional rats. Br. J. Nutr. 20, 257-261.

LETERME, P.; BECKERS, Y.; THEWIS, A., 1990: Trypsin inhibitors in peas: varietal effect and influence on digestibility of crude protein by growing pigs. Anim. Feed. Sci. Technol. 29, 45-55.

LIEBERT, F., 1994: Feed treatment and aspect of nutrient digestion resp. utilization in chicken. In: $3^{\text {rd }}$ International Kahl-Symposium. Hamburg-Bergedorf.

LIEBERT, F., 1995a: Der Einfluss einer abgestuften Energieversorgung auf Nährstoff- und Energieverwertung beim Broiler. Arch. Geflügelk. 59, 269-273. 
LIEBERT, F., 1995b: Methodische Untersuchungen zur Beurteilung von Lysinverwertungskennzahlen von Schweinen nach extremen Veränderungen von Proteinmenge und -zusammensetzung. Arch. Anim. Nutr. 48, 319-327.

LIEBERT, F.; KÖHLER, R.; WECKE, C., 1996: Untersuchungen zu den Proteolysebedingungen im Verdauungstrakt von Broilerküken sowie zur Stickstoff- und Phosphorverwertung in Abhängigkeit von der Trypsin-Inhibitor-Aktivität in der Nahrung und Phytaseergänzung. 1. Methoden und Ergebnisse der Trypsinaktivitätsmessung in Pankreasgewebe und Dünndarmchymus. J. Anim. Physiol. a. Anim. Nutr. 75, 193-199.

LIENER, I. E.; ROSE, J. E., 1953: Soyin, a toxic protein from soybean. III. Immunochemical properties. Proc. Soc. Exp. Biol. Med. 83, 539- 544.

LIENER, I.E. 1958: Inactivation studies on the soybeans hemagglutinin. J. Biol. Chem. 233, 401-405.

LIENER, I. E, 1976: Phytohemagglutinins (Phytolectins). Ann. Rev. Plant Physiol. 27, 291-319.

LIENER, I. E, 1979a: Significance for humans of biologically active factors in soybeans and other food legumes. J. Am. Oil Chem. Soc. 56, 121-129.

LIENER, I. E., 1979b: The nutritional significance of plant protease inhibitors. Proc. Agric.Res. 5, 159-161.

LIENER, I. E.; DONATUCCI, D.; TARCZA, J., 1985: Effect of long-term feeding of soybased diets on the pancreas of Cebus monkeys. Fed. Proc. 44, 1496.

LIKUSKI, H. J. A. and FORBES, R. M., 1965: Effects of calcium and phytic acid on the utilization of dietary zinc. J. Nutr. 85, 230-234.

MADAR, Z.; BIRK, Y.; GERTLER, A., 1974: Native and modified BOWMAN-BIRK trypsin inhibitor comparative effect on pancreatic enzymes upon digestion by quails 
(Coturnix coturnic japonica). Comp. Biochem. Biophys. 48, 251-256.

MADAR, Z.; TENCER, Y.; GERTLER, A.; BIRK, Y., 1976: The comparative effect of prolonged feeding with raw and heated soybean meal on the growth response, pancreatic enlargement and pancreatic enzyme of chicks.

Nutr. Metabol. 20, 234-242.

MADAR, Z.; BIRK, Y.; GERTLER, A., 1979: The fate of Bowman-Birk trypsin inhibitor from soybeans. Comp. Biochem. Biophys. 62, 1057-1061.

MADDAIAH, V.T.; KURNICK, A.A.; REID, B.L., 1964: Phytic acid studies. Proc. Soc. Exp. Biol. Med. 115, 391-393.

MAGA, J.A., 1982: Phytate; its chemistry, occurance, food interactions, nutritional significance and method of analysis. J. Agric. Food Chem. 30: 1-9.

MARQUARDT, R.R.; McKIRDY, J.A; WARD, A.T.; CAMPBELL, L.D., 1975: Aminoacid, hemagglutinin and trypsin inhibitor levels, and proximate analysis of faba beans (Vicia faba) and faba bean fractions. Can. J. Anim. Sci. 55, 421-429.

MARQURDT, R.R.; CAMPBELL, L.D; WARD, A.T., 1976: Studies with chicks on the growth depressing factor (s) in faba beans (Vicia faba L. var.minor).

J. Nutr. 106, 275-284.

MARSMAN, G. J. P.; GRUPPEN, H.; van der POEL, A.F.B., 1993: Effect of extrusion on the in vitro protein digestibility of toasted and untoasted soybean meal. In:van der POEL, A. F. B.; HUISMAN, J.; SAINI, H. S. (Eds.): Recent advances of research in antinutritional factors in legume seeds. Pudoc, Wageningen, The Netherlands, 461-465

MARSMAN, G. J. P.; GRUPPEN, H.; van der POEL, A. F. B.; KWAKKEL, R.P.; VERSTEGEN, M. W. A.; VORAGEN, A. G. J., 1997: The effect of thermal processing and enzyme treatments of soyabean meal on growth performance, ileal 
nutrient digestibilities and chyme characteristics in broiler chicks. Poultry Sci. 76, 864-872.

McNAUGHTON, J. L.; REECE, F. N., 1980: Effect of moisture content and cooking time on soy bean meal urease index, trypsin inhibitor content, and broiler growth. Poultry Sci. 59, 2300-2304.

MELANDRI, M., 1998: Practical experiences with expanded turkey feed in italy. In: $4^{\text {th }}$ International Kahl-Symposium. Future Aspects in Animal Nutrition and Compound Feed Technology. Febr. $16^{\text {th }}-17^{\text {th }}$, Reinbek, 8.3-8.8.

MIURA, Y.; MURAYAMA, H.; TSUZUKI, S.; SUGIMOTO, E.; TORII,K.; FUSHIKI, T., 1997: Long-term consumption of an amino acid diet reduces the pancreatic enzyme secretion response to a trypsin inhibitor in rats.

J. Nutr. 127, 1377-1381.

MOY, L.Y; BILLINGS, P.C.A, 1994: A proteolytic activity in a human breast cancer cell line which is inhibited by the anticarcinogenic Bowman-Birk protease. Cancer Letters 85, 205-210.

NAGEL, W.; WILLIG, F.; PESCHKE, W.; SCHMIDT, F., 1965: Über die Bestimmung von Trypsin und Chymotrypsin mit Aminosäure-p-nitroaniliden. HoppeSeyler's Z. Physiol. Chem. Bd. 340, 1-2.

NAIM, M.; GERTLER, A.; BIRK, Y., 1982: The effect of of dietary raw and autoclaved soya-bean protein fractions on growth, pancreatic enlargment and pancreatic enzymes in rats. Br. J. Nutr. 47, 281-288.

NAUMANN, K.; BASSLER, R., 1976-1997: Die chemische Untersuchung von Futtermitteln. Methodenbuch Band III, Verlag J. NEUMANN-NEUDAM.

NIES, E.; IVY, C. A.; NESHEIM, M. C., 1972: Stimulation of gallbladder emptying and pancreatic secretion in chicks by soybean whey protein. 
Proc. Soc. Exp. Biol. Med. 140, 291-296.

NITSAN, Z.; LIENER, I. E., 1976: Enzymatic activities in the pancreas, digestive tract and feces of rats fed raw or heated soy flour. J. Nutr. 106, 300-305.

NOLAND, P. R.; CAMPBELL, D. R.; GATE, R. K. Jr.; SHARP, R. N.; JOHNSON, 1976: Evaluation of processed soybeans and grains in diets for young pigs. J. Anim. Sci. 43, 763-769.

NRC National Research Council, 1994: Nutrient requirements of poultry. Ninth Revised Edition. National Academy Press. Washington, D. C.

NWOKOLO, N.; BRAGG, D. B., 1977: Influence of phytic acid and crude fiber on the availability of minerals from four protein supplements in growing chickens. Can. J. Anim. Sci. 57, 475-477.

O'DELL, B.L.; DE BOLAND, A. 1976: Complexation of phytate with proteins and cations in corn germ and oilseed meals. J. Agric. Food Chem. 24, 804 - 808.

O'DELL, B. L.; SAVAGE, J. E., 1960: Effect of phytic acid on zinc availability. Proc. Soc. Exp. Biol. Med. 103, 304-306.

OAKENFULL, D. G.; DOROTHY, E. F.; HOOD, R. L., 1979: Effects of saponins on bile acids and plasma lipids in the rat. Br. J. Nutr. 42, 209-216.

OBERLEAS, D., 1973: Phytates. In: STRONG, F. M. (Ed.): Toxicants occuring naturally in foods, Nat. Acad. Sci., Waschington, 363-371.

OGAWA, M.; TANAKA, K.; KASAI, Z., 1975: Isolation of high phytin containing particles from rice grains using an aqueous polymer two phase system. Agric. Biol. Chem. 39, 695-700.

OLOGHOBO, A. D; FETUGA, B. L., 1984: Distribution of $P$ and phytate in some Nigerian varieties of legumes and some effects of processing. J. Food Sci. 49, 199-203. 
ÖNNIG, G.; ASP, N.-G., 1995: Effect of oat saponins and different types of dietary fiber on the digestion of carbohdrates. Br. J. Nutr. 74, 229-237.

OSELLA, C. A.; GORDO, N. A.; GONZALEZ, R. J.; TOSI, E.; RE, E., 1997: Soyabean heat treated using a fluidised bed. Lebensmittel, Wissenschaft und Technologie 30, 676-670.

PAHLE, T.; KÖHLER, R.; HALLE, I.; JEROCH, H.; GEBHARDT, G., 1983: Methodische Untersuchungen zur Bestimmung der Verdaulichkeit des Rohproteins beim Hühnergeflügel. Arch. Tierernährung. 33, 363-370.

PAHLE, T.; KÖHLER, R.; HALLE, I.; JEROCH, H.; GEBHARDT, G., 1985: Die Bestimmung der Rohproteinverdaulichkeit beim Hühnergeflügel mit der $\propto-\mathrm{NH}_{2}-\mathrm{N}-$ Methode. Arch. Tierernährung. 35, 82-87.

PALLAUF, J.; RIMBACH, G., 1993: Enzymeinsatz in der Tierernährung am Beispiel der Phytase. In: Vitamine und weitere Zusatzstoffe bei Mensch und Tier, Hrsg.: FLACHOWSKY, G. und SCHUBERT, R. 4. Symposium, Jena, 30.9.-1.10.1993, 354-363.

PAPATRYPHON; E.; HOWELL, R.A.; SOARES, J. H. Jr., 1999: Growth and mineral absorption by striped bass Morone saxatilis fed a plant feedstuff based diet supplemented with phytase. J. Wld.Aquacult. Soc. 30, 161-173.

PARSONS, C. M.; HASHIMOTO, K.; WEDEKIND, K. J.; HAN, Y.; BAKER, D. H., 1992: Effect of overprocessing on availability of amino acids and energy in soybean meal. Poultry Sci. 71, 133-140.

PEISKER, M., 1990: Hydrothermische Behandlung und Futterwert. Die Mühle + Mischfuttertechnik 127, 400-405.

PETRES, J.; CZUKOR, B., 1990: Inactivation of trypsin inhibitor, lectins and urease in soybeans by hydrothermical treatment. Die Nahrung 34, 905-913. 
PÉREZ, J. M.; BOURDON , D., 1992: Energy and protein value of peas for pigs: synthesis of French results. Proceedings of the $1^{\text {st }}$ European Conference on Legume Seeds. 1-3. june 1991. Angers, France, 489-490.

PRIEBS, H.; THOMANECK, D.; HEINZ, T., 1987: Bestimmung der scheinbaren Verdaulichkeit des Rohproteins beim Hühnergeflügel mit Hilfe der $\propto-\mathrm{NH}_{2}-\mathrm{N}-$ Methode. Arch. Tierernährung. 37, 467-474.

PRICE, K. R.; CURL, C. L.; FENWICK, G. R., 1986: The saponin content and sapogenol composition of the seed of 13 varieties of legume. J. Sci. Food Agric. 37, $1185-1191$.

PUSZTAI, A.; CLARKE, E. M. W.; KING, T. P.; STEWART, J. C., 1979:

Nutritional evaluation of kidney beans (Phaseolus vulgaris): Chemical composition, lectin content and nutritional value of selected cultivars. J. Sci. Food Agric. Technol. 30, 843-848.

PUSZTAI, A.; CLARKE, E. M. W.; GRANT, G.; KING, T. P., 1981: The toxicity of phaseolus vulgaris lectins. Nitrogen balance and immunochemical studies.

J. Sci. Food Agric. Technol. 32, 1037-1046.

PUSZTAI, A.; GRANT, G.; BROWN, D.J.; STEWART, J. C.; BARDOCZ, S., 1992: Nutritional evaluation of the trypsin inhibitor from cow pea (Vigna unguiculata Walp). Br. J. Nutr. 68, 783-791.

QIN, G. X.; ter ELST, E. R.; BOSCH, M. W.; van der POEL, A. F. B., 1996: Thermal processing of whole soya beans: Studies on the inactivation of antinutritional factors and effects on ileal digestibility in piglets. Anim. Feed. Sci. Technol. 57, 313-324.

QIN, G. X; VERSTEGEN, M. W. A.; BOSCH, M. W.; van der POEL, A. F. B., 1997: Effects of steam toasting on the digestibility and nitrogen utilization of Argentine and Chinese soybeans in growing pigs. J. Anim. Physiol. a. Anim. Nutr. 78, 1-9.

RIMBACH, M.; LIEBERT, F., 1999: N-Umsatzparameter aktueller Broilergenotypen in 
differenzierten Altersabschnitten. Proc. Soc. Nutr. Physiol. 8, 49.

RODHOUSE, S. L.; HERKELMAN, K. L.; VEUM, T. L., 1992: Effect of extrusion on the ileal and fecal digestibilities of lysine, nitrogen, and energy in diets for young pigs. J. Anim. Sci. 70, 827-835.

ROY, D. M; SCHNEEMAN, B. O, 1981: Effect of soy protein, casein and trypsin inhibitor on cholesterol, bile acids and pancreatic enzymes in mice. J. Nutr. 111, 878-885.

SACHS, L., 1968: Statistische Auswertungsmethoden. Springer-Verlag Berlin. Heidelberg. New York.

SCHEUERMANN, S.E.; LANTZSCH, H.-J.; MENKE, K. H., 1988: In vitro und in vivo Untersuchungen zur Hydrolyse von Phytat. 1. Löslichkeit von Phytat. J. Anim. Physiol. a. Anim. Nutr. 60, 55-63.

SCHULZE, H.; HUISMAN, J.; VERSTEGEN, M. W. A.; van LEEUWEN, P., 1992: Effect of soya trypsin inhibitors in the diet on trypsin activities in pancreatic tissue and ileal digesta and trypsin inhibitor activity in small intestinal digesta of piglets. Proceedings of the $1^{\text {st }}$ anglo-french symposium on human and animal nutrition. 9-12 sept. 1992. Rennes, France, 84.

SETH, P. C. C.; CLANDININ, D. R.; HARDIN, R. T., 1975: In- vitro uptake of zinc by rapeseed meal and soybean meal. Poultry Sci. 54, 626-629.

SIBBALD, J. D. R, 1980: The effect of heat on the clearance time, true metabolizable energy and true available amino acids of raw soybean flakes. Poultry Sci. 59, 2358-2360.

SOUTHON, S.; JOHNSON, I. T.; GEE, J.M.; PRICE, K. R., 1988: The effect of gypsophila saponins in the diet on mineral status and plasma cholesterol concentration in the rat. Br. J. Nutr. 59, 49-55.

TABEKHIA, M. M.; LUH, B. S., 1980: Effect of germination, cooking and canning on 
phosphorus and phytat retention in dried beans. J. Food Sci. 45, 406.

TAGLE, M. A., 1974: Factores tóxicos de leguminosas cultivadas en Chile. II. Inhibitor de tripsina. Arch.Latinoamer. Nutr. 24, 183-281.

THOMPSON, L. U; CHO, Y., 1984: Chemical composition and functional properties of acylated low phytate rapeseed protein isolate. J. Food. Sci. 49, 1584-1588.

TSCHESCHE, R.; TAUSCHER, M.; FEHLHABER, H.-W.; WULFF, G., 1969: Avenacosid A, ein bidesmosidisches Steroidsaponin aus Avena sativa. Chemische Ber. 102, 2072-2082.

TRAYLOR, S. L.; JOHNSTON, S.L.; BEHNKE, K. C.; HANCOCK, J. R.; FROETSCHNER, J. R.; SORRELL, P.; FAIRCHILD, F. J.; HINES, R. H., 1997: Conditions during expander processing affect nutrient digestibility in finishing pigs fed soyabean meal and raw soyabeans. J. Anim. Sci. 75 (Suppl. 1), 65.

VALDEBOUZE, P.; BERGERON, E.; GABORIT, T.; DELORT-LAVAL, J.; 1980: Content and distribution of trypsin inhibitors and hämagglutinins in some legume seeds. Can. J. Plant Sci. 60, 695-701.

VAN der GRIFT, W. L.; KNABE, D. A.; TANKSLEY, T. D.;

ANDERSON, S. A.;1983:Digestibility of nutrients in raw and heated soyflakes for pigs. J. Anim. Sci. 57, 1215-1224.

VAN der POEL, A. F. B.; BLONK, J.; VAN ZUILICHEM, D. J.; VAN OORT, M. G., 1990: Thermal inactivation of lectins and trypsin inhibitor activity during steam processing of dry beans (Phaseolus vulgaris L.) and effects on protein quality. J. Sci. Food Agric. 53, 215-228.

VAN OORT, M. G.; HAMER, R. J.; SLAGER, E. A., 1989: The trypsin inhibitor assay; improvement of an existing method. In: HUISMAN, J.; VAN DER POEL, A. F. B.; LIENER, I. E. (Eds.): Recent advances of research in antnutritional factors in legumeseeds. Pudoc, Wageningen, The Netherlands, 110-113. 
WALDROUP, P. W.; RAMSEY, B.E.; HELLWIG, H. M.; SMITH, N. K., 1985:

Optimum processing for soybean meal in broiler diets. Poultry Sci.2314-2319.

WISEMAN, J., 1984: Developments in non ruminant nutrition. Feed Int., Feb., 14-19.

WONDRA et al., 1995: zit. n. HANCOCK, J. D., 1998.

WPSA (World Poultry Science Assosiation), 1984: The prediction of apparent metabolizable energy values for poultry in compound feeds. Wld's Poultry Sci. J., Vol. 40, 181-182.

YEN, J. T.; JENSEN, A. H.; SISSON, J., 1977: Effect of dietary raw soybean and soybean trypsin inhibitor on trypsin and chymotrypsin activities in the pancreas and in small intestinal juice of growing swine. J. Nutr. 107, 156-165.

YOSHIDA, H.; KAJIMOTO, G., 1988: Effects of microwave treatment on the trypsin inhibitor and molecular species of tryglycerides in soybeans. J. Food Sci. 53, 1756-1761.

XIAN, J.; FARRELL, D.J., 1991: The nutritive value of microwave-processed raw soyabeans determined with chickens, rats and rabbits. Anim. Feed. Sci. Technol. 34, 127-139.

ZHANG, L.; WAN, X. S.; DONAHUE, J. J.; WAREN, J.H.; KENNEDY, A. R. R., 1999: Effekte des Hemmnisses Bowman-Birk auf clonogenic des cisplatin- oder strahlungsinduzierter Cytotoxizität des Überlebens und in den menschlichen zervikalen und Krebszellen des Kopfes und des Ansatzes der Brust. Nahrung und Krebs 33, $165-173$.

ZHANG, Y.; PARSONS, C. M.; WEINGARTNER, K. E.; WIJERATNE, W. B., 1993: Effects of extrusion and expelling on the nutritional quality of conventional and Kunitz trypsin inhibitor free soybeans. Poultry Sci. 72, 2299-2307. 
9.Tabellenanhang 
Tab. 1: Nährstoffzusammensetzung der Futtermischungen

\begin{tabular}{|c|c|c|c|c|c|c|c|c|c|c|c|}
\hline $\begin{array}{l}\text { Mischungen } \\
\text { Inhaltsstoffe } \\
\text { (i. \% T) }\end{array}$ & $\mathbf{A}$ & B & $\mathrm{C}$ & D & $\mathbf{E}$ & $\mathbf{F}$ & G & $\mathbf{H}$ & I & $\mathbf{K}$ & MW \\
\hline $\mathrm{T}(\%)$ & 88,79 & 90,41 & 89,59 & 90,01 & 90,18 & 89,21 & 89,56 & 89,57 & 89,84 & 89,96 & 89,71 \\
\hline Rohprotein & 24,44 & 24,80 & 24,44 & 24,62 & 24,73 & 24,46 & 24,48 & 24,44 & 24,47 & 24,59 & 24,55 \\
\hline Rohfett & 10,67 & 10,89 & 11,11 & 10,78 & 10,70 & 10,47 & 10,75 & 10,99 & 10,39 & 10,20 & 10,70 \\
\hline Rohasche & 6,82 & 6,91 & 6,86 & 7,04 & 7,15 & 6,98 & 6,81 & 7,07 & 6,74 & 6,89 & 6,93 \\
\hline Rohfaser & 3,90 & 3,73 & 3,80 & 3,92 & 3,89 & 3,71 & 3,32 & 3,40 & 3,59 & 3,30 & 3,66 \\
\hline $\mathrm{NfE}$ & 54,17 & 53,67 & 53,79 & 53,64 & 53,53 & 54,38 & 54,64 & 54,10 & 54,81 & 55,02 & 54,16 \\
\hline Stärke & 41,24 & 41,24 & 41,24 & 41,24 & 41,24 & 41,24 & 41,24 & 41,24 & 41,24 & 41,24 & 41,24 \\
\hline Zucker & 3,85 & 3,85 & 3,85 & 3,85 & 3,85 & 3,85 & 3,85 & 3,85 & 3,85 & 3,85 & 3,85 \\
\hline $\begin{array}{l}\text { Methionin } \\
+ \text { Cystin }\end{array}$ & 1,05 & 1,05 & 1,05 & 1,05 & 1,05 & 1,05 & 1,05 & 1,05 & 1,05 & 1,05 & 1,05 \\
\hline Lysin & 1,11 & 1,11 & 1,11 & 1,11 & 1,11 & 1,11 & 1,11 & 1,11 & 1,11 & 1,11 & 1,11 \\
\hline Threonin & 0,93 & 0,93 & 0,93 & 0,93 & 0,93 & 0,93 & 0,93 & 0,93 & 0,93 & 0,93 & 0,93 \\
\hline $\begin{array}{l}\text { ME }_{\text {N-korr }} \quad(\mathrm{MJ} / \mathrm{kg} \\
\text { T) }\end{array}$ & 14,84 & 14,97 & 14,99 & 14,90 & 14,89 & 14,77 & 14,87 & 14,94 & 14,74 & 14,70 & 14,86 \\
\hline
\end{tabular}


Tab. 2: Daten der N- korrigierten scheinbar umsetzbaren Energie (MEn) in den Futtermischungen

\begin{tabular}{|c|c|c|c|}
\hline Gruppe & MEn (MJ/kg T) & Gruppe & MEn (MJ/kg T) \\
\hline \multirow[t]{6}{*}{$\mathbf{A}$} & 14,26 & $\mathbf{F}$ & 14,28 \\
\hline & 13,87 & & 14,50 \\
\hline & 13,35 & & 13,86 \\
\hline & 14,23 & & 13,75 \\
\hline & 14,16 & & 14,76 \\
\hline & 13,87 & & 14,36 \\
\hline MW & 13,96 & MW & 14,25 \\
\hline $\mathbf{s}$ & $\mathbf{0 , 3 5}$ & $\mathbf{s}$ & $\mathbf{0 , 3 8}$ \\
\hline \multirow[t]{6}{*}{ B } & 14,90 & $\mathbf{G}$ & 14,77 \\
\hline & 15,10 & & 14,71 \\
\hline & 14,85 & & 14,53 \\
\hline & 14,53 & & 14,91 \\
\hline & 14,75 & & 14,61 \\
\hline & 15,07 & & 14,66 \\
\hline MW & 14,87 & MW & 14,70 \\
\hline $\mathbf{s}$ & 0,21 & $\mathbf{s}$ & 0,13 \\
\hline \multirow[t]{6}{*}{$\mathbf{C}$} & 13,84 & $\mathbf{H}$ & 14,32 \\
\hline & 14,20 & & 14,56 \\
\hline & 14,20 & & 14,47 \\
\hline & 14,70 & & 14,13 \\
\hline & 14,79 & & 13,73 \\
\hline & 14,12 & & 14,44 \\
\hline MW & 14,31 & MW & 14,28 \\
\hline $\mathbf{s}$ & $\mathbf{0 , 3 6}$ & $\mathbf{S}$ & $\mathbf{0 , 3 1}$ \\
\hline \multirow[t]{6}{*}{ D } & 14,00 & $\mathbf{I}$ & 14,22 \\
\hline & 14,08 & & 14,39 \\
\hline & 14,60 & & 14,72 \\
\hline & 14,82 & & 14,44 \\
\hline & 14,36 & & 14,62 \\
\hline & 13,75 & & 14,46 \\
\hline MW & 14,27 & MW & 14,47 \\
\hline $\mathbf{s}$ & $\mathbf{0 , 4 0}$ & $\mathbf{s}$ & 0,18 \\
\hline \multirow[t]{6}{*}{$\mathbf{E}$} & 14,31 & $\mathbf{K}$ & 14,44 \\
\hline & 13,93 & & 13,36 \\
\hline & 13,88 & & 14,65 \\
\hline & 14,29 & & 14,23 \\
\hline & 13,48 & & 14,25 \\
\hline & 14,55 & & 13,98 \\
\hline MW & 14,07 & MW & 14,15 \\
\hline $\mathbf{S}$ & $\mathbf{0 , 3 8}$ & $\mathbf{S}$ & $\mathbf{0 , 4 5}$ \\
\hline
\end{tabular}

*) Ausreisser-Test n. DIXON $(\propto \leq 0,05)$ 
Tab. 3: Daten der Trypsinaktivität im Chymus

\begin{tabular}{|c|c|c|c|}
\hline Gruppe & U/g Chymus & U/Überstand insgesamt & U/ml Überstand \\
\hline \multirow[t]{6}{*}{$\mathbf{A}$} & 4,27 & 17,72 & 3,69 \\
\hline & 3,16 & 17,19 & 3,55 \\
\hline & 6,89 & 48,19 & 5,60 \\
\hline & 7,46 & 45,08 & 5,67 \\
\hline & 7,02 & 57,69 & 5,95 \\
\hline & 6,81 & 52,15 & 5,38 \\
\hline MW & 5,93 & 39,67 & 4,97 \\
\hline $\mathbf{s}$ & 1,77 & 17,72 & 1,06 \\
\hline \multirow[t]{6}{*}{$\mathbf{B}$} & 4,64 & 20,19 & 4,13 \\
\hline & 7,54 & 41,33 & 4,36 \\
\hline & 6,50 & 30,85 & 5,17 \\
\hline & 5,95 & 33,89 & 3,44 \\
\hline & $13,14^{*}$ & $62,95^{*}$ & $5,72 *$ \\
\hline & 9,63 & 40,04 & 3,53 \\
\hline MW & 7,90 & 38,21 & 4,39 \\
\hline $\mathbf{s}$ & 3,06 & 14,30 & 0,90 \\
\hline \multirow[t]{6}{*}{$\mathbf{C}$} & 2,03 & 12,00 & 2,50 \\
\hline & 2,39 & 15,91 & 3,62 \\
\hline & 7,38 & 51,43 & 5,21 \\
\hline & 8,40 & 51,07 & 5,34 \\
\hline & 9,16 & 36,93 & 3,76 \\
\hline & 3,85 & 30,87 & 3,21 \\
\hline MW & 5,54 & 33,03 & 3,94 \\
\hline $\mathbf{s}$ & 3,16 & 16,85 & 1,12 \\
\hline \multirow[t]{6}{*}{ D } & 3,67 & 15,76 & 3,26 \\
\hline & 2,37 & 13,56 & 2,74 \\
\hline & 12,37 & 83,38 & 8,41 \\
\hline & 10,50 & 80,23 & 8,02 \\
\hline & 6,10 & 42,76 & 4,35 \\
\hline & 4,85 & 40,96 & 4,04 \\
\hline MW & 6,64 & 46,11 & 5,14 \\
\hline $\mathbf{s}$ & 3,96 & 30,24 & 2,45 \\
\hline \multirow[t]{6}{*}{$\mathbf{E}$} & 4,26 & 23,79 & 4,85 \\
\hline & 3,68 & 62,35 & 6,52 \\
\hline & 8,33 & 70,20 & 7,77 \\
\hline & 11,54 & 73,13 & 7,54 \\
\hline & 6,84 & 50,03 & 4,97 \\
\hline & 4,46 & 46,75 & 4,89 \\
\hline MW & 6,52 & 54,37 & 6,09 \\
\hline $\mathbf{s}$ & 3,03 & 18,32 & 1,37 \\
\hline
\end{tabular}

*) Ausreisser-Test n. DIXON $(\propto \leq 0,05)$ 
Tab. 4: Daten der Trypsinaktivität im Chymus

\begin{tabular}{|c|c|c|c|}
\hline Gruppe & U/g Chymus & U/Überstand insgesamt & U/ml Überstand \\
\hline \multirow[t]{6}{*}{$\mathbf{F}$} & 4,78 & 38,94 & 3,64 \\
\hline & 6,38 & 41,12 & 4,06 \\
\hline & 5,28 & 31,64 & 3,25 \\
\hline & 3,20 & 17,78 & 1,82 \\
\hline & 5,40 & 35,29 & 3,33 \\
\hline & 4,46 & 31,46 & 3,20 \\
\hline MW & 4,91 & 32,70 & 3,22 \\
\hline $\mathbf{s}$ & $\mathbf{1 , 0 7}$ & 8,27 & 0,76 \\
\hline \multirow[t]{6}{*}{$\mathbf{G}$} & 6,19 & 28,16 & 2,79 \\
\hline & 10,08 & 29,84 & 3,01 \\
\hline & 2,78 & 16,33 & 1,47 \\
\hline & 5,83 & 41,38 & 4,03 \\
\hline & 5,01 & 29,84 & 2,87 \\
\hline & 4,84 & 28,59 & 2,77 \\
\hline MW & 5,79 & 29,02 & 2,82 \\
\hline $\mathbf{s}$ & 2,41 & 7,95 & $\mathbf{0 , 8 2}$ \\
\hline \multirow[t]{6}{*}{$\mathbf{H}$} & 0,17 & 1,32 & 0,12 \\
\hline & 1,21 & 7,39 & 0,78 \\
\hline & 0,86 & 4,12 & 0,42 \\
\hline & 0,13 & 0,67 & 0,07 \\
\hline & 1,66 & 8,18 & 0,85 \\
\hline & 0,38 & 2,06 & 0,20 \\
\hline MW & 0,73 & 3,96 & 0,41 \\
\hline $\mathbf{s}$ & 0,62 & 3,19 & 0,34 \\
\hline \multirow[t]{6}{*}{$\mathbf{I}$} & 6,00 & 42,98 & 4,40 \\
\hline & 5,06 & 34,98 & 3,60 \\
\hline & 5,61 & 35,88 & 3,48 \\
\hline & 6,36 & 34,99 & 3,73 \\
\hline & 4,96 & 32,61 & 3,10 \\
\hline & 3,97 & 21,85 & 2,31 \\
\hline MW & 5,33 & 33,88 & 3,44 \\
\hline $\mathbf{s}$ & $\mathbf{0 , 8 5}$ & 6,86 & $\mathbf{0 , 7 0}$ \\
\hline \multirow[t]{6}{*}{$\mathbf{K}$} & 1,26 & 8,95 & 0,88 \\
\hline & 0,43 & 2,74 & 0,26 \\
\hline & 0,38 & 1,62 & 0,16 \\
\hline & 1,68 & 10,18 & 0,90 \\
\hline & 1,98 & 8,96 & 0,94 \\
\hline & 0,90 & 5,85 & 0,57 \\
\hline MW & 1,11 & 6,38 & 0,62 \\
\hline $\mathbf{s}$ & 0,66 & 3,57 & 0,34 \\
\hline
\end{tabular}

*) Ausreisser-Test n. DIXON $(\propto \leq 0,05)$ 
Tab. 5: Daten des Wachstumsversuchs

\begin{tabular}{|c|c|c|c|c|c|}
\hline Gruppe & $\begin{array}{l}\text { LM in } \mathbf{g} \\
\text { (7. LT ) }\end{array}$ & $\begin{array}{l}\text { LM in } \mathrm{g} \\
(28 . \mathrm{LT})\end{array}$ & LMZ (g/d) & FV (g/d) & FA (g/g) \\
\hline \multirow[t]{6}{*}{$\mathbf{A}$} & 160,4 & 1137,9 & 46,5 & 72,0 & 1,55 \\
\hline & 163,2 & 1201,0 & 49,4 & 77,9 & 1,58 \\
\hline & 159,6 & 1168,1 & 48,0 & 73,1 & 1,52 \\
\hline & 159,6 & 1183,6 & 48,8 & 75,7 & 1,55 \\
\hline & 159,2 & 1204,0 & 49,8 & 78,1 & 1,57 \\
\hline & 154,9 & 1138,3 & 46,8 & 72,9 & 1,56 \\
\hline MW & 159,5 & 1172,2 & 48,2 & 74,9 & 1,55 \\
\hline $\mathbf{s}$ & 2,7 & 29,4 & 1,3 & 2,7 & 0,02 \\
\hline \multirow[t]{6}{*}{ B } & 160,8 & 1129,0 & 46,1 & 64,3 & 1,46 \\
\hline & 159,0 & 1122,8 & 45,9 & 71,0 & 1,55 \\
\hline & 159,3 & 1132,1 & 46,3 & 72,8 & 1,57 \\
\hline & 148,5 & 1100,7 & 45,3 & 68,4 & 1,51 \\
\hline & 167,0 & 1154,4 & 47,0 & 69,9 & 1,49 \\
\hline & 162,2 & 1051,4 & 42,3 & 68,3 & 1,54 \\
\hline MW & 159,5 & 1115,1 & 45,5 & 69,1 & 1,52 \\
\hline $\mathbf{s}$ & 6,1 & 35,6 & 1,6 & 2,9 & 0,04 \\
\hline \multirow[t]{6}{*}{$\mathbf{C}$} & 153,9 & 1233,0 & 51,4 & 78,4 & 1,53 \\
\hline & 160,8 & 1225,2 & 50,7 & 76,1 & 1,50 \\
\hline & 151,7 & 1172,8 & 48,6 & 74,8 & 1,54 \\
\hline & 156,7 & 1161,0 & 47,8 & 71,0 & 1,48 \\
\hline & 163,9 & 1214,2 & 50,0 & 74,8 & 1,50 \\
\hline & 158,5 & 1111,3 & 45,4 & 70,1 & 1,54 \\
\hline MW & 157,6 & 1186,3 & 49,0 & 74,2 & 1,51 \\
\hline $\mathbf{s}$ & 4,5 & 46,7 & 2,2 & 3,1 & 0,02 \\
\hline \multirow[t]{6}{*}{ D } & 151,9 & 1129,8 & 46,6 & 70,0 & 1,46 \\
\hline & 165,8 & 1235,3 & 50,9 & 75,4 & 1,48 \\
\hline & 159,1 & 1169,4 & 48,1 & 71,6 & 1,49 \\
\hline & 160,2 & 1057,9 & 42,7 & 64,9 & 1,52 \\
\hline & 160,9 & 1114,3 & 45,4 & 69,4 & 1,53 \\
\hline & 161,6 & 1150,4 & 47,1 & 71,2 & 1,51 \\
\hline MW & 159,9 & 1142,8 & 46,8 & 70,4 & $\mathbf{1 , 5 0}$ \\
\hline $\mathbf{s}$ & 4,5 & 59,2 & 2,7 & 3,4 & $\mathbf{0 , 0 3}$ \\
\hline \multirow[t]{6}{*}{$\mathbf{E}$} & 159,2 & 1180,9 & 48,7 & 75,8 & 1,56 \\
\hline & 156,6 & 1211,7 & 50,2 & 77,1 & 1,53 \\
\hline & 156,2 & 1235,4 & 51,4 & 76,8 & 1,49 \\
\hline & 164,8 & 1324,7 & 55,2 & 81,9 & 1,48 \\
\hline & 155,0 & 1179,8 & 48,8 & 72,6 & 1,49 \\
\hline & 157,2 & 1174,3 & 48,4 & 72,6 & 1,50 \\
\hline MW & 158,2 & 1217,8 & 50,5 & 76,1 & 1,51 \\
\hline $\mathbf{s}$ & 3,5 & 57,4 & 2,6 & 3,4 & $\mathbf{0 , 0 3}$ \\
\hline
\end{tabular}

*) Ausreisser-Test n. DIXON $(\propto \leq 0,05)$ 
Tab. 6: Daten des Wachstumsversuchs

\begin{tabular}{|c|c|c|c|c|c|}
\hline Gruppe & $\begin{array}{l}\text { LM in } g \\
\text { (7. LT ) }\end{array}$ & $\begin{array}{l}\text { LM in } g \\
\text { (28.LT ) }\end{array}$ & LMZ (g/d) & $F V(g / d)$ & FA (g/g) \\
\hline \multirow[t]{6}{*}{$\mathbf{F}$} & 147,4 & 1132,3 & 46,9 & 72,5 & 1,55 \\
\hline & 148,1 & 1162,8 & 48,3 & 74,2 & 1,54 \\
\hline & 151,7 & 1070,2 & 43,7 & 68,7 & 1,57 \\
\hline & 152,2 & 1146,8 & 47,4 & 72,5 & 1,53 \\
\hline & 147,5 & 1138,0 & 47,2 & 75,2 & 1,59 \\
\hline & 150,0 & 1065,8 & 43,6 & 68,3 & 1,57 \\
\hline MW & 149,5 & 1119,3 & 46,2 & 71,9 & 1,56 \\
\hline $\mathbf{s}$ & 2,1 & 41,1 & 2,0 & 2,8 & 0,02 \\
\hline \multirow[t]{6}{*}{$\mathbf{G}$} & 151,4 & 1084,6 & 44,4 & 68,7 & 1,55 \\
\hline & 153,1 & 1124,8 & 46,3 & 73,0 & 1,58 \\
\hline & 146,5 & 1126,0 & 46,6 & 73,2 & 1,57 \\
\hline & 147,8 & 1089,7 & 44,9 & 68,3 & 1,52 \\
\hline & 146,9 & 1000,4 & 40,6 & 65,0 & 1,60 \\
\hline & 145,8 & 1055,1 & 43,3 & 68,7 & 1,59 \\
\hline MW & 148,6 & 1080,1 & 44,4 & 69,5 & 1,57 \\
\hline $\mathbf{s}$ & 3,0 & 47,3 & 2,2 & 3,1 & $\mathbf{0 , 0 3}$ \\
\hline \multirow[t]{6}{*}{$\mathbf{H}$} & 151,1 & 932,0 & 37,2 & 63,3 & 1,70 \\
\hline & 149,6 & 969,6 & 39,0 & 65,6 & 1,68 \\
\hline & 153,7 & 975,2 & 39,1 & 68,5 & 1,75 \\
\hline & 150,5 & 992,8 & 40,1 & 68,8 & 1,72 \\
\hline & 147,0 & 867,8 & 34,3 & 60,9 & 1,77 \\
\hline & 154,0 & 941,7 & 37,5 & 63,4 & 1,69 \\
\hline MW & 151,0 & 946,5 & 37,9 & 65,1 & 1,72 \\
\hline $\mathbf{s}$ & 2,6 & 44,6 & 2,1 & 3,1 & 0,04 \\
\hline \multirow[t]{6}{*}{ I } & 145,6 & 1128,4 & 46,8 & 71,2 & 1,52 \\
\hline & 152,3 & 1090,9 & 44,7 & 69,2 & 1,55 \\
\hline & 151,2 & 1093,6 & 44,9 & 70,7 & 1,58 \\
\hline & 152,8 & 1111,3 & 45,6 & 70,9 & 1,55 \\
\hline & 145,9 & 1107,0 & 45,8 & 71,1 & 1,55 \\
\hline & 148,4 & 1038,7 & 42,4 & 67,6 & 1,59 \\
\hline MW & 149,4 & 1095,0 & 45,0 & 70,1 & 1,56 \\
\hline $\mathbf{S}$ & 3,2 & 30,7 & 1,5 & 1,4 & $\mathbf{0 , 0 2}$ \\
\hline \multirow[t]{6}{*}{$\mathbf{K}$} & 147,7 & 1091,1 & 44,9 & 71,3 & 1,59 \\
\hline & 145,9 & 1096,2 & 45,3 & 72,4 & 1,60 \\
\hline & 146,5 & 1091,2 & 45,0 & 72,6 & 1,61 \\
\hline & 153,2 & 1125,8 & 46,3 & 73,7 & 1,59 \\
\hline & 147,3 & 1080,6 & 44,4 & 69,7 & 1,57 \\
\hline & 147,3 & 1102,8 & 45,5 & 69,2 & 1,52 \\
\hline MW & 148,0 & 1098,0 & 45,2 & 71,5 & 1,58 \\
\hline $\mathbf{s}$ & 2,6 & 15,5 & 0,6 & 1,7 & $\mathbf{0 , 0 3}$ \\
\hline
\end{tabular}

*) Ausreisser-Test n. DIXON $(\propto \leq 0,05)$ 
Tab. 7: Daten des Wachstumsversuchs (Energie- und Nährstoffansatz)

\begin{tabular}{|c|c|c|c|c|c|}
\hline Gruppe & $\begin{array}{c}\text { Fett-Ansatz } \\
\text { g/d }\end{array}$ & $\begin{array}{c}\text { RA-Ansatz } \\
\text { g/d }\end{array}$ & $\begin{array}{l}\text { T-Ansatz } \\
\text { g/d }\end{array}$ & $\begin{array}{c}\text { Energie- } \\
\text { Ansatz kJ/d }\end{array}$ & $\begin{array}{c}\text { Protein-Ansatz } \\
\text { g/d }\end{array}$ \\
\hline \multirow[t]{6}{*}{$\mathbf{A}$} & 4,9 & 1,4 & 15,8 & 423 & 9,6 \\
\hline & 6,0 & 1,5 & 16,8 & 462 & 9,3 \\
\hline & 4,2 & 1,4 & 14,6 & 384 & 9,0 \\
\hline & 6,1 & 1,2 & 15,9 & 447 & 8,5 \\
\hline & 6,2 & 1,4 & 16,4 & 457 & 8,8 \\
\hline & 5,2 & 1,3 & 14,5 & 400 & 8,1 \\
\hline MW & 5,4 & 1,4 & 15,7 & 429 & 8,9 \\
\hline $\mathbf{s}$ & 0,8 & 0,1 & 0,9 & 32 & 0,5 \\
\hline \multirow[t]{6}{*}{ B } & 6,1 & 1,3 & 15,4 & 434 & 8,0 \\
\hline & 5,1 & 1,2 & 14,6 & 404 & 8,3 \\
\hline & 5,2 & 1,2 & 14,6 & 402 & 8,2 \\
\hline & 6,1 & 1,3 & 15,5 & 437 & 8,1 \\
\hline & 4,3 & 1,2 & 14,5 & 385 & 8,9 \\
\hline & 5,0 & 1,1 & 14,1 & 391 & 7,9 \\
\hline MW & 5,3 & 1,2 & 14,8 & 409 & 8,3 \\
\hline $\mathbf{s}$ & 0,7 & 0,1 & 0,5 & 22 & 0,3 \\
\hline \multirow[t]{6}{*}{$\mathbf{C}$} & 4,8 & 1,3 & 15,1 & 407 & 9,0 \\
\hline & 5,9 & 1,4 & 16,2 & 447 & 8,8 \\
\hline & 5,6 & 1,3 & 15,9 & 440 & 9,1 \\
\hline & 4,8 & 1,4 & 15,6 & 418 & 9,4 \\
\hline & 6,2 & 1,3 & 16,3 & 455 & 8,8 \\
\hline & 5,0 & 1,3 & 14,7 & 400 & 8,3 \\
\hline MW & 5,4 & 1,3 & 15,6 & 428 & 8,9 \\
\hline $\mathbf{s}$ & 0,6 & 0,1 & 0,6 & 23 & 0,4 \\
\hline \multirow[t]{6}{*}{ D } & 5,4 & 1,2 & 14,9 & 414 & 8,3 \\
\hline & 6,0 & 1,3 & 16,9 & 469 & 9,6 \\
\hline & 5,4 & 1,4 & 16,2 & 438 & 9,4 \\
\hline & 4,2 & 1,1 & 13,3 & 359 & 8,0 \\
\hline & 5,5 & 1,3 & 15,3 & 423 & 8,5 \\
\hline & 5,2 & 1,3 & 14,7 & 403 & 8,2 \\
\hline MW & 5,3 & 1,3 & 15,2 & 418 & 8,7 \\
\hline $\mathbf{S}$ & 0,6 & $\mathbf{0 , 1}$ & 1,2 & 37 & 0,7 \\
\hline \multirow[t]{6}{*}{$\mathbf{E}$} & 5,6 & 1,3 & 16,3 & 446 & 9,4 \\
\hline & 6,2 & 1,4 & 17,2 & 476 & 9,6 \\
\hline & 6,2 & 1,3 & 16,8 & 469 & 9,2 \\
\hline & 8,8 & 1,5 & 19,1 & 560 & 8,8 \\
\hline & 5,5 & 1,3 & 15,8 & 435 & 9,1 \\
\hline & 5,4 & 1,3 & 15,9 & 434 & 9,1 \\
\hline MW & 6,3 & 1,4 & 16,8 & 470 & 9,2 \\
\hline $\mathbf{s}$ & 1,3 & $\mathbf{0 , 1}$ & 1,2 & 47 & $\mathbf{0 , 3}$ \\
\hline
\end{tabular}

*) Ausreisser-Test n. DIXON $(\propto \leq 0,05)$ 
Tab. 8: Daten des Wachstumsversuchs (Energie und Nährstoffansatz)

\begin{tabular}{|c|c|c|c|c|c|}
\hline Gruppe & $\begin{array}{c}\text { Fett-Ansatz } \\
\text { g/d }\end{array}$ & $\begin{array}{c}\text { RA-Ansatz } \\
\text { g/d }\end{array}$ & $\begin{array}{c}\text { T-Ansatz } \\
\text { g/d }\end{array}$ & $\begin{array}{c}\text { Energie- } \\
\text { Ansatz kJ/d }\end{array}$ & Protein-Ansatz g/d \\
\hline \multirow[t]{6}{*}{$\mathbf{F}$} & 6,9 & 1,4 & 17,2 & 486 & 8,8 \\
\hline & 6,0 & 1,2 & 16,1 & 449 & 8,9 \\
\hline & 4,1 & 1,2 & 13,5 & 359 & 8,2 \\
\hline & 6,1 & 1,2 & 16,0 & 449 & 8,7 \\
\hline & 5,8 & 1,2 & 15,7 & 439 & 8,6 \\
\hline & 4,6 & 1,3 & 14,2 & 382 & 8,3 \\
\hline MW & 5,6 & 1,3 & 15,4 & 427 & 8,6 \\
\hline $\mathbf{S}$ & 1,1 & 0,1 & 1,3 & 47 & $\mathbf{0 , 3}$ \\
\hline \multirow[t]{6}{*}{$\mathbf{G}$} & 4,8 & 1,1 & 13,4 & 371 & 7,5 \\
\hline & 6,0 & 1,3 & 15,8 & 444 & 8,5 \\
\hline & 4,9 & 1,5 & 16,1 & 426 & 9,6 \\
\hline & 4,2 & 1,2 & 14,0 & 374 & 8,5 \\
\hline & 3,7 & 1,0 & 12,6 & 335 & 7,8 \\
\hline & 5,4 & 1,1 & 14,3 & 402 & 7,8 \\
\hline MW & 4,9 & 1,2 & 14,4 & 392 & 8,3 \\
\hline $\mathbf{s}$ & 0,8 & 0,2 & 1,4 & 40 & 0,8 \\
\hline \multirow[t]{6}{*}{$\mathbf{H}$} & 5,0 & 1,0 & 12,8 & 360 & 6,8 \\
\hline & 4,2 & 1,0 & 12,2 & 335 & 6,9 \\
\hline & 4,8 & 1,1 & 12,8 & 356 & 6,9 \\
\hline & 5,4 & 1,0 & 13,2 & 377 & 6,8 \\
\hline & 3,8 & 1,0 & 11,1 & 303 & 6,3 \\
\hline & 4,0 & 1,0 & 11,6 & 319 & 6,6 \\
\hline MW & 4,5 & 1,0 & 12,3 & 341 & 6,7 \\
\hline $\mathbf{S}$ & 0,6 & $\mathbf{0 , 0}$ & 0,8 & 28 & 0,2 \\
\hline \multirow[t]{6}{*}{ I } & 6,0 & 1,3 & 15,8 & 443 & 8,5 \\
\hline & 5,0 & 1,3 & 14,4 & 394 & 8,1 \\
\hline & 5,2 & 1,2 & 14,8 & 407 & 8,4 \\
\hline & 5,4 & 1,2 & 14,7 & 408 & 8,1 \\
\hline & 5,9 & 1,1 & 15,2 & 430 & 8,2 \\
\hline & 3,8 & 1,2 & 13,1 & 347 & 8,1 \\
\hline MW & 5,2 & 1,2 & 14,7 & 405 & 8,2 \\
\hline $\mathbf{S}$ & 0,8 & 0,1 & $\mathbf{0 , 9}$ & 33 & 0,2 \\
\hline \multirow[t]{6}{*}{$\mathbf{K}$} & 5,7 & 1,2 & 14,6 & 410 & 7,7 \\
\hline & 4,8 & 1,2 & 14,2 & 385 & 8,2 \\
\hline & 5,2 & 1,3 & 14,9 & 409 & 8,5 \\
\hline & 5,3 & 1,2 & 14,4 & 399 & 7,9 \\
\hline & 5,8 & 1,2 & 14,7 & 416 & 7,7 \\
\hline & 4,6 & 1,2 & 14,1 & 381 & 8,3 \\
\hline MW & 5,2 & 1,2 & 14,5 & 400 & 8,0 \\
\hline $\mathbf{s}$ & 0,5 & $\mathbf{0 , 0}$ & $\mathbf{0 , 3}$ & 14 & $\mathbf{0 , 3}$ \\
\hline
\end{tabular}

*) Ausreisser-Test n. DIXON $(\propto \leq 0,05)$ 
Tab. 9: Daten des Stoffwechselversuchs

\begin{tabular}{|c|c|c|c|c|c|c|}
\hline Gruppe & $\begin{array}{l}\text { LM (g) } \\
\text { Beginn } \\
\text { HP }\end{array}$ & $\begin{array}{l}\text { LM (g) } \\
\text { Ende d. } \\
\text { HP }\end{array}$ & $\begin{array}{l}\text { Mittlere } \\
\text { LM (kg) }\end{array}$ & $\mathbf{L M}_{\mathrm{kg}}{ }^{0.67}$ & $\begin{array}{c}\text { N- } \\
\text { Aufnahme/ } \\
\mathbf{L M}_{\mathbf{k g}} \\
(\mathbf{m g} / \mathbf{d})\end{array}$ & $\begin{array}{c}\text { N-Ausscheidung/ } \\
\text { LM }_{\mathrm{kg}}^{0.67} \\
(\mathrm{mg} / \mathrm{d})\end{array}$ \\
\hline \multirow[t]{6}{*}{$\mathbf{A}$} & 361 & 588 & 0,47 & 0,61 & 3522 & 1474 \\
\hline & 388 & 629 & 0,51 & 0,64 & 3307 & 1375 \\
\hline & 387 & 663 & 0,53 & 0,65 & 3508 & 1705 \\
\hline & 393 & 685 & 0,54 & 0,66 & 3500 & 1341 \\
\hline & 398 & 641 & 0,52 & 0,64 & 3397 & 1432 \\
\hline & 396 & 670 & 0,53 & 0,66 & 3455 & 1539 \\
\hline MW & 387 & 646 & 0,52 & 0,64 & 3448 & 1478 \\
\hline $\mathbf{s}$ & 14 & 35 & $\mathbf{0 , 0 2}$ & $\mathbf{0 , 0 2}$ & 83 & 132 \\
\hline \multirow[t]{6}{*}{ B } & 342 & 522 & 0,43 & 0,57 & 3009 & 1220 \\
\hline & 370 & 545 & 0,46 & 0,59 & 2945 & 1082 \\
\hline & 362 & 590 & 0,48 & 0,61 & 3312 & 1300 \\
\hline & 384 & 644 & 0,51 & 0,64 & 3329 & 1541 \\
\hline & 395 & 611 & 0,50 & 0,63 & 3043 & 1266 \\
\hline & 379 & 531 & 0,46 & 0,59 & 2936 & 1060 \\
\hline MW & 372 & 574 & 0,47 & 0,61 & 3096 & 1245 \\
\hline $\mathbf{s}$ & 19 & 49 & $\mathbf{0 , 0 3}$ & $\mathbf{0 , 0 3}$ & 179 & 175 \\
\hline \multirow[t]{6}{*}{$\mathrm{C}$} & 407 & 688 & 0,55 & 0,67 & 3508 & 1608 \\
\hline & 421 & 704 & 0,56 & 0,68 & 3436 & 1476 \\
\hline & 384 & 685 & 0,53 & 0,66 & 3645 & 1575 \\
\hline & 323 & 553 & 0,44 & 0,58 & 3298 & 1295 \\
\hline & 308 & 461 & 0,38 & 0,53 & 2930 & 1096 \\
\hline & 454 & 692 & 0,57 & 0,69 & 3428 & 1545 \\
\hline MW & 383 & 631 & 0,51 & 0,63 & 3374 & 1432 \\
\hline $\mathbf{s}$ & $\mathbf{5 7}$ & 100 & 0,08 & $\mathbf{0 , 0 7}$ & 245 & 199 \\
\hline \multirow[t]{6}{*}{ D } & 407 & 665 & 0,54 & 0,66 & 3362 & 1463 \\
\hline & 368 & 660 & 0,51 & 0,64 & 3577 & 1592 \\
\hline & 352 & 621 & 0,49 & 0,62 & 3711 & 1497 \\
\hline & 350 & 575 & 0,46 & 0,60 & 3495 & 1412 \\
\hline & 374 & 588 & 0,48 & 0,61 & 3557 & 1408 \\
\hline & 432 & 710 & 0,57 & 0,69 & 3334 & 1553 \\
\hline MW & 381 & 637 & 0,51 & 0,64 & 3506 & 1488 \\
\hline $\mathbf{s}$ & 33 & 51 & 0,04 & $\mathbf{0 , 0 3}$ & 142 & 75 \\
\hline \multirow[t]{6}{*}{$\mathbf{E}$} & 391 & 634 & 0,51 & 0,64 & 3354 & 1345 \\
\hline & 382 & 667 & 0,52 & 0,65 & 3493 & 1592 \\
\hline & 392 & 709 & 0,55 & 0,67 & 3381 & 1494 \\
\hline & 372 & 603 & 0,49 & 0,62 & 3354 & 1381 \\
\hline & 392 & 654 & 0,52 & 0,65 & 3390 & 1647 \\
\hline & 479 & 741 & 0,61 & 0,72 & 3271 & 1264 \\
\hline MW & 401 & 668 & $\mathbf{0 , 5 3}$ & 0,66 & 3374 & 1454 \\
\hline $\mathbf{s}$ & 39 & 50 & $\mathbf{0 , 0 4}$ & $\mathbf{0 , 0 3}$ & 72 & 149 \\
\hline
\end{tabular}

*) Ausreisser-Test n. DIXON $(\propto \leq 0,05)$ 
Tab. 10: Daten des Stoffwechselversuchs

\begin{tabular}{|c|c|c|c|c|c|c|}
\hline Gruppe & $\begin{array}{l}\text { LM (g) } \\
\text { Bginn d. } \\
\text { HP }\end{array}$ & $\begin{array}{l}\text { LM (g) } \\
\text { Ende d. } \\
\text { HP }\end{array}$ & $\begin{array}{l}\text { Mittlere } \\
\text { LM (kg) }\end{array}$ & $\mathbf{L M}_{\mathrm{kg}}{ }^{\mathbf{0 . 6 7}}$ & $\begin{array}{c}\text { N- } \\
\text { Aufnahme/ } \\
\mathbf{L M}_{\mathbf{k g}} \mathbf{6 7} \\
(\mathrm{mg} / \mathrm{d})\end{array}$ & $\begin{array}{c}\text { N-Ausscheidung/ } \\
\text { LM }_{\mathrm{kg}} \\
(\mathrm{mg} / \mathrm{d})\end{array}$ \\
\hline \multirow[t]{6}{*}{$\mathbf{F}$} & 345 & 632 & 0,49 & 0,62 & 3606 & 1624 \\
\hline & 320 & 591 & 0,46 & 0,59 & 3660 & 1442 \\
\hline & 334 & 602 & 0,47 & 0,60 & 3653 & 1494 \\
\hline & 354 & 599 & 0,48 & 0,61 & 3580 & 1729 \\
\hline & 349 & 615 & 0,48 & 0,61 & 3495 & 1459 \\
\hline & 371 & 643 & 0,51 & 0,63 & 3536 & 1504 \\
\hline MW & 346 & 614 & 0,48 & 0,61 & 3588 & 1542 \\
\hline $\mathbf{s}$ & 17 & 20 & 0,02 & 0,02 & 65 & 112 \\
\hline \multirow[t]{6}{*}{$\mathbf{G}$} & 387 & 644 & 0,52 & 0,64 & 3478 & 1429 \\
\hline & 280 & 443 & 0,36 & 0,51 & 2670 & 1027 \\
\hline & 356 & 617 & 0,49 & 0,62 & 3635 & 1505 \\
\hline & 384 & 652 & 0,52 & 0,64 & 3330 & 1355 \\
\hline & 382 & 640 & 0,51 & 0,64 & 3434 & 1406 \\
\hline & 261 & 507 & 0,38 & 0,53 & 3657 & 1433 \\
\hline MW & 342 & 584 & 0,46 & 0,60 & 3368 & 1359 \\
\hline $\mathbf{s}$ & 57 & 87 & $\mathbf{0 , 0 7}$ & 0,06 & 363 & 170 \\
\hline \multirow[t]{6}{*}{$\mathbf{H}$} & 343 & 574 & 0,46 & 0,59 & 3743 & 1684 \\
\hline & 370 & 548 & 0,46 & 0,59 & 2998 & 1187 \\
\hline & 327 & 515 & 0,42 & 0,56 & 3208 & 1401 \\
\hline & 346 & 575 & 0,46 & 0,59 & 3603 & 1674 \\
\hline & $361 *$ & $603 *$ & $0,48^{*}$ & $0,61 *$ & 3428* & $1722 *$ \\
\hline & 354 & 568 & 0,46 & 0,60 & 3403 & 1529 \\
\hline MW & 350 & 564 & 0,46 & 0,59 & 3397 & 1533 \\
\hline $\mathbf{s}$ & 15 & 30 & 0,02 & 0,02 & 268 & 208 \\
\hline \multirow[t]{6}{*}{ I } & 362 & 610 & 0,49 & 0,62 & 3380 & 1547 \\
\hline & 367 & 637 & 0,50 & 0,63 & 3504 & 1531 \\
\hline & $338^{*}$ & $629 *$ & $0,48^{*}$ & $0,61 *$ & $3727 *$ & $1460 *$ \\
\hline & 356 & 619 & 0,49 & 0,62 & 3544 & 1611 \\
\hline & 363 & 615 & 0,49 & 0,62 & 3471 & 1491 \\
\hline & 358 & 607 & 0,48 & 0,61 & 3569 & 1543 \\
\hline MW & 357 & 620 & 0,49 & 0,62 & 3532 & 1530 \\
\hline $\mathbf{s}$ & 10 & 12 & $\mathbf{0 , 0 1}$ & $\mathbf{0 , 0 1}$ & 116 & 52 \\
\hline \multirow[t]{6}{*}{$\mathbf{K}$} & 352 & 583 & 0,47 & 0,60 & 3548 & 1523 \\
\hline & 350 & 594 & 0,47 & 0,60 & 3622 & 1872 \\
\hline & 351 & 609 & 0,48 & 0,61 & 3601 & 1438 \\
\hline & 328 & 574 & 0,45 & 0,59 & 3684 & 1633 \\
\hline & 329 & 564 & 0,45 & 0,58 & 3608 & 1666 \\
\hline & 361 & 624 & 0,49 & 0,62 & 3624 & 1508 \\
\hline MW & 345 & 591 & 0,47 & 0,60 & 3614 & 1607 \\
\hline $\mathbf{s}$ & 13 & 22 & $\mathbf{0 , 0 2}$ & $\mathbf{0 , 0 1}$ & 44 & 155 \\
\hline
\end{tabular}

*) Ausreisser-Test n. DIXON $(\propto \leq 0,05)$ 
Tab. 11: Daten des Stoffwechselversuchs

\begin{tabular}{|c|c|c|c|c|c|c|}
\hline Gruppe & $\begin{array}{c}\text { N-Bilanz } \\
/ \mathbf{L M}_{\mathbf{k g}} \mathbf{0 , 6 7} \\
(\mathbf{m g} / \mathbf{d}) \\
\end{array}$ & $\begin{array}{c}\mathrm{N}- \\
\text { Retention }\end{array}$ & b-Wert & $\mathbf{P N u}_{3500}$ & $\begin{array}{c}\text { N- } \\
\text { Verdaulich- } \\
\text { keit (\%) } \\
\end{array}$ & $\begin{array}{c}b c^{-1} \\
c=4,58\end{array}$ \\
\hline \multirow[t]{6}{*}{$\mathbf{A}$} & 2049 & 2549 & 0,000381 & 72,60 & 81,73 & 83,25 \\
\hline & 1932 & 2432 & 0,000369 & 71,48 & 80,97 & 80,61 \\
\hline & 1804 & 2304 & 0,000314 & 65,73 & 76,43 & 68,60 \\
\hline & 2160 & 2660 & 0,000421 & 75,99 & 84,94 & 91,98 \\
\hline & 1964 & 2464 & 0,000369 & 71,46 & 78,66 & 80,57 \\
\hline & 1916 & 2416 & 0,000349 & 69,48 & 82,82 & 76,17 \\
\hline MW & 1971 & 2471 & 0,000367 & 71,12 & 80,92 & 80,20 \\
\hline $\mathbf{s}$ & 122 & 122 & 3,54E-05 & $\mathbf{3 , 4 0}$ & 3,02 & 7,73 \\
\hline \multirow[t]{6}{*}{ B } & 1789 & 2289 & 0,000362 & 70,81 & 86,56 & 79,08 \\
\hline & 1863 & 2363 & 0,000392 & 73,60 & 86,50 & 85,70 \\
\hline & 2012 & 2512 & 0,000393 & 73,69 & 86,28 & 85,93 \\
\hline & 1788 & 2288 & 0,000327 & 67,17 & 82,72 & 71,39 \\
\hline & 1777 & 2277 & 0,000355 & 70,07 & 84,69 & 77,45 \\
\hline & 1876 & 2376 & 0,000397 & 74,04 & 85,61 & 86,81 \\
\hline MW & 1851 & 2351 & 0,000371 & 71,56 & 85,39 & 81,06 \\
\hline $\mathbf{s}$ & 90 & 90 & 2,81E-05 & 2,72 & 1,49 & 6,14 \\
\hline \multirow[t]{6}{*}{$\mathbf{C}$} & 1900 & 2400 & 0,000339 & 68,49 & 79,45 & 74,08 \\
\hline & 1960 & 2460 & 0,000363 & 70,95 & 79,72 & 79,39 \\
\hline & 2070 & 2570 & 0,000375 & 72,02 & 80,41 & 81,87 \\
\hline & 2003 & 2503 & 0,000392 & 73,58 & 85,99 & 85,65 \\
\hline & 1834 & 2334 & 0,000385 & 72,97 & 85,13 & 84,14 \\
\hline & 1883 & 2383 & 0,000342 & 68,83 & 77,94 & 74,80 \\
\hline MW & 1942 & 2442 & 0,000366 & 71,14 & 81,44 & 79,99 \\
\hline $\mathbf{s}$ & 86 & 86 & $2,2 \mathrm{E}-05$ & 2,12 & $\mathbf{3 , 3 0}$ & 4,80 \\
\hline \multirow[t]{6}{*}{ D } & 1899 & 2399 & 0,000354 & 69,98 & 82,75 & 77,25 \\
\hline & 1985 & 2485 & 0,000356 & 70,23 & 84,40 & 77,79 \\
\hline & 2214 & 2714 & 0,000416 & 75,61 & 85,27 & 90,93 \\
\hline & 2082 & 2582 & 0,000395 & 73,83 & 86,15 & 86,29 \\
\hline & 2149 & 2649 & 0,000410 & 75,14 & 84,54 & 89,66 \\
\hline & 1780 & 2280 & 0,000324 & 66,91 & 80,24 & 70,88 \\
\hline MW & 2018 & 2518 & 0,000376 & 71,95 & 83,89 & 82,13 \\
\hline $\mathbf{s}$ & 162 & 162 & 3,67E-05 & 3,45 & 2,11 & 8,01 \\
\hline \multirow[t]{6}{*}{$\mathbf{E}$} & 2010 & 2510 & 0,000388 & 73,18 & 83,30 & 84,65 \\
\hline & 1901 & 2401 & 0,000341 & 68,67 & 82,06 & 74,46 \\
\hline & 1887 & 2387 & 0,000348 & 69,44 & 82,73 & 76,08 \\
\hline & 1974 & 2474 & 0,000376 & 72,17 & 83,33 & 82,21 \\
\hline & 1744 & 2244 & 0,000310 & 65,26 & 79,37 & 67,71 \\
\hline & 2007 & 2507 & 0,000397 & 73,97 & 86,42 & 86,64 \\
\hline MW & 1920 & 2420 & 0,000360 & 70,45 & 82,87 & 78,63 \\
\hline $\mathbf{s}$ & 101 & 101 & $3,28 \mathrm{E}-05$ & 3,29 & 2,28 & 7,16 \\
\hline
\end{tabular}

*) Ausreisser-Test n. DIXON $(\propto \leq 0,05)$ 
Tab. 12: Daten des Stoffwechselversuchs

\begin{tabular}{|c|c|c|c|c|c|c|}
\hline Gruppe & $\begin{array}{c}\text { N-Bilanz } \\
/ \mathbf{L M} \mathbf{M g}_{\mathbf{k g}} \\
(\mathbf{m g} / \mathbf{d}) \\
\end{array}$ & $\begin{array}{c}\mathrm{N}- \\
\text { Retention }\end{array}$ & b-Wert & $\mathbf{P N u}$ & $\begin{array}{c}\text { N- } \\
\text { Verdaulich- } \\
\text { keit }(\%) \\
\end{array}$ & $\begin{array}{c}b c^{-1} \\
(c=4,58)\end{array}$ \\
\hline \multirow[t]{6}{*}{$\mathbf{F}$} & 1982 & 2482 & 0,000353 & 69,87 & 81,31 & 77,02 \\
\hline & 2218 & 2718 & 0,000424 & 76,19 & 84,15 & 92,54 \\
\hline & 2158 & 2658 & 0,000403 & 74,52 & 82,70 & 88,05 \\
\hline & 1850 & 2350 & 0,000319 & 66,35 & 79,19 & 69,78 \\
\hline & 2036 & 2536 & 0,000380 & 72,50 & 83,01 & 83,00 \\
\hline & 2032 & 2532 & 0,000374 & 71,98 & 79,62 & 81,79 \\
\hline MW & 2046 & 2546 & 0,000375 & 71,90 & 81,66 & 82,03 \\
\hline $\mathbf{s}$ & 130 & 130 & 3,68E-05 & 3,48 & 1,97 & 8,04 \\
\hline \multirow[t]{6}{*}{ G } & 2049 & 2549 & 0,000386 & 73,04 & 84,23 & 84,32 \\
\hline & 1643 & 2143 & 0,000364 & 70,96 & 85,55 & 79,43 \\
\hline & 2130 & 2630 & 0,000395 & 73,86 & 82,25 & 86,35 \\
\hline & 1976 & 2476 & 0,000380 & 72,47 & 86,35 & 82,94 \\
\hline & 2029 & 2529 & 0,000384 & 72,90 & 84,53 & 83,97 \\
\hline & 2224 & 2724 & 0,000426 & 76,39 & 84,27 & 93,09 \\
\hline MW & 2008 & 2508 & 0,000389 & 73,27 & 84,53 & 85,02 \\
\hline $\mathbf{s}$ & 199 & 199 & 2,09E-05 & 1,80 & 1,39 & 4,56 \\
\hline \multirow[t]{6}{*}{$\mathbf{H}$} & 2058 & 2558 & 0,000361 & 70,75 & 73,33 & 78,96 \\
\hline & 1811 & 2311 & 0,000370 & 71,55 & 79,73 & 80,77 \\
\hline & 1807 & 2307 & 0,000344 & 69,04 & 74,92 & 75,22 \\
\hline & 1929 & 2429 & 0,000338 & 68,36 & 74,88 & 73,82 \\
\hline & 1706* & $2206 *$ & $0,000298 *$ & $63,79 *$ & 76,65 & $65,01 *$ \\
\hline & 1875 & 2375 & 0,000343 & 68,85 & 75,00 & 74,84 \\
\hline MW & 1864 & 2364 & 0,000342 & 68,72 & 75,75 & 74,77 \\
\hline $\mathbf{s}$ & 121 & 121 & 2,51E-05 & 2,71 & 2,21 & 5,48 \\
\hline \multirow[t]{6}{*}{ I } & 1833 & 2333 & 0,000334 & 67,92 & 83,08 & 72,90 \\
\hline & 1973 & 2473 & 0,000360 & 70,61 & 82,14 & 78,64 \\
\hline & $2266 *$ & $2766^{*}$ & $0,000434 *$ & $77,02 *$ & 82,77 & $94,88^{*}$ \\
\hline & 1934 & 2434 & 0,000345 & 69,08 & 81,08 & 75,32 \\
\hline & 1980 & 2480 & 0,000365 & 71,14 & 84,23 & 79,84 \\
\hline & 2026 & 2526 & 0,000369 & 71,50 & 84,19 & 80,65 \\
\hline MW & 2002 & 2502 & 0,000368 & 71,21 & 82,66 & 80,37 \\
\hline $\mathbf{s}$ & 145 & 145 & 3,52E-05 & 3,15 & 1,21 & 7,68 \\
\hline \multirow[t]{6}{*}{$\mathbf{K}$} & 2025 & 2525 & 0,000371 & 71,67 & 82,01 & 81,06 \\
\hline & 1750 & 2250 & 0,000292 & 63,04 & 75,69 & 63,68 \\
\hline & 2162 & 2662 & 0,000410 & 75,12 & 81,85 & 89,61 \\
\hline & 2051 & 2551 & 0,000365 & 71,10 & 80,21 & 79,73 \\
\hline & 1942 & 2442 & 0,000341 & 68,68 & 77,17 & 74,48 \\
\hline & 2116 & 2616 & 0,000392 & 73,56 & 79,37 & 85,60 \\
\hline MW & 2008 & 2508 & 0,000362 & 70,53 & 79,38 & 79,03 \\
\hline $\mathbf{S}$ & 147 & 147 & 4,17E-05 & 4,27 & 2,54 & 9,12 \\
\hline
\end{tabular}

*) Ausreisser-Test n. DIXON ( $\propto \leq 0,05)$ 
Tab.13: Daten der ilealen Verdaulichkeit von Aminosäuren

\begin{tabular}{|c|c|c|c|c|}
\hline Gruppe & $\begin{array}{c}\text { Arginin } \\
(\%)\end{array}$ & $\begin{array}{c}\text { Methionin + } \\
\text { Cystin (\%) }\end{array}$ & $\begin{array}{c}\text { Threonin } \\
(\%)\end{array}$ & $\begin{array}{c}\text { Lysin } \\
(\%)\end{array}$ \\
\hline \multirow[t]{4}{*}{$\mathbf{A}$} & 94,32 & 81,91 & 83,27 & 88,31 \\
\hline & 92,91 & 73,15 & 81,99 & 88,86 \\
\hline & 92,64 & 71,76 & 81,52 & 87,56 \\
\hline & 91,98 & 70,07 & 80,50 & 86,77 \\
\hline MW & 92,96 & 74,22 & 81,82 & 87,87 \\
\hline $\mathbf{s}$ & 0,99 & 5,28 & 1,15 & 0,91 \\
\hline \multirow[t]{4}{*}{ B } & 94,61 & 72,73 & 82,33 & 90,93 \\
\hline & 94,53 & 76,52 & 85,40 & 90,36 \\
\hline & $95,62 *$ & 77 & 84,41 & 89,45 \\
\hline & 94,67 & 79,41 & 83,37 & 88,69 \\
\hline MW & 94,86 & 76,42 & 83,88 & 89,86 \\
\hline $\mathbf{s}$ & $\mathbf{0 , 5 1}$ & 2,76 & 1,33 & 0,99 \\
\hline \multirow[t]{4}{*}{$\mathrm{C}$} & 93,01 & 84,22 & 86,17 & 89,73 \\
\hline & 96,20 & 83,45 & 86,85 & 91,03 \\
\hline & 98,33 & 84,34 & 87,71 & 90,11 \\
\hline & 91,25 & $79,54 *$ & 82,09 & $85,38^{*}$ \\
\hline MW & 94,70 & 82,89 & 85,71 & 89,06 \\
\hline $\mathbf{s}$ & 3,17 & 2,27 & 2,49 & 2,51 \\
\hline \multirow[t]{4}{*}{ D } & 97,49 & 78,26 & 84,70 & 87,40 \\
\hline & 96,58 & 83,82 & 89,22 & 90,60 \\
\hline & 94,54 & 75,89 & 84,21 & 87,62 \\
\hline & 96,22 & 88,05 & 86,03 & 90,98 \\
\hline MW & 96,21 & 81,51 & 86,04 & 89,15 \\
\hline $\mathbf{s}$ & 1,23 & 5,48 & 2,26 & 1,90 \\
\hline \multirow[t]{4}{*}{$\mathbf{E}$} & 95,26 & 78,56 & 88,69 & $91,39 *$ \\
\hline & 91,18 & 76,59 & 86,12 & 86,47 \\
\hline & 92,31 & 91,92 & 85,31 & 87,35 \\
\hline & 92,52 & 87,69 & 83,77 & 87,24 \\
\hline MW & 92,82 & 83,69 & 85,97 & 88,11 \\
\hline $\mathbf{s}$ & 1,73 & 7,31 & 2,06 & 2,22 \\
\hline
\end{tabular}

*) Ausreisser-Test n. DIXON $(\propto \leq 0,05)$ 
Tab. 14: Daten der ilealen Verdaulichkeit von Aminosäuren

\begin{tabular}{|c|c|c|c|c|}
\hline Gruppe & $\begin{array}{c}\text { Arginin } \\
(\%)\end{array}$ & $\begin{array}{c}\text { Methionin } \\
+ \text { Cystin (\%) }\end{array}$ & $\begin{array}{c}\text { Threonin } \\
(\%)\end{array}$ & $\begin{array}{c}\text { Lysin } \\
(\%)\end{array}$ \\
\hline \multirow[t]{4}{*}{$\mathbf{F}$} & 89,72 & 81,39 & 84,53 & 83,47 \\
\hline & 90,98 & 83,9 & 82,86 & 83,53 \\
\hline & 86,81 & 82,48 & 80,69 & 80,55 \\
\hline & 84,14 & 77,75 & 80,02 & 76,47 \\
\hline MW & 87,91 & 81,38 & 82,02 & 81,01 \\
\hline $\mathbf{s}$ & 3,06 & 2,63 & 2,06 & $\mathbf{3 , 3 3}$ \\
\hline \multirow[t]{4}{*}{$\mathbf{G}$} & 93,68 & 85,68 & 87,24 & 87,95 \\
\hline & 92,98 & 84,18 & 86,49 & 88,81 \\
\hline & 91,11 & 81,28 & 84,77 & 85,64 \\
\hline & 93,95 & 82,05 & 88,13 & 87,62 \\
\hline MW & 92,93 & 83,30 & 86,66 & 87,51 \\
\hline $\mathbf{s}$ & 1,28 & 2,01 & 1,43 & 1,34 \\
\hline \multirow[t]{4}{*}{$\mathbf{H}$} & 81,15 & 68,04 & 70,72 & 72,25 \\
\hline & 87,12 & 73,6 & 75,34 & 77,82 \\
\hline & 86,45 & 70,44 & 75,67 & 76,28 \\
\hline & 79,17 & 63,76 & 66,54 & 70,58 \\
\hline MW & 83,47 & 68,96 & 72,07 & 74,23 \\
\hline $\mathbf{s}$ & 3,92 & 4,15 & 4,32 & 3,38 \\
\hline \multirow[t]{4}{*}{$\mathbf{I}$} & 89,52 & 75,41 & 77,95 & 86,34 \\
\hline & 89,82 & 74,91 & 77,24 & 87,03 \\
\hline & 93,33 & $81,13 *$ & $84,18^{*}$ & 87,59 \\
\hline & 88,61 & 74,4 & 77,84 & 83,04 \\
\hline MW & 90,32 & 76,46 & 79,30 & 86,00 \\
\hline $\mathbf{s}$ & 2,07 & 3,14 & 3,27 & 2,04 \\
\hline \multirow[t]{4}{*}{$\mathbf{K}$} & 92,20 & 79,79 & 82,55 & 87,52 \\
\hline & 92,01 & 77,55 & 78,93 & 88,37 \\
\hline & 92,96 & 81,29 & 82,02 & 89,70 \\
\hline & 90,29 & 78,19 & 80,02 & 86,39 \\
\hline MW & 91,87 & 79,21 & 80,88 & 88,00 \\
\hline $\mathbf{s}$ & 1,13 & $\mathbf{1 , 6 8}$ & 1,70 & 1,40 \\
\hline
\end{tabular}

*) Ausreisser-Test n. DIXON Ausreisser-Test n. DIXON $(\propto \leq 0,05)$ 



\section{Danksagung}

Mein besonderer Dank gilt Herrn Prof. Dr. F. Liebert für die Überlassung des Themas und für die hilfreiche Unterstützung bei der Planung und Durchführung der Arbeit.

Frau Prof. Dr. E. Pawelzik vom Institut für Agrikulturchemie danke ich herzlich für die Übernahme des Korreferates.

Ganz besonders danke ich Frau Dr. H. Rosenow für die Korrektur der vorliegenden Arbeit und freundliche Hilfsbereitschaft während meines Aufenthaltes am Institut für Tierphysiologie und Tierernährung.

Ferner gilt mein herzlicher Dank Frau H. Marbell, allen Mitarbeitern und Mitdoktoranden (Amad, Khaled, Martin und Lee) des Institutes sowie all denjenigen, die zum Erfolg der Arbeit beigetragen haben.

Meiner Schwester Asnakech Timerga und meinem Bruder Benyam Tesfaye danke ich für die besondere Unterstützung, die ich in der letzten Phase der Arbeit bekommen habe. 



\section{Lebenslauf}

\section{Persönliche Daten}

Name:

Geburtsdatum:

Geburtsort:

Familienstand

Nationalität

\section{Schulausbildung}

1974-1980

1981-1986

1989-1990

\section{Studium}

1990-1995

1995

Seit 1998
Nassir Oumer Ahmed

17. September 1969

Addis Abeba/Äthiopien

ledig

äthiopisch
Volksschule in Addis Abeba

Volkshochschule in Addis Abeba und anschließend Abitur

Deutsche Sprache am Herder-Institut in Leipzig

Studium am Institut für tropische- und subtropische

Landwirtschaft der Universität Leipzig

Diplom- Agraringenieur

Doktorand am Institut für Tierphysiologie und

Tierernährung der Georg-August-Universität, Göttingen 